\title{
Recent Developments in Polymer Microfluidic Devices with Capillary Electrophoresis and Electrochemical Detection
}

\author{
Mamun Rashid ${ }^{*, a}$, Yue-Hua Dou ${ }^{\mathrm{b}}$, Vincent Auger ${ }^{\mathrm{a}}$ and Zulfiqur Ali ${ }^{\mathrm{a}}$ \\ ${ }^{a}$ Technology Futures Institute, Teesside University, TS1 3BA, UK \\ ${ }^{b}$ Centre for Biomedical Research, Hull York Medical School, The University of Hull, HU6 7RX
}

\begin{abstract}
We review recent work on the development of polymer microfluidic devices using capillary electrophoresis (CE) for fluid driving and separation and electrochemical detection (ED). A variety of commonly used off-chip and integrated electrochemical detection approaches, including amperometric, conductimetric and potentiometric detection approaches, have been given. We describe fabrication approaches for the creation of microfluidic architecture in a polymer substrate and electrode integration. The methods for polymer surface modification to enhance the microfluidic device properties are also described as well as developments in power supply for the creation of a robust CE-ED microfluidic device system. A variety of applications are described for the CE-ED systems.
\end{abstract}

Keywords: Microfluidic device, electrochemical detection, polymer microfabrication, surface modification, capillary electrophoresis.

\section{INTRODUCTION}

Micro total analysis system ( $\mu$ TAS) has developed rapidly in the past decade since it first appeared in $1990[1,2]$. More generally this area has become known as microfluidics and implies the ability to manipulate fluids in a chip format. Capillary electrophoresis (CE) on a microfluidic device offers fast and highly efficient separation of small inorganic and organic species as well as large biomolecules. Numerous recent reviews exemplify the different applications of capillary electrophoresis [3-17]. Many detection methods have been employed in CE microfluidic device, these include laser induced fluorescence (LIF), nonfluorescence optical detection, electrochemical, chemiluminescence, electrochemiluminescence, Infrared [18], Raman [19] and surface plasmon resonance [20]. Much work has been done on the use of capillary electrophoresis separation on microfluidic device with laser-induced fluorescence for detection [21-25]. Laser induced fluorescence is attractive for the high limit of detection (LOD), but is limited to compounds which fluoresce or are amenable to derivatization with a fluorophore. In recent years, electrochemical detection has also attracted interest because of its advantages in cost, design flexibility, ease of miniaturization and its sensitivity and selectivity. There is increasing interest in the use of polymer substrates for microfluidic device development because of the advantages of cost and amenability for high replication [26- 28]. This review will focus on recent developments in polymer based microfluidic devices with electrochemical detection.

\section{ELECTROCHEMICAL DETECTION ON MICRO- FLUIDIC DEVICE}

Three electrochemical detection modes, amperometry, conductimetry and potentiometry have been commonly used for detection in capillary electrophoresis on microfluidic device [29-31]. Amperometric detection is an attractive because of its high sensitivity and the ease with which it can

*Address correspondence to this author at the Technology Futures Institute, Teesside University, TS1 3BA, UK; Tel: +441642342428;

Fax: +441642342401; E-mail: m.rashid@tees.ac.uk be integrated as a detection element in a microfluidic device system. It does, however, suffer from interferences from the high voltage (HV) used in electrophoresis which is commonly used within for sample separation and transport within microfluidic device. There is, therefore, often a need for decoupling to ground the separation voltage prior to the detection cell and much work has been done in this field in the past few years. There is increasing interest in using conductimetry for detection. It can be used to detect substances that do not have any electrochemical activity and is therefore a complementary technique to amperometric detection. Conductimetry does, however, suffer from lower sensitivity.

\subsection{Amperometric Detection}

In 1998, Wolley et al. first reported amperometric detection techniques for $\mu$-CE chip [32]. The technique can be implemented in either a three-electrode (working, auxiliary and reference) or two-electrode (working and reference) systems [33]. In amperometry mode, the potential of the working electrode is set at a constant value and only those substances that are oxidized or reduced at the set potential are detected as they emerge from the micro channel [34]. Although amperometry is the most commonly used electrochemical detection method in microfluidic devices; two shortcomings limit its commercial application. Firstly, decoupling is required to minimize the high voltage electric field, (in the order of several hundred $V / \mathrm{cm}$ ) at the end of channel, before the species reach the detector where the working electrode (WE) holds a constant potential below 2.0 V. Secondly, there is need to improve the reproducibility of the detection current. The reproducibility of the detection current greatly depends on the stability of the WE and the reproducibility of the position of the WE to the outlet of separation channel.

Three decoupling methods, end-channel (Fig. 1), offchannel (Fig. 2) and in-channel detection (Fig. 3), are typically used and these differ in the relative position of the WE to the channel outlet (29).

\subsubsection{End-Channel}

In the end channel mode, the working electrode is typically placed several tens of micrometers away from the end 
of channel. The gap between the outlet and the WE can effectively isolate the high separation voltage from the detector [32] (Fig. 1a). The end channel detection mode was adapted from the end-column detection mode for conventional capillary electrophoresis with capillaries of internal diameter less than $5 \mu \mathrm{m}$ [35]. Based on conventional end column detection mode, microfluidic device CE-ED with end-channel detection mode is a popular detection mode. Different electrode materials such as gold, platinum, copper, carbon in different forms (paste, glassy, fibre, ink, pyrolyzed photoresist film, nanotubes and diamonds have been reported. The alignment of the working electrode can be either on-chip or off-chip. In off-chip mode, the WE is fixed in an extra apparatus, such as a screen-printed electrode on a substrate [36], a hand-made microelectrode controlled by a three dimensional adjustor $[37,38]$ or alignment of the WE and the outlet through a guide tube [39-42]. In the three dimensional adjustor, the probe microelectrode which is also known as the tip electrode is precisely positioned several micrometers away from end channel [43]. The distribution of electric field (E) at the end channel is strongly dependent on the microelectrode potential, tip-to-channel distance, and separation potential [44]. Scanning electrochemical microscopy (SECM) coupling imaging has been used to detect the electric-field distribution at the end of the separation channel [45]. The offchip mode has the advantage that the WE can replaced, if fouled, without the need to expensive disposal of the whole microfluidic device and the chip microfabrication is simplified. The off-chip mode does, however, suffer from relatively poor current reproducibility. The peak current partly depends on the distance between the channel outlet and the $\mathrm{WE}$ and the poor current reproducibility arises from the difficulty in reproducibly position the WE. The extra device for fixing and alignment of the WE limits the degree of integration and miniaturization of the microfluidic device CE-ED systems. This is not a problem for the on-chip mode where generally, the WE is microfabricated on the substrate and its position is easily controlled. There is now an increasing interest in the use of the on-chip mode.

The end-channel detection mode is relatively simple and only needs to adjust the distance between the exit of the separation channel and the surface of the working electrode. However, a residual electric field will exists in the endchannel detection reservoir which will lower sensitivity, shift the detection potential [46] and lead to broadening of the electrophoresis peaks. To improve the efficiency of endchannel detection, Ertl et al. [47] proposed CE chips with a sheath-flow supported electrochemical detection system. Gravity-driven buffers flow along the sheath-flow channels (Fig. 1b), that join the end of the separation channel from each side, and carry analytes to the electrochemical detector instead of use of electro osmotic flow (EOF) [48]. The detection limit of a standard sample of catechol is $4.1 \mu \mathrm{M}$ with a distance of $250 \mu \mathrm{m}$ from the outlet of the separation channel to the working electrode; this is about 5 to 10 times longer than is the case normally. At this long distance, the separation voltage is considered to be effectively isolated. Sufficiently small inner dimensions of separation channels with wider outlet are an alternative approach to diminish the HVfield interference in electrochemical detection. Wilke and Büttgenbach introduced a $1000 \mu \mathrm{m}$ width channel outlet in the fully integrated micro machined capillary electrophoresis chip to isolate the interference [49]. This sudden change in channel geometry can decrease the resistance of the end channel and thus greatly reduce the electric field in the detection region (Fig. 1c). Analyte diffusion appears between the end of the separation channel and working electrode which limits the separation efficiency and detection sensitivity $[50,51]$. The electrophoretic current will produce an iR drop at the detection reservoir which alters the potential of the WE with shifts in half-wave potential of the hydrodynamic voltammogram. Shifts of $+130 \mathrm{mV}$ in the half wave potentials for both dopamine and catechol has been reported when the applied separation voltage was increased from 15 $\mathrm{kV}$ to $30 \mathrm{kV}$ [46]. In the end-channel detection mode, an increase of the cross-sectional area of the separation channel positively shifts half wave potential for oxidizing dopamine and catechol [52]. For dopamine at the field strength 288 $\mathrm{V} / \mathrm{cm}$, increased crossed sectional area shifts half-wave potentials from $285 \mathrm{mV}$ to $330-400 \mathrm{mV}$. The gap between the WE and RE has a pronounced effect on the HV field interference and detection performance [32]. The positioning of the WE and RE on an equi-potential surface eliminates the $\mathrm{HV}$-field interference [53]. A gap of 50-20 $\mu \mathrm{m}$ between the WE and the separation channel was shown to produce a positive $(+15 \mathrm{mV})$ shift in half-wave potential for dopamine [53]. An increased of channel-to-electrode distance from $20 \mu \mathrm{m}$ to $50 \mu \mathrm{m}$ significantly increases both the migration time and peak widths with a decrease in peak heights. The workingto-reference electrode spacing is more critical as compared to the working-to-channel distance when considering background noise, detection potential shift, detection sensitivity and separation efficiency. An integrated reference electrode situated close to the WE dramatically reduces the noise caused by the HV field. The half wave potential of the oxidized analytes shifted from $+160 \mathrm{mV}$ to $+470 \mathrm{mV}$ when the working-to-reference electrode spacing increased from 100 $\mu \mathrm{m}$ to $500 \mu \mathrm{m}$. In end channel CE-ED, the $100 \mu \mathrm{m}$ gap between the WE and RE partially reduced the HV-field interference and increased sensitivity [54]. An array of working electrodes at the end of the separation channel significantly decreased the background current to $\sim 1 \mathrm{nA}$ [50]. Recently, Álvarez and co-workers have developed various end-channel designs for integration of gold wire electrodes in CE-ED microfluidic device [40, 41, 55-60]. Álvarez et al. introduced guide channel at the end of the separation channel for the working electrode wire. In this approach, the 50-100 $\mu \mathrm{m}$ gold wire is in contact with the solution at the end of the channel [56]. Epoxy resin adhesive tape fixed the position of the working electrode wire at the end channel and reduced the capacitive currents $[56,61]$. Hydrogen peroxide, ascorbic acid and uric acid were measured simultaneously in $70 \mathrm{~s}$ with good reproducibility. Single and dual-channel (Пdesign) microfluidic device electrophoresis with end channel electrochemical detection system has been reported for dopamine, p-aminophenol (pAP), hydroquinone (HQ) [57, 62]. Recently, Castaño-Álvarez et al. reported neurotransmitter detection using SU-8 based microfluidic device electrophoresis with integrated end channel electrochemical detection [63]. The space between the gold working electrode and separation channel was $20 \mu \mathrm{m}$ for high separation efficiency. Previously, the same group reported end channel capillary electrophoresis microfluidic devices made of various materi- 
als, e.g., poly(methylmethacrylate) (PMMA) [58, 60], thermoplastic olefin polymer of amorphous structure (TOPAS)[55, 59], and Polydimethylsiloxane (PDMS) [62]. Klett et al. [53,64] developed an end-column design in conventional CE. An array of gold microband electrodes on a detection chip were placed at a distance of $10 \mu \mathrm{m}$ between the working and reference electrodes (Fig. 1d). This design ensures that both electrodes are identically affected by the presence of the CE electric field and thus no shift in the halfwave potential when the CE high voltage was applied. In a similar approach, Baldwin [65] suspected an effect on the reference position. The discrepancy may be due to the different micro device design. End channel electrochemical detection mode is very successful and effective for the analysis of real samples [66, 67]. Recently, Peng and coworkers placed the WE $25 \mu \mathrm{m}$ away from the separation channel and the detection limits ranged from $1 \times 10^{-8}$ to $2 \times 10^{-7} \mathrm{~g} / \mathrm{mL}$ for phenolic Compounds [68, 69].

\subsubsection{Off-Channel}

In the off-channel mode, the analytes first pass through a decoupler, before they reach the WE. In the absence of decoupler, bubbles are continuously formed in the front part of the WE when a separation voltage is higher than $1200 \mathrm{~V}$ and $\mathrm{a}+0.7 \mathrm{~V}$ potential (vs $\mathrm{Ag} / \mathrm{AgCl}$ ) applied to the WE [70, 71]. A decoupler can ground the separation potential and protect the EC detector from damage arising from surges in current. In capillary electrophoresis with ED, a bare or coated fracture near the end of capillary has been presented as decouplers. Coatings can be made from porous glass [72], graphite [73] and polymers such as Nafion [74]. Zhang et al. [75] used a Teflon tube as a decoupler for amperometric detection of ofloxacin and pasiniazid in urine. Decouplers can also be from Pd tube [70], because Pd can effectively reduce $\mathrm{H}^{+}$and absorb hydrogen. This allows hydrogen, generated from the hydrolysis of water at the cathode during separation, to diffuse faster before the formation of hydrogen bubbles. Furthermore, etched holes or scores which are filled with lower conductivity materials such as epoxy [71] or cellulose ace- tate [76], near the end of a capillary have been employed as decouplers. This design separates the capillary into two parts, and isolates the detector from the interference of high voltage electric field. Indium tin oxides (ITO) material was found to decouple the electrochemical detection circuit from the interference of a separation electric field and measured dopamine, catechol, DNA ladder, and hydrogen peroxide [77]. Recently, Sha et al. [78] used porous etched joint decoupler on the EC detection. The porous joint successfully eliminates the electrophoretic high-voltage field on the carbon fibre working electrode. The detection limits of propyl gallate (PG) and tertbutylhydroquinone (TBHQ) was recorded $2.51 \times 10^{-6}$ and $4.88 \times 10^{-6} \mathrm{~mol} \mathrm{~L}^{-1}$.

In microfluidic device with electrochemical detection, the decouplers employed have mainly followed the design concepts used in conventional CE. On-chip decoupler has the advantage of no dead volume or sample leakage and can be micro-fabricated as part of the overall chip. Before 2002, there were relatively a few papers on off-channel detection with a decoupler design. Yin reviewed off-channel design with decoupler in electrochemiluminescence cells [79]. Rossier et al. [80] proposed an array of micro-holes of 5 10 $\mu \mathrm{m}$ in diameter made from UV excimer laser as a decoupler in a poly (ethylene terephthalate) (PET) microchannel (Fig. 2a). The shift of the half-wave potential of analytes is only about $15 \mathrm{mV}$ under an electric field of $50 \mathrm{~V} / \mathrm{cm}$ when the separation current was $5 \mu \mathrm{A}$ [81]. The limit detection is around $5 \mu \mathrm{M}$ for aminophenol. Chen et al. [82] obtained a better LOD of $0.29 \mu \mathrm{M}$ for catecholamine and $0.47 \mu \mathrm{M}$ for dopamine on a polymethylmethacrylate (PMMA) chip with a $3 \mathrm{~mm}$ width deposited Pd film decoupler just $1 \mathrm{~mm}$ before the working electrode. In this study, the electric field strength was recorded to reach as high as $714 \mathrm{~V} / \mathrm{cm}$.

We have seen development in new design and optimization in decoupling (Fig. 2b). Lai et al. [83] found that $700 \AA$ thickness of a Pd film is sufficient for most solutions in a PDMS/ glass chip. The chip was used for routine detection for dopamine with an LOD of $0.25 \mu \mathrm{M}$ and a maximum al- la

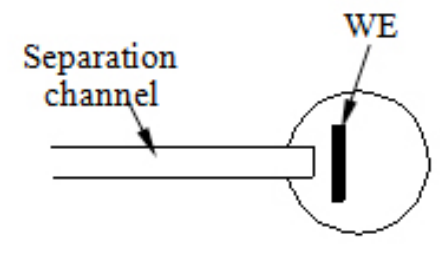

lb

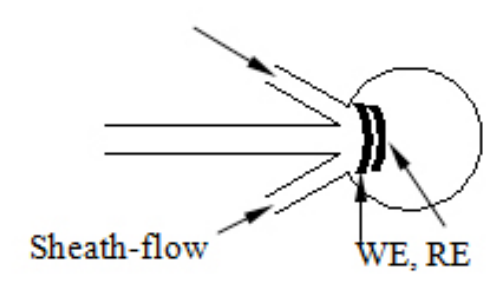

Detection
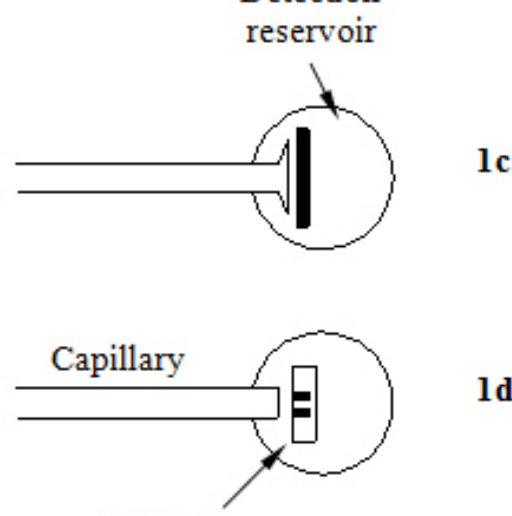

WE, RE on a

detection chip

Fig. (1). End-Channel Configuration.

(1a). Basic end-channel configuration (32). (1b). Sheath-flow driven design (47). (1c). Widened channel outlet (49). (1d). micro band array electrodes with distance of $10 \mu \mathrm{m}$ between the WE and RE in conventional CE (53). (To simplify the drawing, not all the electrodes are included; same in Fig. (2) and Fig. (3)). 
$2 \mathbf{a}$
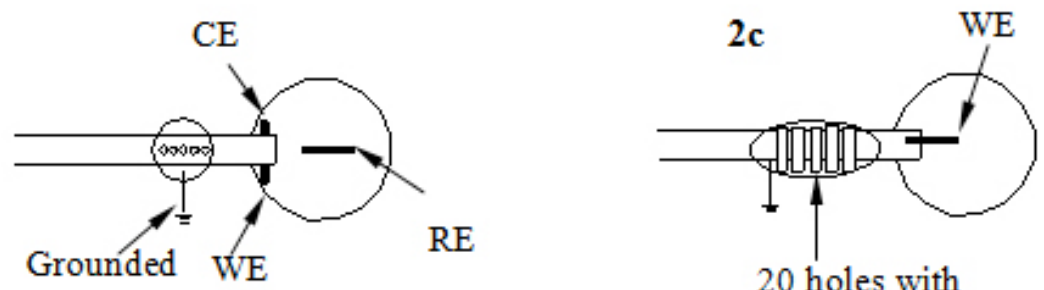

20 holes with

cellulose acetate

film

2b

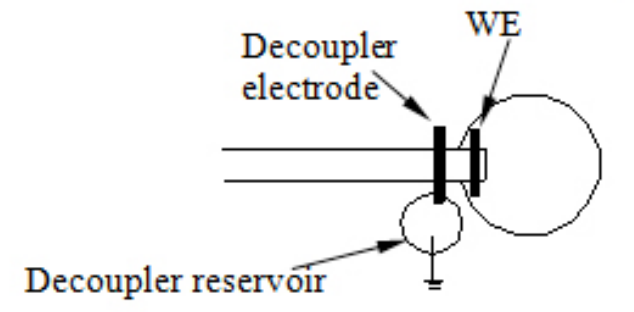

Fig. (2). Off-Channel Configuration.

(2a). Drilled holes near the end of a separation channel [80]. (2b). Designs with Pd or Pt decouple electrode [82-85]. (2c). Holes array with cellulose acetate film [86].

lowed electric field strength of reach $800 \mathrm{~V} / \mathrm{cm}$. A Pd microwire with a $50 \mu \mathrm{m}$ gap between the separation and electrode channels isolated the electrode channel from the separation channel [84]. Lacher et al. [85] optimized the Pd decoupler size and the spacing between the decoupler and the working electrode. A maximum electric field of $1200 \mathrm{~V} / \mathrm{cm}$ was used in this PDMS/ glass microfluidic device giving a plate number of $248000 / \mathrm{m}$. The LOD for dopamine was around $0.5 \mu \mathrm{M}$. Dawoud et al. [87] electroplated palladium nanoparticles on the gold microelectrodes and the concentration detection limit for 8-hydroxy-deoxyguanosine DNA adduct (8-OH-dG) is in the order of $100 \mathrm{nM}$. Kovarik et al. [88] reported their work on coupling a carbon microelectrode with a Pd decoupler. The LOD for dopamine is estimated to be $2.3 \mu \mathrm{M}$ with a linear range from 5 to $200 \mu \mathrm{M}$. In the amperometric detection of the 8-hydroxy-deoxyguanosine (8$\mathrm{OH}-\mathrm{dG})$ DNA adduct, electroplated Pd nanoparticles integrated on gold decoupler provides significantly improved detection limit, separation efficiency, and resolving power [89]. Wu et al. [90] tried electrodeposited Pt nanoparticles as a decoupler and pseudo-reference electrode. The potential shift was found to be nearly cut to zero and a LOD of 0.125 $\mu \mathrm{M}$ for dopamine was achieved. The maximum electric field and plates are around $85 \mathrm{~V} / \mathrm{cm}$ and $4800 / 5 \mathrm{~cm}(96000$ plates $/ \mathrm{m}$ ), respectively, which are far lower than with the use of $\mathrm{Pd}$ as a decoupler. This is mainly due to better adsorption of hydrogen on Pd metal surface than a Pt surface. As a consequence of this a higher voltage can be applied before interruption of the channel by bubbles. Du et al. [91] reported the fabrication of a Pt decoupler coupled with copper WE on a PDMS-glass hybrid microfluidic device. Glucose in human plasma was successfully determined with a linear response from $10 \mu \mathrm{M}$ to $1 \mathrm{mM}$. Recently, Lin et al. used Pt decoupler and a renewable working electrode $(\mathrm{Cu})$ for the electrochemical detection of dopamine and catechol analytes over the concentration range 10-1000 $\mu \mathrm{M}$ [92]. In the CE chip, the $\mathrm{Pt}$ and $\mathrm{Cu}$ wires were aligned horizontally on the separation channel. The distances between the decoupler and the end of separation channel and the centre of the WE electrode was fixed at $1000 \mu \mathrm{m}$ and $200 \mu \mathrm{m}$ respectively. Embedded gold nanoelectrode ensemble (GNEE) working and Pt decoupler electrodes provide a significantly higher signal response than unmodified electrode [93]. For dopamine analytes, the GNEE decoupler electrode reduces the amplitude of the charge current ( $3.5 \mathrm{nA}$ vs. $18.7 \mathrm{nA}$ ) and the baseline drift. Compared to the conventional Pd decoupler, the baseline current drift measured with GNEE decoupler is three times smaller [94]. In CE microfluidic device, for a mixture of $1 \mathrm{mM}$ Dopamine and catechiol, response with GNEE decoupler electrode almost five times higher than conventional Pd decoupler.

Lunte et al. [86] developed a chip-based cellulose acetate decoupler for electrochemical detection (Fig. 2c). The decoupler is constructed by etching a series of twenty $30 \mu \mathrm{m}$ holes using a $\mathrm{CO}_{2}$ laser in the cover plate of the microfluidic device, and filling the holes with a thin film of cellulose acetate. The decoupler shows excellent isolation of the detection circuit from the separation electric field. Field strength of $1700 \mathrm{~V} / \mathrm{cm}$ can be applied with noise level of less than $1 \mathrm{pA}$ at a carbon fiber electrode, and gives the lowest reported detection limit for dopamine in a microfluidic device $\mathrm{CE}$ with electrochemical detection of $0.025 \mu \mathrm{M}$ up to date [86]. Arnett et al. [95] used laser etched decoupler and carbon fiber working electrode for the electrochemical detection of 8-oxoguanine and 8-hydroxy-2-deoxyguanosine in the rat cerebral cortex. An alternative approach to reduce the electrophoretic current is to bypass the current by a field decoupler near the end of the separation channel. This additional pathway provides a junction for the electrolyte and ground the separation current just before the working electrode [96]. There is, however, a need to improve the mass production of this design.

\subsubsection{In-Channel}

In the in-channel detection mode, analytes migrate over the electrode while they are still confined to the channel, which allows low analyte diffusion and higher sensitivities. The main drawback of the in-channel detection mode is the necessary isolation of the high separation voltage from work- 

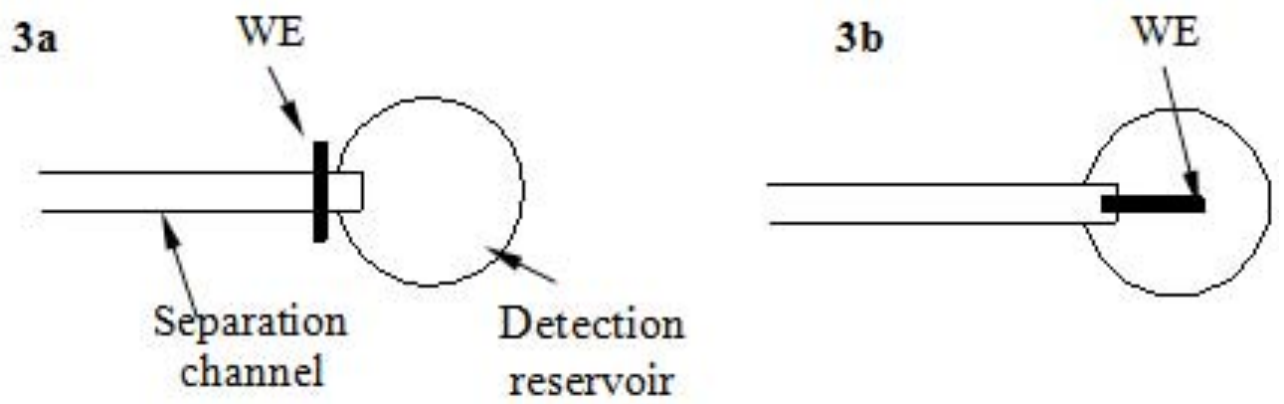

Fig. (3). In-Channel Configuration.

(3a). WE is perpendicular to the channel, detected by a floating potentiostat [97]. (3b). WE faces the flow [98].

ing electrode. Employing an electrically isolated potentiostat as electrical isolation approach [97] can allow placement of the working electrode inside the channel (Fig. 3).

This avoids the difficulty in fabricating a decoupler in off-channel detection and the loss of efficiency and band broadening with end-channel mode [99]. A floating potentiostat was designed and data are transmitted over an electrically isolated RS-232 port while the detection circuitry is not grounded. This design enables the placement of the WE directly in the channel and a separation performance in plate height and peak symmetry can match the result by Laser Induced fluorescence (LIF) [97]. However, the LOD for catechol is $4 \mu \mathrm{M}$ mainly due to the background noise from the non-shielding potentiostat. For the same analytes, inchannel amperometric detection mode decreased the total plate height by a factor of 4.6 compare to end-channel mode [100]. A similar tendency was observed for small, inorganic ion nitrite. Single carbon fiber electrode introduced in the end part of the micro channel directly detected electroactive and non-electroactive analytes in-channel amperometric mode [101]. This group also reported in-channel amperometric detection mode for the analysis of inorganic anions in $\mathrm{CE}$ chip [102]. Low-noise algorithms, amplifies and improved layout will lead to a better result. No gap between the channel outlet and the working electrode prevents the analyte dispersion, increases peak resolution and sensitivity for the amperometic detection [60, 103]. A very low separation voltage (below $+500 \mathrm{~V}$ ) allows placement of the working electrode within the separation channel $(20 \mu \mathrm{m}$ away from the outlet [55]. In in-channel detection mode, low separation voltage offers low baseline noise level with reduced Joule heating. Recently, Chen et al. [104] used a dual in-channel configuration for amperometric detection in microfluidic capillary electrophoresis chip. They applied two parallel separation channel containing the working and reference electrode separately. The WE and RE are placed equally exactly $200 \mu \mathrm{m}$ from the outlets and the counter electrode was placed $100 \mu \mathrm{m}$ from the channel outlet. Separation voltage causes a potential shift between the working and the reference electrode and deteriorates the detection signals significantly. An amperometric signal ( $0.1 \mathrm{pA})$ was measured without any potential shift with the LOD $1.8 \mathrm{nM}$ for dopamine. An increase in coulometric efficiency $\left(\mathrm{C}_{\text {eff }}\right)$ of an inchannel amperometric detector was reported with gold particle deposition [105]. 10 lines of gold working electrodes (50 $\mu \mathrm{m}$ wide and $50 \mu \mathrm{m}$ spacing) were fabricated in channel to enhance the separation efficiency and limit of detection. An external electric field induces a potential difference between array of microband electrodes and enables in-channel electrochemical detection of electroactive species such as ascorbic acid and $\mathrm{Fe}(\mathrm{CN})_{4}^{6}{ }_{4}^{-}[106]$. The induced potential difference between the electrodes can be controlled by the external electric field and can isolate the separation voltage in $\mathrm{CE}$ microfluidic device. Besides this, in-channel fabricated single carbon fiber electrode was reported to efficiently separate $\mathrm{Pb}^{2+}, \mathrm{Cd}^{2+}$ and $\mathrm{Cu}^{2+}$ with in 80 seconds [107]. The detection limit of $\mathrm{Pb}^{2+}, \mathrm{Cd}^{2+}$ and $\mathrm{Cu}^{2+}$ were $1.3,3.3$ and $7.4 \mu \mathrm{M}$ with the theoretical plate number of $1.2 \times 10^{5}, 2.5 \times 10^{5}, 1.9 \times 10^{5}$ $\mathrm{m}^{-1}$, respectively.

\subsection{Pulsed Amperometric Detection}

Though constant potential amperometry is the most widely used electrochemical detection mode in microfluidic chip, other electrochemical detection methods such as pulsed amperometric detection (PAD) and voltammetry are also used.

Direct current (DC) amperometry detection is limited to a small number of easily oxidizable or reducible analytes. However pulsed amperometric detection is an alternative waveform that can increase the number of electrochemically detectable analytes in real samples. Besides this, in the constant potential amperometry mode, working electrodes are easily fouled because of adsorption of oxidized products on the electrode surface, especially for noble metal electrodes. This problem is obviated in PAD since a high potential is first applied to clean the electrode surface followed by switching to a negative potential to regenerate the electrode surface, and finally setting to a potential for analyte detection. PAD has found wide application in the detection of compounds containing amine, alcohol, or sulfur moieties, which can easily foul metal electrodes in capillary electrophoresis [108, 109]. Wen [110] studied waveform shape, waveform frequency and various signal analysis methods in order to get improved $\mathrm{S} / \mathrm{N}$ in PAD in conventional $\mathrm{CE}$. They found the addition of a multiple-step potential waveform to a bipolar pulse could enhance the $\mathrm{S} / \mathrm{N}$ up to 10 times.

Fanguy et al. [111] gave the first report on the use of PAD at a platinum working electrode in a PDMS/glass microfluidic device. Glucose, maltose and xylose were separated and measured with a detection limit of $20 \mu \mathrm{M}$ for glucose. Garcia et al. [112] determined underivatized carbohy- 
drates, amino acids and sulfur-containing antibiotics with PAD through the end-column configuration. A gold microwire working electrode was aligned at the end of the separation channel in a perpendicular channel to isolate the detector from the separation current. Detection limits of 6 fmol $(5 \mu \mathrm{M})$ for penicillin and ampicillin, and $455 \mathrm{fmol}$ (350 $\mu \mathrm{M}$ ) for histidine were obtained. Garcia et al. [113] proposed the use of post-column $\mathrm{pH}$ modification in microfluidic device electrophoresis for glucose determination with PAD. Sodium dodecyl sulfate was used to stabilize flow rate and enhance the detection signal. A linear relationship between the peak current and the concentration of glucose was found between $10^{-2}-10^{-15} \mathrm{M}$, with a limit of detection of $1.2 \mu \mathrm{M}$. This group further applied PAD to nitrogen-containing compounds such as creatinine, creatine and uric acid [114]. The results obtained with urine samples were comparable with the standard clinical assay based on the Jaffe reaction. They also developed analysis method for levoglucosan from smoke samples that can be used to fast locate forest fire or air pollution sources [115]. In the presence of $30 \mathrm{mM}$ sodium dodecylsulfate surfactant, pulsed amperometric detection method successfully detect the antioxidants propyl gallate , octyl gallate, lauryl gallate (LG), and nordihydroguaiaretic acid (NDGA) [116]. Four synthetic antioxidants were analyzed within 2 min and the limit of detection was recorded 1$4 \mu \mathrm{m}$ by microfluidic device-MEKC (Micellar electrokinetic chromatography) with pulsed amperometric detection mode. Besides, phosphatidic acid and deoxycholate enhanced electrochemical response for glucose, penicillin, phenol, and homovanillic acid [117]. $25 \mu \mathrm{m}$ width Au electrode simultaneously measured three phenolic pollutants in base mediumin which addition of alkyl sulfates improved the reproducibility of the migration times $\left(t_{M}\right)$ and peak currents $\left(I_{p}\right)$ [118]. Pulsed amperometric detection mode allows detection of $5 \mathrm{nM}$ for dopamine, $74 \mathrm{nM}$ for glutathione, and $100 \mathrm{nM}$ for glucose in CE microfluidic device [84]. A Pd microware acts as a decoupler and isolates the separation voltage from the $\mathrm{Au} / \mathrm{Pt}$ working electrode. Pulsed amperometric detector based on boron-doped diamond (BDD) thin film electrode successfully detects $1.0-100 \mu \mathrm{M}$ salbutamol, terbutaline and clenbuterol [119]. Garcia et al. [120] reviewed pulsed electrochemical detection mode for capillary electrophoresis. They also reported integrated pulsed amperometric detection (iPAD) coupled with microfluidic device electrophoresis to the analysis of various carbohydrates [121]. Manica et al. [122] utilized electrical potential waveforms similar to PAD to clean Pt working electrodes. This method was applied in the analysis of histamine and serotonin, which can absorb strongly to metal surfaces and gave detection limits of $78 \mathrm{nM}$ and $17 \mu \mathrm{M}$ for serotonin and histamine, respectively. Repeated use of the Pt electrode and application of electrochemical treatment did not affect the noise, metal adhesion and physical appearance of the electrode. Garcia et al. used unmodified gold electrode for stable detection of phenolic pollutants in base medium on a PDMS microfluidic device [123]. The electro-oxidation of phenolic compounds depends on the $\mathrm{pH}$, concentration and temperature and a thin insulating polymeric layer [124, 125]. Ding et al. [126] demonstrated CE microfluidic device with PAD for the analysis of phenolic acids in water samples. Separation potential, buffer $\mathrm{pH}$ and composition, injection time and PAD parameters were optimized for the separation and detection of six pheno- lic acids. PAD applies three-potential waveform to the working electrode and the redox cycle serves to regenerate a clean, oxide-free noble metal surface for the electrochemical detection, allowing high signal stability and even real-time monitoring of nonsteroidalanti-inflamatory agents in serum [127].

\subsection{Voltammetry}

Voltammetric detection appeared early in microfluidic chip design with the work of Rossier [128]. Rossier studied the electrochemical response of carbon microband electrodes placed in a microchannel by cyclic voltammetry and chronoamperometry. Ueno et al. [129] used voltammetry, chronoamperometry and computer simulation to evaluate the electrochemical response in polymer microchannels. It was found that the electrode responses in the microchannel chip were best described by one-dimensional diffusion along the channel length. The restricted space and speed of solution flow in the channel greatly affected the collection efficiency. Holland el al. reviewed fundamental concepts of amperometric and voltammetric detection techniques coupled with $\mathrm{CE}$ chip [130]. Recently, Du et al. [131] used linear potential and chronoamperometry in capillary electrophoresis to reveal the oxidation mechanism of thiosulfate. Cyclic chronopotentiometry (CCP) detection mode in end-column $\mathrm{CE}$ chip was used to separate and quantitatively detect sugars in honeys [132]. Earlier, Henley et al. [133] modelled mass transport and potential distribution of electro osmotic flow in the microfluidic devices. Linear sweep voltammetry detector in a microfluidic channel demonstrated the effects of IR drop on the voltammetric response of working electrode. Forry et al. [134] used fast-scan cyclic voltammetry (FSCV) at carbon-fiber microelectrodes to probe electric fields inside microfluidic channels. FSCV also takes the advantage of measuring electro active analytes that are not separated in the channel.

A technique related to FSCV is sinusoidal voltammetry (SV). In the case of SV, a large amplitude sine wave is used as the excitation waveform with data analysis performed in the frequency domain [135]. SV is becoming increasingly popular in Microfluidic device based CE because of its improved sensitivity, lower background noise and wide application of substances. Hebert [135] et al. compared amperometry and SV and found that SV is about an order of magnitude more sensitive than constant potential amperometry. Carbohydrates were studied with SV at a planar copper electrode with mass detection limits of less than 200 amol for glucose and sucrose [136]. Planar carbon electrodes made from pyrolyzed photo resist films are integrated on a PDMS/quartz hybrid microfluidic device [137]. SV detection of various neurotransmitters at these carbon electrodes demonstrates that the electrodes are stable with low capacitance and have high sensitivity; the detection limit for dopamine is $100 \mathrm{nM}$. Single nucleotide polymorphism (SNP) has been screened by capillary gel electrophoresis with SV detection in the same group [138]. This chip-based screening system takes the advantage of accuracy of the thermostable polymerase with the help of an electrochemically labeled chain terminator in the single base extension reaction. The terminator is incorporated only when its Watson-Crick complementary base is present at the mock SNP site. 
Other voltammetry detection methods such as squarewave and adsorptive-stripping voltammetry have also studied on microfluidic devices [139]. Square wave voltammetry is a sensitive electrochemical method for the detection of absorbed ion on the electrode surface. In square-wave voltammetry a potential wave is applied to the working electrode. Ramaley and Krause [140] invented square-wave voltammetry but Osteryoungs [141] extensively developed the method. Gerhaddt et al. [142] used modified Osteryoung SWV techniques in capillary electrophoresis. In this modified methods, instrument collects current data during the entire square-wave cycle. Recently, Lindsay et al. [143] reported droplet-based electrochemical digital magnetofluidics system for automated clinical diagnostics and drug discovery. Square-wave voltammetry and chronoamperometry was used for rapid measurements of microdroplets containing magnetic microparticles. CE chip integrated with square wave voltammetry successfully quantifies avidin in transgenic plant [144].

Anodic stripping voltammetry is an extremely sensitive and popular electrochemical technique for measuring heavy metals. Stripping analysis consists of two step processes, electrolytic deposition of trace amount heavy metals on the working electrode and dissolution (stripping) of the deposit. In the conventional anodic stripping voltammetry (ASV), mercury $(\mathrm{Hg})$ or mercury precursor acts as a working electrode. For disposable in situ sensing applications, mercury or mercury precursors is not ideal for working electrode. Recently, Zou et al. [145] introduced bismuth (Bi) as an alternative working electrode for in situ heavy metal ions measurement. They used square wave anodic stripping voltammetry in $\mathrm{CE}$ chip for $\mathrm{Pb}$ (II) and $\mathrm{Cd}$ analysis and the limit of detection was recorded $8 \mathrm{ppb}$ and $9.3 \mathrm{ppb}$, respectively. Naseri et al. demonstrated catalytic adsorptive stripping voltammetry [146] and stripping voltammetry [147] in an electrochemical micro-flow cell. Bismuth-film working electrode detected $\mathrm{Ni}$ (II) by square wave adsorptive stripping voltammetry in disposable CE microfluidic device [148].

\subsection{Conductimetric and Potentiometric Detection}

Microfluidic devices with electrochemical detection have been mainly based on the amperometric mode because of its high sensitivity and simplicity of integration with the microfluidic device. This approach is, however, limited to the detection of electrochemical active species and therefore has limited applications. Conductimetry and potentiometry are good complementary approaches since they are more universal for ionic species [149-151].

In conductimetric detection, differences in the conductivity or impedance of analyte zones and the background electrolyte are measured when they flow through the detector fabricated on microfluidic devices. This is a universal detection approach, applicable to all charged species, that has been applied in CE on microfluidic device in either the galvanic [152-154] or the contactless mode [155, 156]. Conductimetric detection has been used in the analysis of metals ions, amino acids, protein and DNA. In conductimetric detection systems, usually background electrolytes exhibit a comparatively lower specific conductance from those of the analyte ions. However, high concentration of background electrolytes is necessary to reduce electrodispersion effect in CE chip. Background electrolyte suppressor technique prior to detection can enhance signal-to-noise ratio. However, it is difficult to miniaturise the suppressor in CE-EC systems. Conductivity detection method work best for small, mainly inorganic ions with high mobility. Contact conductivity and contactless conductivity are the two main approaches of the conductivity detection (CD) mode. In the contact conductivity that is also known as galvanic mode, a pair of sputtered or platinum wire electrodes is placed in the channel as the detector. Contactless detection is preferred to galvanic detection for several reasons including obviation of gas bubbles and fouling of electrodes, effective isolation from high electric separation fields and easier alignment of electrodes and detector. Contactless conductivity, which is also known as capacitive coupled contactless conductivity detection $\left(C^{4} D\right)$, has experienced a rapid attention in recent years. The detector is placed outside or close to the channel instead of inside which makes the alignment of the electrodes much easier. No contact between the electrodes and the buffer in the channel, thus no gas bubbles are formed at the electrodes and no fouling of the electrodes. This mode can especially isolate the separation high voltage electric field from the detector. In CE microfluidic device, capacitatively coupled contactless conductivity detection mode enhanced detection limit down to ppb level [157]. A review on contactless conductivity in CE can be found in reference [158, 159]. Kuban et al. [160] found that the sensitivity of detection can be improved by applying lower frequency, high excitation voltage, and widen gap between electrodes to get lower stray capacitance. Hoffmann et al. reported high sensitive DNA detection by capacitively coupled contactless conductivity measurement in CE microfluidic device [161]. CE chip was fabricated and characterized by several polymeric substrate, such as PMMA, polystyrene, polycarbonate, cycloolefine copolymer, polyether ether ketone (PEEK) [161, 162]. Recently, several review articles were published concerning different aspects of capillary electrophoresis with the contactless conductivity detection [163-164].

Wang [166] used a combination of conductivity and amperometric detection on a single microfluidic device for the simultaneously determination of both ionic explosives and electroactive nitroaromatic species. This group has also designed a new injection layout to achieve simultaneous measurements of anions and cations on a PMMA microfluidic device [167]. In order to understand the separation process, Wang et al. [168] created a movable detection system by placing the detector at different points along the micro channel; and this design allowed the optimisation for the detection of low-energy ionic explosives as well as nerve agent degradation products. Recently, Vázquez integrated dual contactless conductivity and end-channel amperometric detection on PDMS/glass CE microfluidic device [169]. Laugere et al. [170] proposed a four-electrode contactless conductivity detector for $\mathrm{CE}$ microdevices. This configuration was found to be more sensitive in detection in varying conductivity of background electrolyte without the need for adjustment of the detection frequency. Generally, when buffer is changed, there is a need to readjust the measurement frequency to get optimal sensitivity, linearity and accuracy. An LOD of around $5 \mu \mathrm{M}$ was obtained for potassium. 
Recently, Kuban used external contactless conductivity detector in CE chip [171]. Two copper electrodes were placed in anti-parallel position and the gap between the electrodes was $0.5 \mathrm{~mm}$. A Faraday shield was placed between the two copper electrodes to reduce direct capacitive coupling between the electrodes.

Contactless conductivity detection on chip has also been used to determine aliphatic amines in nonaqueous background electrolytes that are UV absorbable [172]. Acidic background electrolyte increases the sensitivity and the detection of limit in the order of $1 \mathrm{mM}$ [173]. Tanyanyiwa [174] developed capacitively coupled contactless conductivity detector to measure heavy metal ions with detection limits of $2.1,2.8$, and $6.8 \mu \mathrm{M}$ for $\mathrm{Mn}^{2+}, \mathrm{Zn}^{2+}$, and $\mathrm{Cr}^{3+}$, respectively. Citric and lactic acids in food and beverage and three antiinflammatory nonsteroid drugs have been also analysed with good results. Contactless conductivity detection on a PMMA microfluidic chip was used to determine underivatized anionic sulfonates, carboxylates and artificial sweeteners, and cationic dopamine, ephedrine and metanephrine [175]. Amino acids and sugars were measured in a glass micro channel because the poor chemical resistance of PMMA chips under strong alkaline conditions. The detection limits for the species examined are in the range of 1 to $30 \mu \mathrm{M}$ [175]. The sensitivity of contactless conductivity detection mode for bio molecules, such as amino acids, peptides and proteins, depends on the background electrolyte and the $\mathrm{pH}$ range [176]. Recently we have seen contactless conductivity detection of chlorhexidine digluconate [177], polyhexamethylene biguanide [177], salbutamol [178], and tobramycin [179]. Tuma et al. [180, 181] reported contactless conductivity detection $\left(C^{4} D\right)$ systems for free amino acids in the amniotic fluid. The background electrolyte was consisted of $1.7 \mathrm{M}$ acetic acid and $0.1 \%$ hydroxyethyl-cellulose ( $\mathrm{pH} 2.15)$ and the LOD values were between $1.5 \mu \mathrm{M}$ (arginine) and 6.7 $\mu \mathrm{M}$ (aspartic acid). Electrophoretic separation of phenolic acids (derivatives of benzoic and cinnamic acids) was measured with contactless conductometric detection in less than 6 mins [182]. $\mathrm{Cu}$ wire acts as a shield for the indirect conductometric measurements and the LOD was recorded $2.3 \mu \mathrm{M}$ to $3.3 \mu \mathrm{M}$. External contactless conductivity detector in $\mathrm{CE}$ chip is quite popular for the detection of biochemical species, such as amino acids, peptide, proteins, immunoglobulin and DNA [171], inorganic ions [183], small amines [184], vitamin C [185], benzoate [185], sorbate [185]. Other applications, such as enzymatic assay of organophosphate nerve agents [186], nitrogen mustard degradation products [187], lithium in whole blood [188] and basic drugs [189] have been released recently on microfluidic devices with conductimetric detection.

Conductivity detection undertaken by direct current is termed as potential gradient detection (PGD) [190]. The technique is based on the measurement of variations of electric field strength between zone boundaries during electrophoresis [191]. The difference in mobility of ions due to different charges produces various migration zones and is detectable by PGD. Feng [192] separated three metals in 1 min with plate numbers of 60400 plates $/ \mathrm{m}, 64150$ plates $/ \mathrm{m}$ and 77700 plates $/ \mathrm{m}$ for $\mathrm{K}^{+}, \mathrm{Na}^{+}$and $\mathrm{Li}^{+}$, respectively; this is competitive with conductivity detection on a microfluidic device [193]. Determination of alkaloids, strychnine and brucine in nonaqueous $\mathrm{CE}$ is applicable as well in Feng's work [192]. A novel potential gradient detection system coupled with a portable CE chip separated DNA fragments in polymer solution [194]. Feng et al. [195] also applied PGD to non-UV active compounds detection. This group also detected native neomycin components in a portable CE chip without any derivatization step [196]. CE coupled with potential gradient detection method separated and detected enoxacin, ofloxacin, fleroxacin, and pazufloxacin in $2.8 \mathrm{~min}$ with the detection limit of 23 to $65 \mathrm{ng} / \mathrm{mL}$ [197].

In CE microfluidic device, potentiometric detection is less widely used than amperometric and conductivity detection but is a useful alternative for non-electroactive ions. Potentiometry is based on ion-selective electrodes coated by semi-permeable membranes that allow access to specific ions and produce a potential signal that can be related to the ion concentration described by the Nernst equation [198, 199]. Chloride ion-selective electrode (ISE) potentiometrically analysed liquid food samples near and below the lower end of the linear (Nernstian) response region without any pretreatment [200]. Water-soluble anionic, cationic and nonionic surfactants generate pore in the molecular sieves and modify surfactant sensors for the potentiometric detection $[201,202]$. A novel potentiometric chip sensor for $\mathrm{Ba}^{2+}$ ions based on a solvent polymeric membrane has been designed to overcome technical problems of ruggedness for industrial processes [203]. This mode has been rarely coupled with a microfluidic device since ion-selective electrodes are not typically used in the detection of multiple species simultaneously. Sekula et al. [204] used conductive rubber phase coated ion-selective electrodes for potentiometric detection of organic amines, drugs, and biogenic amines. The semipermeable coating was constructed by potassium tetrakis(pchlorophenyl) borate (TCPB), bis(2-ethylhexyl) sebacate (DOS), and high molecular mass poly(vinyl chloride) (PVC). Non-nernstian $\mathrm{SmFeO}_{3} \mathrm{Pt} / \mathrm{YSZ} / \mathrm{Pt}$ sensor potentiometrically detected volatile organic compound (VOCs) in CE chip [205]. A potentiometric approach has some advantages for $\mathrm{CE}$ based microfluidic device including no requirement for electrical decoupling and simplification of fabrication of the detector. The latter often arises from the independent nature of the detector signal and the geometrical size of the electrode.

\subsection{New Detection Schemes}

Klett et al. [206] developed a potentiostatless detection scheme for CE by using two gold microband electrodes which were positioned $10 \mu \mathrm{m}$ apart and $50 \mu \mathrm{m}$ out of the capillary tip. The potential difference $(\Delta E)$ and current between these two electrode were recorded when the CE separation high voltage was applied. High voltage induced $\Delta E$ is found a function of the applied separation high voltage and that the current between the electrodes depends on the $\mathrm{CE}$ voltage and concentration of a redox couple $\mathrm{Fe}(\mathrm{CN})_{6}^{3-} / \mathrm{Fe}(\mathrm{CN})_{6}^{4-}$ which is similar to that in threeelectrode potentiostatic setup. This approach can minimize the whole instrument size for amperometric detection and is of great potential for application in portable CE microfluidic devices. 
Xu et al. [98] found that non-electroactive species can be determined by indirect amperometry through a single carbon fiber electrode which was aligned in the end part of a microchannel (Fig. 3b). The potential difference induced by the $\mathrm{CE}$ separation electric field between the WE and the RE brings about the change of the reduction potential of dissolved oxygen, which can be used as an electroactive indicator to determine non-electroactive analytes. This mode takes the advantage that the adverse effect of separation electric field on detector can be turned into a universal analytical method and decoupling between $\mathrm{CE}$ and electrochemical detector is unnecessary.

\section{FABRICATION OF POLYMER MICROFLUIDIC DEVICES:}

Microfluidic device systems have followed developments in micro electromechanical systems (MEMS) which have wide applications in a variety of sectors. Many of the processes used in the semiconductor industry are widely applicable for lab-on-a-chip developments. A variety of substrates, including glass, polymers and silicon, are used for the development of microfluidic device systems. Glass substrates have the advantage of transparency to visible light wavelengths, no fluorescence and good chemical stability. Microfluidic devices based on glass are difficult to manufacture in large volumes and therefore are expensive. In recent years, polymers and plastics substrates have become more popular materials for microfluidic devices because of their low cost, relatively simple fabrication process [207], potential of disposable use, ease for high replication and availability of a wide variety of materials with different physical and chemical properties.

Replication and direct writing are two major approaches to fabricate polymer devices in $\mu$ TAS (Micro Total Analytical Systems). Replication methods using polymer substrate often use a moulding master. Metals and alloys are the most commonly used materials for the manufacture of micro moulding master [208]. Because of good mechanical properties such as high strength, hardness and durability, metal withstands the sheer force in the moulding process. Silicon is also used as a mould material and has the advantage of allowing fine feature replication [209]. The success in the replication technology mainly depends on the mould structure and surface property of the mould. The key factors include, surface roughness of the mould and the ability to separate the mould from melted substrate.

Several methods are employed for fabrication of master moulds, these include:

- Electroforming mainly (LIGA) based (lithography, electroplating, molding) technologies (LIGA, UVLIGA, IB-LIGA, EB-LIGA);

- Mechanical techniques such as CNC (Computer Numerical Control) milling, micro electrical discharge machining $(\mu \mathrm{EDM})$, micro mechanical milling and electrochemical machining (ECM) using ultra-short pulses

- Excimer and ultra-short pulse laser ablation

- $\quad$ Silicon wet etching

- $\quad$ Reactive ion etching
Mechanical techniques such as $\mathrm{CNC}$ micro milling machine offer long master lifetimes with good geometrical definition at reasonable cost [210]. CNC milling is ideal for the large features (above $100 \mu \mathrm{m}$ ) and has tolerances around $10 \mu \mathrm{m}[211,212]$. CNC milling can be limited when there is requirement for highly complex and fine feature fluidic architectures. Aluminium and stainless steel are the most popular materials for the $\mathrm{CNC}$ milling mould [213]. Micro electro discharge machining ( $\mu \mathrm{EDM}$ ) offers the fabrication of quasi three-dimensional structures in conducting materials [214, 215]. The protocol offers high degree of flexibility in terms of substrate and geometries, but the mould surface is comparatively rough. Considering current micromachining techniques and suitable thermal properties, silicon is a good material for the casting and embossing mould. Wet etching process combined with the lithography process offer a low and high aspect ratio structures. In hot embossing, a silicon mould significantly reduces the fabrication time compared to a metal mould. Non-rectangular shape in the microstructure is the only drawback in the easy process. Deep reactive ion etching (DRIE) offers better high aspect ratio structure with vertical walls [216, 217]. Fast reactive ion etching causes high surface roughness and poor de-embossing characteristics.

Conventional lithography combined with electroplating offers very small and complex structures in the replication technology [218-220]. In the lithography process, a photoresist coated substrate with a conducting electroplating seed layer is exposed to the light and consequently developed. The developing process removes the photoresist from the expected electroplated area. The substrate is later placed in the galvanic bath for the electroplating. Migration of ions between the bath and the conducting seed layer, allows metal growth in the resist free area. The thickness of the electroplated layer is dependent on the applied current, charge, mass, density of the bath, temperature and $\mathrm{pH}$. Considering Faraday's Law,

$x=\frac{1}{\rho} \frac{m}{q} \frac{1}{A} t$

Where $x$ is the film height, $\rho$ is the density of nickel, $I$ is the plating current, $A$ is the surface area plated, $t$ is the applied time and $m$ and $q$ are the mass and charge of one mole of metal. Nickel is a popular metal for electroplating since it can provide a very smooth with good surface chemistry. A LIGA based mould can be used for more than 1000 cycles with the negligible surface roughness $(<10 \mathrm{~nm})$ [221]. In LIGA, poor adhesion to the substrate seed layer and non uniform deposition are the two main issues for consideration. $\mathrm{X}$-ray LIGA also offers very small, complex features with very high aspect ratio structure [222-224].

Polymers can be used as alternative moulds materials and have the advantage of reduction of cost, complexity and fabrication time. Casted PDMS polymer is alternative mould material for the hot embossing and soft lithography process [225]. PDMS is thermally stable and inactive substrate at the $200^{\circ} \mathrm{C}$ processing temperature, offering a soft mould for the soft embossing process. The operating parameter for the soft embossing is almost identical of hot embossing, except the applied force. Usually very weak force $(50 \mathrm{~N})$ force is ap- 
plied in the soft embossing process [226]. Double casted PDMS layer much more stable at the elevated high temperature. Introduction of various polymers such as polyurethanes, epoxies and Teflon increase the thermal stability of the PDMS layer. Negative photoresist SU- 8 has been reported as an injection mould and replication parts in polycarbonate and polypropylene [227, 228]. In de-embossing process, the poor adhesion of SU-8 to the base substrate causes very shorter life line. Micro contact printing [229], hot imprinting [230], X-ray lithography [231, 232] and ion beam lithography [233] are becoming more popular with an increasing demand for polymer micro fluidic devices.

Casting which is also known as soft lithography is a suite of non-photolithographic methods for replicating a negative master [234]. Because of the materials properties, process simplicity, replication accuracy and wide application, casting is one the most popular methods for relatively low volume replication. The polymeric microstructure offers good optical properties with high transparency and is applicable for biological systems. In the soft lithographic methods, a mixture of base elastomer and its curing agent are spread eventually over the mould microstructures. Addition of curing agent, a three dimensional bands are formed in the base elastomer $[235,236]$. Vacuum desiccators with low vacuum $(25-28$ in $\mathrm{mmHg}$ ) are sufficient for degassing and removal of air bubbles. The curing can take place at room temperature or at the elevated temperature. The curing time is directly related to the applied temperature. The temperature and the ratio of the curing agent determine the stiffness of the elastomeric layer. After curing, the soft/rigid elastomeric layer can simply be peeled away from the mould. The soft lithography process offers high replication accuracy at the ambient laboratory condition. Usual clean room environment facility is not essential for the casting process. Reservoir and detection holes can be punched or drilled into the cured materials. The cured materials have excellent adhesion property, which allows a wide choice of bond strength. Plasma treatment of the PDMS elastomer offers permanent bond between two PDMS layers which leads to layer-by-layer construction process. Casting process offers highly complex three-dimensional mixers, flexible valves and pumps within microfluidic channels which enables cell culturing and protein crystallization integrated on microfluidic devices [237-239]. Recently, soft lithography process developed thermo set polymer devices with stable surface properties and good chemical compatibility [240]. Addition of active electronic components into base elastomer and curing agent alters the physical and chemical properties of polymers. Compared to other replication methods, casting has the advantage of easily obtaining high aspect ratio or 3D channels [241-245]. This is especially true for elastomers though it suffers from longer curing time and low mass-yield. A simplified casting method has been developed to produce PMMA channel without specialized instruments [246]. A pre-polymer solution is cast against a silicon master and then polymerised under $\mathrm{UV}$, akin to fast prototyping of PDMS devices [247].

Hot embossing is a popular approach for the fabrication of polymeric microstructure [216, 236]. In the hot embossing process, the polymer wafer and the master structure are heated above the glass transition temperature and a controlled force is applied under vacuum. The assembly is cooled gradually below the glass transition temperature with the applied force and vacuum for the demoulding. The success of the replication process depends on uniform temperature distribution, high vacuum and good surface quality of the mould. In hot embossing, cycle time plays an important role for the mass production of the polymeric microstructure. Typically, the cycle time is 4 to $15 \mathrm{mins}$ for a $4 \mathrm{inch} / 8 \mathrm{inch}$ wafer. The large thermal mass of the insert mould causes the long cycle time for the embossing process [248]. In the recent years, a number of different mould heating methods have been developed including hot gas heating [249], optical heating [250], infrared radiation (IR) [249] and ultrasonic heating [251] for shorter cycle time. A mould with low thermal inertia (LTI) is capable of rapid thermal response in a fraction of seconds and reduces dramatically the cycle time [252].

Nowadays, the low aspect ratio microstructure and rapid production microthermoforming are quite popular [253]. Hot embossing equipment can perform the microthermoforming with negative mould and counter plate. The counter plate is integrated with vacuum and pressure ports. A thin polymer foil is clamped and heated in the mould. Above the glass transition temperature, the elastic film is stretched by a compressed gas pressure and replicates the mould structure [254]. Compared to the hot embossing, the replication accuracy is limited with low aspect ratio structure [255].

Injection moulding is widely used for high polymer fabrication and has the advantage of very short cycle time, which enables a high volume manufacture at low cost [256]. The dried polymer materials are introduced into a hopper and screws are used to transport the polymer from the hopper to the moulding tool. In this section, because of high temperature, the polymer melts and exhibits a pseudo-plastic behaviour [257]. Melted polymer is than injected under high temperature and pressure into the micro structured mould. The liquid polymer flows within the complex microstructure of the mould. For a good aspect ratio structure, a holding time and pressure is applied. In the demoulding process, the mould and the substrate cool together. A good replication of the mould is dependent on, mould temperature, injection speed, injection pressure, holding time and pressure [258]. The injection speed and pressure favour the degradation of the thermoplastic polymer. Microinjection moulding techniques offer high aspect ratio structure but suffers from the requirement of a mechanically complicated moulding tool.

Injection compression moulding process offers compact disc (CD)-based fluidic platform with high aspect ratio in shorter cycle time [259]. This process is a combination of injection moulding and hot embossing within the compression process. In this process, the melted polymer is injected in the flat cavity mould with a piston for compact thin polymer devices. The drawback to this approach is that it is only applicable for very thin micro fluidic devices.

Direct techniques allow rapid fabrication of single microfluidic devices without the need for fabrication of a master mould. This process is fast for the prototyping of single microfluidic device, allowing a wide variety of design alternatives to be considered. The approach is, however, less amenable for mass production since it can be time consuming. 
Photolithography is a popular approach for microfluidic device fabrication. Computer aided design (CAD) programmes such as Macromedia Freehand or Autodesk AutoCAD can be used for the design of the mask. In recent years there has been increasing interest in the use of a thick SU-8 photoresist for polymer fabrication [260]. EPON SU-8 is a negative tone epoxy patternable resist that is mechanically reliable, optically transparent, chemically resistant and hydrophilic. The thickness of the photo resist changes with the spin coating speed and spin time [228]. A thicker photoresist can offer a good structural height for devices. Initially the base substrate is coated with the photoresist and exposed to light, typically g or i-line, through a photo mask [261]. Development of the photoresist thus leads to the three dimensional micro channels. The oligomers in SU-8 photoresist have high density of epoxy-groups that can form tightly cross-linked structure during curing [262, 263].

Recently, direct lithography followed by deep plasma etching of polymer has been reported for the fabrication of polymer based microfluidic devices [264, 265]. Instead of a stencil mask, structured photoresist is used as a mask for the activated plasma to etch the polymer substrate in the plasmaexposed region [265]. The implementation of this method overcomes essential requirements of mould fabrication and simultaneously offers surface modification of the microfluidic channel. Anisotropic plasma etching alters the physical property of the microfluidic channels, in terms of surface roughness and the hydrophobic/hydrophilic nature of the surface. Hydrogels are photostructurable polymers that can show significant volume change depending on the polarity of the solvent or the $\mathrm{pH}$ environment [266]. Hydrogel and other photosensitive pre-polymer mixture can thus be used to create micro channel structure in the presence of controlled exposed light [267]. In the lithography process, unexposed or un-reacted pre-polymers remain in liquid form and easy to be removed. Gelatine is a popular as sacrificial materials to form hydrogel micro fluidic network [268].

Laser based technologies for microfabrication involves the use of UV laser pulses that are absorbed by the polymer, leading to bond breaking by either thermal degradation or photo degradation [269]. The micro channel depth depends on the absorption depth of the polymer, heat of vaporization of the work material, laser wavelength and the laser pulse duration [270]. The geometry of the microstructure was realised by using a mask or moving the substrate base controlled from a CAD file. Usually a deep UV $(<480 \mathrm{~nm})$ is utilized to ablate polymers. Shorter wavelength Excimer lasers, offer higher precision of features. It is relatively easy to produce channels in a wide variety of commercial polymers such as polycarbonate (PC), Poly methyl methacrylate (PMMA), polystyrene (PS), Polyethylene terephthalate (PET) and poly tetrafluoroethylene (PTFE) [271]. The interaction between the laser light and polymer materials alter the hydrophilic/hydrophobic nature of polymer surface which can be of benefit for electro osmotic flow. A potential drawback is a higher surface roughness than alternative approaches.

Stereolithograophy allows a real three-dimensional micro fabrication process. In this process a light sensitive liquid polymer is used with two high intensity light beams. The light beams penetrate through the liquid resin and cross link- ing polymerization only occurs at the point where the two light beams meet. Usually the laser focuses and scans in the $\mathrm{X}-\mathrm{Y}$ direction, and the resin container moves in $\mathrm{Z}$ direction. The height of the structure is determined by the exposure length and dose. The main advantage of this technique is that it is relatively easy and fast for fabrication of a single chip. However, the process is time consuming and not amenable to high replication, additionally cross-linked polymers have a relatively high surface roughness.

Plasma etching is a relatively new approach for the fabrication of microfluidic devices [272, 273]. The plasma of a diluted gas contains highly reactive gas radicals. The chemically aggressive radicals can react preferentially with organic materials and generate reaction by-products, which are subsequently desorbed from the surface. Channels and even holes can be made by plasma etching with an appropriate mask. Recently, Gogolides et al. reported PMMA and PEEK fabrication technology using lithography and plasma etching $[265,274,275]$. Deep anisotropic $\mathrm{O}_{2}$ plasma etching, controls micro channels roughness and emphasizes stable-intime (non-ageing) super hydrophilic nature [265, 274]. Ion beam lithography is a powerful technique for manufacturing microstructures directly without a mask. In this technique, a small beam spot of megaelectronvolt $(\mathrm{MeV})$ ions is scanned over the polymeric substrate and generate a latent image of the pattern. Gonin et al. [276] have used the technique to fabricate 3D PMMA micro channels. Recently Whitlow et al. [277] have used $56 \mathrm{MeV} 14 \mathrm{~N}^{3+}$ and a $3 \mathrm{MeV}^{4} \mathrm{He}^{2+}$ beams from K130 cyclotron and a 1.7 MeV Pelletron accelerators to fabricate microfluidic patterns on PMMA.

A wide variety of methods of devices bonding have been described, including thermal [278] and pressure bonding [279]. Common bonding methods for lidding of polymer channels include plasma [272, 247], glue [280-282], lamination [283-286], UV/ozone surface treatment [287], laser welding [288] and solvent bonding [289-296]. A successful bonding process is justified with preserved channel integrity, geometry and structure with high bonding strength. Detailed reviews of the approaches and issues for bonding have been described [269, 271].

\subsection{Polymer Properties for Lab-on-a-Chip Development}

The use of polymers as substrates for separation devices requires some consideration of their chemical and physical properties. The polymer channel must have chemical resistance to both the analytes and the running buffer. Becker et al. [269] has listed the chemical resistance features of several common polymers to different chemicals such as bases, acids and organic solvents. Polystyrene and polyvinylchloride can resist strong acids, bases and alcohols. PMMA, PC and polyester are not stable in strong bases or ketones and esters. These polymers are available for use in CE analysis when a limited $\mathrm{pH}$ range, around neutral, can be employed. Lee et al. [297] studied solvent compatibility in PDMS microfluidic devices. Other physical characters such as thermal conductivity, dielectric strength of polymers are also included in Becker's paper [269]. Good thermal conductivity enables better Joule heat dissipation and thus higher separation voltage can be applied which in turn leads to a higher number of plates. The dielectric strength properties of the polymer determines the voltage that can be applied across an insulator 
before breakdown occurs. Polyethylene has the highest dielectric strength and thermal conductivity amongst commonly used polymers. Recently, Shadpour et al. [298] compared physicochemical properties of various polymers.

Understanding of the zeta potential or surface charge of polymers is important for the EOF in the channel [299]. Kirby et al. [300] proposed the use of pC (the negative logarithm of the counter ion concentration) as a useful normalization for the zeta potential $(\xi)$ on polymer substrates in contact with univalent counterions (e.g. sodium, potassium). At high $\mathrm{pH}, \mathrm{PDMS}$, polycarbonate and poly(ethylene terephthalate)/poly(ethylene terephthalate glycol) (PETG) have $\zeta / \mathrm{pC}$ in the range of -30 to $-35 \mathrm{mV}$. In the case of poly(tetrafluoroethylene), $\mathrm{PE}, \mathrm{PVC}$ and $\mathrm{PS}$, the $\zeta / \mathrm{pC}$ value are in the range of -20 to $-25 \mathrm{mV}$ for high $\mathrm{pH}$. As a comparison, the $\zeta / \mathrm{pC}$ value at high $\mathrm{pH}$ for silica is $-50 \mathrm{mV}$. The higher the absolute value of $\zeta / \mathrm{pC}$ is, the larger the $\zeta$ will be. This can be used to predict $\zeta$ potential of polymers and thus EOF.

The surface charge density and the EOF are greatly determined by the polymer material, surface treatment or modification methods and even the fabrication route. For example, PMMA channels from laser ablation have higher EOF than that from hot embossing because reactive carboxylate species are incorporated into the surface during the ablation process [301]. Pugmire et al. [302] found that microfluidic devices fabricated by laser ablation under different atmospheres show different surface properties. PETG, PVC and PC micro channels have been found to hold greater EOF and keep native chemical structures when the ablation atmosphere is oxygen rather than nitrogen or argon. In the case of PMMA, the ablation atmosphere was found to have no effect on its surface characteristic.

Most polymer substrates are hydrophobic and therefore have lower surface charge density, and consequently EOF, than that of glass and silica. A lower EOF will lead to lower efficiency because of longer migration time, and band broadening. Highly negatively charged glass channel walls do, however, have the disadvantage of adsorption of biological substances such as proteins, which results in peak tailing and highly asymmetric peaks [303]. Polymers have good biocompatibility but nonetheless in some situations adsorption of biological species on the polymer walls will lead to changes in the polarity and consequently change in the fluidic transport. Recently, Chen et al. [304] reviewed biocompatible polymer materials for the protein research. Much work on the surface modification of polymer microchannels has been developed and reviewed recently [305-308]. Environmentally sensitive polymers, also known as smart polymers, provide some interesting new properties that could be employed for bioassay in microfluidic devices [309].

Epoxy based microfluidic devices offer physical, chemical stability as well as biocompatibility [310]. SU-8 is epoxy based photoresist with high viscous before curing and is inert to analytes after development. As is the case for a number of other thick photoresists, SU-8 is mechanically strong and optically transparent for wavelength above $350 \mathrm{~nm}$ [311, 312 ]. It does, however, suffer from a relatively high coefficient of thermal expansion that causes stress and fracture at elevated temperatures [313].

\subsection{Surface Modification of Polymer Micro Channels}

Surface modification mainly focuses on the improvement of electrophoretic separation by reducing the interactions between the analytes and channel wall, and the control of EOF, leading to a better peak shape, decreased analysis time and controlled EOF. The velocity $(v)$ of the EOF depends on the dielectric constant $(\varepsilon)$, viscosity $(\eta)$ of the solution, applied electric field $(\mathrm{E})$, and the zeta potential $(\xi)$. The zeta potential value changes with the surface charge of the capillary $(\sigma), \mathrm{pH}$ of the buffer solution, counter-ion concentration and ionic strength, surface modifications, and the presence of adsorbed molecules [314]. Because of the lower surface charge densities and lower surface zeta potentials, EOF in polymeric devices is much lower than the glass-based fluidic chips. For the separation efficiency, polymeric microfluidic devices require some modification for higher surface zeta potentials. Adsorption of polyelectrolyte on the capillary surface provides non-uniform surface charge distribution. Recently, Danger et al. [315] reported non-uniform surface charge distribution and its effect on the EOF in CE microfluidic device. They also found that polyelectrolytes coated capillaries alter the magnitude and direction of the EOF and the hydrodynamic contribution to the total peak dispersion. For unmodified polymeric electrophoresis chip, $\mathrm{pH}$ is a dominant factor, this alters the charge of the channels surfaces and therefore the EOF [316, 317]. For unmodified polyethylenterephthalat based microfluidic devices, electroosmotic flow changes from $1.71 \times 10^{-4}$ to $4.35 \times 10^{-4} \mathrm{~cm}^{2}$ $\mathrm{V}^{-1} \mathrm{~s}^{-1}$ over a $\mathrm{pH}$ range of 3 to 10 in a $50 \mathrm{mM}$ phosphate buffer solution [318]. Besides this, the separation voltage, detection potential and injection time also hinder electro osmotic flow in CE chip [319].

Surface modification approaches are categorised according to the stability of the adsorbed layer, normally as described as dynamic, semi-permanent and permanent. Permanent modification involves the use of chemicals [320, 321], chemical reactions [322-325], physical treatment to polymer microfluidic devices such as by laser ablation [270, 302, 326] or plasma approach. The use of hybrid materials for the microfluidic device provide some interesting properties [327, 328]. A semi-permanent method involves the use of mixtures of double-chained, cationic (didodecyldimethylammonium bromide, DDAB) and zwitterionic surfactants (1, 2dilauroyl-sn-phosphatidylcholine, DLPC) mixture which can provide a semi-permanent coat on the CE chip [329]. The surfactants require a conductive buffer which can lead Joule heating and the formation of bubbles [330-335]. The separation efficiency in capillary electrophoresis is strongly dependent on the Joule heating and heat distribution [336-344].

It is comparatively simple to control the EOF direction by dynamically modifying the channel surface with physically adsorbed chemicals, such as polyelectrolytes [320] and surfactants [321]. Two polyelectrolytes, poly(allylamine hydrochloride) and poly(styrene sulfonate) were alternatively coated to the surface of PS and PETG microfluidic devices [320]. Similar EOFs in PS or PETG microchannels have been obtained and the EOF direction can easily be controlled by the charge characteristic of the coating. Positively charged poly(allylamine hydrochloride) has also been used in a short PET microchannel to get a reversed EOF and 
achieve the separation of three alkali cations, potassium, sodium and lithium [345]. EOF can be increased by adding the anionic surfactant sodium dodecyl sulfate in a running buffer. Anionic surfactant, poly(diallyldimethylammonium chloride) and montmorillonite coated fused-silica capillaries showed a highly stable $\mu \mathrm{EOF}$ (run-to-run RSD less than $1.5 \%, \mathrm{n}=20$ ) and high separation efficiency [346]. Similarly, polyanions of poly(acrylamide-co-2-acrylamido-2methyl-1-propanesulfonate) (PAMAMPS) bi-layer reveal stable $\mu$ EOF ranges from $-5 \times 10^{-5}$ to $35 \times 10^{-5} \mathrm{~cm}^{2} \mathrm{~V}^{-1} \mathrm{~s}^{-1}$ in the $\mathrm{CE}$ microfluidic device [347]. Cationic surfactant dimethyldioctadecylammonium bromide (DODAB) and polyoxyethylene (POE) stearate coated CE chip demonstrated a stable EOF and prevention of adsorption of basic and acidic proteins [348]. Usually in CE chip, the cationic surfactants are quaternary amines with anionic counter-ions (chloride or bromide) [349]. Decreased or even directionreversed EOF can be achieved by using the cationic cetyltrimethylammonium bromide [321, 350]. Dou et al. [351] have enhanced the separation efficiency amino acids, carbohydrates and peptides separated by dynamically modified PDMS microchannels with 2-morpholinoethanesulfonic acid (MES). Their further work in modifying PDMS microchannels with non-ionic surfactant, Brij35, resulted in a hydrophilic surface and eliminated the adsorption of proteins on the PDMS surface [352]. In CE microfluidic device, 1-butyl3-methylimidazolium dodecanesulfonate (BAS) [353] and 1butyl-3-methylimidazolium tetrafluoroborate $\left(\mathrm{BMImBF}_{4}\right)$ [354] can act as supporting electrolyte as well as surface modifier and reduce protein absorption within microfluidic devices. Dynamic coating of PDMS surface has been reviewed by Garcia et al. [117]. Tween 20 [355], phosphatidic acid(PA) [117], polyvinylpyrrolidone (PVP) [356] cetyltrimethylammonium bromide [355], n-dodecyl- $\beta$-Dmaltoside [357], sodium dodecyl sulphate [358], didodecyldimethylammonium bromide [359], 1,2-di-lauroylsn-phosphatidylcholine [360], Triton X-100 [360] and palmityl sulfobetaine [361] have strong effect on the EOF. Sodium dodecyl sulphate is highly soluble in aqueous electrolytes easily absorbed on the surface of the polymer and modifies $\mu \mathrm{EOF}[300,362,363]$. Garcia et al. compared the effect of SDS, DOC and PA on EOF and found that SDS coated polymeric microfluidic device provides the highest electroosmotic flow compared to DOC and PA [363]. Mixture of cetyltrimethylammonium bromide with sodium dodecyl sulphate alters the surface charge of PMMA substrate and suppresses protein adsorption [364]. Nonionic surfactant Pluronic F127 of very low concentrations interacts strongly with cyclic olefin copolymer and decreases the separation voltage with minimal Joule heating [365]. Modified surfaces of the microfluidic devices offer reduced migration time and increase peak skewness [366]. However, in the electrochemical detection systems, surfactants interact with the surface of the detection electrode and this facilitates the electron transfer process [367].

Physical treatments such as laser ablation to PMMA [301, 368], PETG, PVC and PC [302, 369], PS and PET [270], and oxygen plasma to PDMS [247] have been used to directly modify the channel surface. Sulphur dioxide plasma treatment introduces negative charge and modifies the inner surface of the PMMA micro channel and enhances EOF $(\sim 7$ $\times 10^{-4} \mathrm{~m}^{2} \mathrm{~V}^{-1} \mathrm{~s}^{-1}$ ) over a wider $\mathrm{pH}$ range (4-10) [370]. Octafluoropropane $\left(\mathrm{C}_{3} \mathrm{~F}_{8}\right)$ and acrylic acid (AA) plasma have been shown to modify the EOF of PDMS microfluidic devices [371]. Argon plasma pre-treatment improves adhesion of the fluorocarbon (FC) and AA films in the modification process [371]. Polymerization of methyl methacrylate monomer (MMA) with modifying monomer molecules (methylacrylic acid (MAA), 2-sulfoethyl methacrylate (2SEMA), 2-aminoethyl methacrylate (2-AEMA)) changes the surface property of the acrylate layer [372]. The monomer is UV-initiated and polymerisation occurs at the atmosphericpressure. Narrow band $254 \mathrm{~nm}$ excimer laser radiation increases the wet ability of the casted PDMS surface [373]. Water-plasma hydroxylation and UV-initiated photochemical reaction between PMMA and 1,1-bromoundecyltrichlorosilane improve EOF for PMMA channels [374]. Covalent immobilization of poly(ethyleneimine) onto PMMA substrates changes the direction of the electroosmotic flow [375]. UV irradiation forms a layer of carboxylic acid on the surface of the PDMS layer and increases electroosmotic flow [376, 377]. PDMS substrate can be modified with the conventional plasma treatment, but the oxide surface life time is very short and reverts to its hydrophobic nature. Extraction of unreacted monomer by a series of organic solvents can increase the EOF and the lifetime of the modified layer [378]. These treatments can improve surface charge density and thus EOF due to increased surface silanols and carboxylic acids. Svato group copolymerized methyl methacrylate with anionic and cationic alkyl methacrylate monomers, such as methacrylic acid, 2-sulfoethyl methacrylate, and 3(N,Ndimethylaminopropyl)methacrylate (DMAPMA) for the protein analysis [379].

Permanently modifying glass channel surfaces mainly originates from silanization chemistry. A variety of robust approaches are used for permanent modification of polymer surface. As for polymer microfluidic devices, the method of surface treatment depends on the polymer materials. Many reports have been concentrated on formation of a layer of polymer coating [322-325, 380] or a monolithic as a sieving material [105] through ultraviolet graft reactions[381, 382].

PMMA surface was modified to be amine-terminated by using an aminolysis reaction where the surface methyl ester groups are coupled with a monoanion of $\alpha$, $\omega$ diaminoalkanes[322]. The modification resulted in a reversed EOF. Further reaction with n-octadecane-1-isocyanate enabled the polymer channel to perform reverse-phase separation of ion-paired double stranded DNA with better resolution. Brown et al. [383] examined different surface modifications techniques for the poly (methylmethacrylate) microfluidic devices. Wang et al. [382] added a chainmodifier monomer, methylacrylic acid, 2-sulfoethyl methacrylate or 2-aminoethyl methacrylate (AEMA) to solution during copolymerization fabrication process. The EOF increases twice in 6\% MAA-modified PMMA chips than native ones and is very stable and reproducible. A reversed EOF can be obtained through 3\% 2-AEMA modification. Qu et al. [384] introduced silane functional groups $\left(\mathrm{Si}\left(\mathrm{OCH}_{3}\right)_{3}\right)$ during craft copolymerization for fabrication of PMMA. A modified surface for protein analysis was obtained through silica sol-gel entrapped enzyme immobilization. Amphiphilic phospholipid copolymer of 2-methacryloyloxyethyl phos- 
phorylcholine and re-butyl methacrylate (PMB) introduce the phosphorylcholine functional groups onto the PMMA surface [385]. The PMB-modified PMMA microfluidic devices exhibited more stable electroosmotic mobility compared with the untreated one.

PDMS surface was modified to be highly hydrophilic through ultraviolet graft polymerization with acrylic acid, acrylamide, dimediylactylamide, 2-hydroxylethyl acrylate, or PEG monomethoxyl acrylate [324, 386, 387]. Hu et al. [323] have also developed cross-linked coatings on the surface of PDMS by UV polymerization and obtained high separation efficiency for five peptides with theoretical plates up to $18600 / 2.5 \mathrm{~cm}$. Their further work found that pre-treatment with a photoinitiator, benzophenone to the surface of PDMS micro channels, the rate of graft polymerization of monomers such as acrylic acid, poly(ethylene glycol) monomethoxyl acrylate, or poly(ethylene glycol)diacrylate at the surface was greatly accelerated [325]. A stable EOF was obtained and a better resolution for the separation of two fluorescein labelled peptides was achieved. Chemical vapour deposition of reactive gases on PDMS and followed by chemical reaction on the surface altered the physical and chemical properties of PDMS (388). Chen et al. reported chemical vapour deposition of poly (p-xylylene) [389], poly (4-aminomethyl-p-xylylene-co-p-xylylene) and poly (4formyl-p-xylylene-co-p-xylylene) [390] on PDMS substrate. Xiao et al. reported a new atom-transfer radical polymerization to modify PDMS channels with a layer of covalently bonded polyacrylamide [391]. Lui et al. [392] employed surface initiated atom transfer radical polymerization (SIATRP) reaction for the PMMA surface modification. A PEG-functionalized monomer, PEG methyl ether methacrylate (PEGMEMA) was polymerized on the surface of PMMA in the SI-ATRP process. Lately, Sun et al. explored a similar process to grow a PEG-functionalized layer on poly(glycidyl methacrylate)-co-(methyl methacrylate) (PGMAMMA) micro channel surfaces using the SI-ATRP method [393]. Xiao el al. carried out SI-ATRP to graft a thin polyacrylamide layer inside the PDMS micro channel [391]. Recently, a new technique known as in-channel ATRP (atom transfer radical polymerization) to modify surface of the micro channel surface [394]. The modified microchannel surface exhibits low, $\mathrm{pH}$-stable EOF and very much low protein adsorption with high efficiencies. A UV treatment of cyclic olefin copolymer (COC) and polycarbonate fluidic chips reduce the contact angle of water [395]. In UV treated microfluidic devices, lysozyme and cytochromec were well separated within 35 s. Efimenko et al. [396] reported that UV treated PDMS in the presence of oxygen enhances the surface charge energies from $26 \mathrm{~mJ} / \mathrm{m}^{2}$ to $72 \mathrm{~mJ} / \mathrm{m}^{2}$. Roman et al. [397] developed a sol-gel method to improve the hydrophilic of PDMS by homogeneously distribution of $\mathrm{SiO}_{2}$ particles on it. Homogeneously distributed $\mathrm{SiO}_{2}(\sim 10 \mathrm{~nm}$ in diameter) within the PDMS polymer matrix by sol-gel method altered water contact angle from $\sim 108.5^{\circ}$ to $\sim 90.2^{\circ}$. This also resulted in a surface with no adsorption of rhodamine $\mathrm{B}$ and doubling of EOF from the native PDMS. Wu et al. [398] treated PDMS surface with oxygen plasma and then coated with multilayer poly (vinylalcohol) (PVA) under high temperature. Lysozyme, ribonuclease B, bovine serum albumin, P-lactoglobulin and fragments of dsDNA have been separated and detected in the PVA modified microchannels with the plates more than $1,000,000 / \mathrm{m}$. In situ surfaceinitiated polymerization process were shown to produce super hydrophobic PDMS surfaces with a contact angle of water at $155^{\circ}$ [399].

Metal and metal oxide coating on the microfluidic devices can effectively tailor the surface energy of polymer surface. Sputter-coated titanium dioxide $\left(\mathrm{TiO}_{2}\right)$ on PDMS substrate decreased water contact angle from $105^{\circ}$ to $25^{\circ}$ [400]. The coating materials are transparent but metal cracking results in the change of the surface properties. Sputtered gold $(<1.0 \mathrm{~nm})$ on PDMS surface decreased water contact angle to $25^{\circ}$ without cracking [401]. Sputtered $\mathrm{SiO}_{2}$ thin film on COC surface offers high optical transmission properties with high solvent resistivity [402]. In situ fabrication of gold nanoparticles on PDMS substrate can alter the physical and chemical properties of PDMS substrate [403]. Activated PDMS surface with an Ar plasma followed by sputter coated aluminium film (44 nm thick) prolonged hydrophilicity up to 30 days [404]. Metallic nanoparticles functionalized with chemical and biological surface coatings offers stable EOF with enzyme reactors, immunoassays and other biochemical analysis on microfluidic device [405, 406]. Immobilization of poly(diallyldimethylammonium chloride) and $\mathrm{TiO}_{2}$ nanoparticles on PDMS surface through layer-by-layer assembly technique favours the separation of biomolecules (Arginine, phenylalanine, serine and threonine) [407]. A detailed review of PDMS surface modification methods for the microfluidic device application has been carried out by Zhou et al. [408].

Base hydrolysis of hot or wire embossed fabricated PETG channels can yield carboxylic acids and alcohol groups on the surface where amine or fluorescent groups can be integrated through further coupling reactions [230]. An improved EOF was obtained. Permanently modified polycarbonate surface has been studied through chemical reaction with poly (vinyl alcohol) or polyethylenimine during injection moulding when the plastic melts [409].

Electrophoresis separation in channels with a sieving matrix formed from photo initiated polymerization reactions has attracted more attention because of the high efficiency in DNA analysis and protein mapping [381]. Recently, Liu et al. reviewed permanent surface modification techniques for the protein analysis [410, 411]. Lai et al. [328] have developed resin-gas injection technology for bonding and surface modification of polymer microfluidic devices. A layer of dry monolithic stationary hydrogel was formed on the walls of a PMMA microfluidic device, serving as a sieving material for electrophoresis separation of DNA fragments. Local modification of the channel surface with the help of masking during UV exposure is another highlight of this work. Porous polymer monoliths have been formed on the plastic surface through a photo graft reaction followed by UV-initiated in situ polymerization [412]. Adhesion of the monoliths on cyclic olefin copolymer tubes or polypropylene micro channels was dramatically enhanced.

Hybrid materials have often been used to construct a microfluidic device [413-415]. As an example PDMS with glass has the advantages of fast and inexpensive prototyping of a microstructure on polymer material and enhanced EOF 
because the glass surface holds more negative charges and thus improves EOF for the whole channel. Polymerization of butyl methacrylate (BMA) and poly(ethylene glycol) methyl ether methacrylate (PEGMA) introduced a PEG layer on the PMMA microchannel surfaces and reduced protein absorption [416]. Absorbed Teflon solution on a PDMS microfluidic channel increased the hydrophobicity of the channel outlet and generate hydrodynamic droplet for bioanalytical analysis [417]. Epoxy polymerisation and followed by aminopropyl silanization of the PDMS polymeric channels resisted nonspecific protein adsorption [418]. Grafted perfluorooctyltriethoxysilane onto oxidized PDMS substrate forms fluorinated micro channel and separate fluoresceintagged proteins [419].

A microfluidic channel outlet has been recently used to generate separation efficiency in hybrid channels. However, it was limited by the nonuniformity of the surface charge density due to different materials, and increased dispersion causeed peak broadening and tailing [420]. Chen et al. [327] have reported a solution to nonhomogeneous electroosmotic flow in PDMS/glass microchannel. The channel surface was dynamically modified with a stable poly(dimethylacrylamide) coating on both the PDMS and glass surfaces. Improved hydrophilicity on the PDMS surface was observed and the separation of flavin adenine dinucleotide (FAD) and fluorescein with a high efficiency of 105,000 plates $/ \mathrm{m}$ was obtained. Zangmeister [421] reported an approach to spatially immobilize DNA-containing polyacrylamide hydrogels in a PMMA/PC hybrid microchannel. A 3D DNA selective separation matrix was created by ultraviolet/ozone photopolymerization. The lifetime of the gel plugs increased nearly 2.5 times over unmodified channels. Poly (ethyleneoxide) (PEO) has been used to coat PMMA channels to minimize the interaction of DNA with the polymer surface. Besides this, 2-hydroxyethyl cellulose, hydroxypropyl cellulose and polyvinyl pyrrolidone are also popular for PMMA surface coating [422]. Recently Munk et al. [423]reviewed approaches to chemically modify poly(methyl methacrylate), poly(dimethylsiloxane), polycarbonateand cyclic olefin polymeric chips. $\beta$-galactosidase (lactase) covalently attaches polyethylene films and dramatically changes the surface property [424]. Bioactive compounds covalently bond to the polymer surface and change the physical and chemical properties of the surfaces. Wet chemical [383, 424, 425], organosilanization [374], ionized gas treatment [378] and UV irradiation [324, 373] are the most popular techniques for the attachment of bioactive compounds on the functionalized polymer surface. Goddard et al. [426] recently reviewed covalent attachment of the bioactive compounds.

\section{INTERGATION AND APPLICATION}

Efforts in integrating micro devices have focused on miniaturizing the high voltage power supply or detector, improving the degree of automation in sample introduction [427], enhancing the throughputs and development of a standard interface for microfluidic devices [428]. The development of low cost electrodes in micro devices is particularly important for electrochemical detection. Here we mainly focus on the electrode fabrication approaches and the miniaturization of power supply for microfluidic device.

\subsection{Electrode Fabrication for Microfluidic Devices and Application}

Electrode fabrication methods for microfluidic devices involve photolithography together with material deposition techniques, screen-printing techniques, laser ablation, wet chemistry and conventional manual microelectrode fabrication processes. Photolithography with material deposition techniques, such as sputtering and evaporation, are widely used in manufacturing electrodes on microfluidic device, especially for metal electrodes such as Pt [32], Au [429], Pd $[82,85,88]$, carbon or even boron-doped diamond [430]. The choice of the working electrode materials depends on the application. This approach has the advantage that it is relatively easy to locate the position of the electrodes within the channel, is capable of good reproducibility of electrode and amenable to large scale production of devices although costly for small production runs.

Carbon electrodes are most commonly used in CE electrochemical detection techniques for analysis of inorganic and organic species. Such electrodes exhibit attractive electrochemical properties, including wide potential range, low over potential and background noise, rich-surface chemistry, chemical inertness, minimal fouling, low cost and variety forms. Carbon electrode is available in carbon fiber [107], carbon glassy, graphite, carbon paste and film form. Screenprinted electrodes in a manner of end-channel ED coupled with microfluidic devices are low cost and capable of largescale production [36]. Chemical modified screen-printed thick film carbon electrodes have been demonstrated to be flexible, simple with versatile applications [431-433]. Wang's group has accomplished analysis of various species such as carbohydrates, urine, vitamin C [434], amino acids [435], epinephrine [436], hydrazine [431] and organophosphate nerve agent [437]. Compared to the conventional metal electrode, electron transfer rates at carbon electrode are low. A cellulose-single-stranded DNA (cellulose-ssDNA) modified carbon electrode was fabricated to determine dopamine (DA), norepinephrine (NE), 3,4-dihydroxy-L-phenylalanine (L-DOPA), 3,4-dihydroxyphenylacetic acid (DOPAC), and ascorbic acid [438]. The modification of the working electrode improved the sensitivity about 12 times higher than bare one. Earlier, a glass microfluidic device has been developed with single-wall carbon nanotube modified working electrode based on screen-printed carbon electrode . Lower detection potentials were applied in determining hydrazine, phenol, purine and amino acid compounds. Carbon nanotubes were found to promote electron-transfer reactions and impart higher resistance to surface fouling [439]. Integrated microfluidic device with single-wall carbon nanotube modified electrode has a great potential for environmental and bioanalysis applications. Screen-printed electrode modified with multi walled carbon nanotubes (MWCNTs) detects water-soluble vitamins (pyridoxine, ascorbic acid, and folic acid) [440]. Pumera et al. reported comparative study of single-wall and multiwall carbon nanotube for CE microfluidic device [441].

Liu et al. [43] used micro moulding facilitates for simple and sensitive multiple different metal electrode. A LOD of $100 \mathrm{nM}$ for dopamine was obtained without a decoupling consideration [442]. Carbon paste [443], carbon fiber [444, 
445] and carbon ink [88, 446] have also been used as concave filling electrode materials on micro devices and widen the application of a chip. An indirect method for monitoring nitric oxide by determining nitrate and nitrite at such a carbon fibre electrode on micro device with electrochemical detection has been developed by Lunte's group [445]. This method involves directly amperometric detection of nitrite following a $\mathrm{CE}$ separation and conversion of nitrate to nitrite by chemical reduction through $\mathrm{Cu}$-coated $\mathrm{Cd}$ granules. Gawron's work improved the detection selectivity through the dual-electrode detection of a $\mathrm{Cu}$ (II) peptide complex (444). Hebert et al. [137] obtained a pyrolyzed carbon film through pyrolysis procedure for sinusoidal voltammetry detection of neurotransmitters.

Recently, Walker et al. reported a new approach to fabricate microelectrodes on polymeric substrate using airbrush [447]. The airbrushing tool patterns the conductive inks as a thin film on the substrate. The pressurised air atomizes the ink into very tiny droplets and a very fine nozzle tip allows the ink to spread uniformly. As is the case for screen-printed electrodes, airbrushed electrodes separate peak for ferrocyanide at $0.34 \mathrm{~V}$.

$\mathrm{Pt}$ is one of the most widely used metals for electrochemical detection. Early in 1996, Ewing [448] developed a glass micro device with electrochemical detection. Arrays of 100 working Pt microelectrodes were fabricated by photolithography and analyzed samples continuously introduced through a moving sampling capillary. As a noble metal, Pt electrode surface offers favorable electron transfer kinetics and large anodic potential range. Low hydrogen overvoltage is the main drawback of the Pt working electrode and restricts cathodic potential window. Low hydrogen overvoltage range causes formation of oxide layer /hydrogen layer on the electrode surface and alters kinetics of the electrochemical reaction. Pulse amperometric detection mode can overcome the problem by cleaning the absorbed layer on the noble metal electrode surface [449]. An integrated microfluidic glass device with electrochemical detection was reported in 1998 [32] in which Pt working and counter electrodes were fabricated by photolithography coupled with plasma sputtering. The $\mathrm{Ag} / \mathrm{AgCl}$ reference electrode was placed in a detection reservoir. Indirect electrochemical detection with endchannel mode has been adopted to determine DNA restriction fragment and PCR product sizing with LOD of $28 \mathrm{zmol}$ for fragment $603-b p$ of $\Phi X 174$. This micro device with a matching detector initially achieved the concept of microfluidic device. Xia et al. used Pt ultra microelectrode integrated on a three-dimensional adjustor for the electrochemical detection of benzenediols and related pharmaceutical compounds [316]. Pt microelectrode $(10 \mu \mathrm{m})$ sealed with Pyrex tube was placed at the end of the separation channel with $\mathrm{Pt}$ counter electrode and $\mathrm{Ag} / \mathrm{AgCl}$ reference electrode. Endchannel platinum working electrode successfully evaluated $\mathrm{H}_{2} \mathrm{O}_{2}$, l-ascorbic acid, $p$-aminofenol in a $\mathrm{CE}$ microfluidic device [58, 59]. Pt working electrode as well as gold nanoparticles enhanced electrochemical detection of roxithromycin [450].

Martin et al. [429] made a PDMS/glass microfluidic device in which dual gold electrodes were lithographically fabricated on glass. A linear response from 10 to $500 \mu \mathrm{M}$ with a LOD of $4 \mu \mathrm{M}$ was obtained for catechol. Fully integrated microfluidic devices with ED have been created with all $\mathrm{Pt}$ electrodes by Baldwin's group [65] and six gold electrodes by Wilke [49]. In these systems, both $\mathrm{CE}$ and detection have been incorporated on glass substrates by using MEMS based approaches of photolithographic patterning, wet chemical etching, sputtering, and thermal wafer bonding. This represents a maturing of fabrication techniques for micro devices. Compared to $\mathrm{Pt}, \mathrm{Au}$ electrodes are more inert with high hydrogen overvoltage range. The Au electrode is also convenient for self-assembled organosulfur monolayer and stripping voltammetric analysis. Single-wall carbon nanotubes modify the electrochemical property of the bare gold working electrode and exhibits low noise levels for aminophenols and neurotransmitters [451]. Electrochemically prepared mercury/gold electrode offers fast, sensitive and reproducible detection of nitro aromatic explosive compounds [452].

The excellent electrochemical properties of diamond make it a very attractive material for use in the electrochemical detection. A boron-doped diamond thin film WE was fabricated through microwave plasma-assisted chemical vapor deposition [119, 430, 453]. At the selected detection potential, boron-doped diamond microelectrode offers low and stable background current with enhanced sensitivity [454]. This diamond electrode has the advantage of lower noise, strong resistance to fouling and high sensitivity to environmental pollutants $[455,456]$. The LODs for 4-aminophenol and 2-aminonaphthalene are 2.0 and $1.3 \mu \mathrm{M}$, respectively. Boron-doped diamond microelectrode integrated in CE chip detected the level of endogenous norepinephrine in several tissues [457]. Chen et al. reviewed the potential application of boron-doped diamond microelectrode in CE chip [458]. Recently, Gao et al. [459] reported the fabrication method of Boron Doped Diamond Microelectrode (BDDME) for microfluidic devices and electrochemical characteristics of BDDME such as wide potential window, low background current, high electrochemical stability for biological detection as well as detection of trace substances.

Applying laser pulses directly to polymer surfaces forms a defined concave in the bottom or the sides walls of the channel, and carbon paste or ink can be filled in to construct an electrode [81, 128]. The desired microstructure was produced using plasma etching of a sandwich copper/polyimide/copper circuit board combined with chemical etching of copper [273]. It has the advantage of fabricating holes for the flow control, as well as electrodes from gold or other metals in a batch process by means of electroplating at copper etched position. This method enables the mass production of low cost and disposable polymer microfluidic device with electrochemical detection.

A few reports have described fabrication of working electrodes through wet chemistry such as chemical deposition of gold at channel outlet [460], electroplating $\mathrm{Au}$ or $\mathrm{Cu}$ electrode on a microfluidic device [461]. Yan et al. [352,462] obtained a PDMS/glass micro device with gold or copper electrodes for electrochemical detection. They used soft lithography of PDMS to define the geometry of the microelectrodes and followed by electroless chemical deposition process, which included silane and sensitizing of the glass surface first, forming a layer of nanoscopic Ag particles, then the copper formed through reduction of $\mathrm{Cu}^{2+}$ by formalde- 
hyde, and finally a layer of gold can be produced. The similar electroless chemical deposition process has been used to construct gold nanoelectrodes through a model template of polycarbonate membrane [463] and first report of nickel WE to detect alcohols and sugars on a glass microfluidic device [464]. Recently, photo-directed electroless plating combined with electroplating techniques was used for the fabrication of $\mathrm{Au}$ microelectrode [465]. In this technique, gold nanoparticles was deposited on the patterned microstructure and later the nano-particles served as the catalyst for the electroless plating. Scanning electrochemical analyzer electroplates the gold microelectrode and generates $\mathrm{Ag} / \mathrm{AgCl}$ reference and $\mathrm{Pt}$ courter electrode for the electrochemical detection techniques [466]. Electrochemical deposition of gold particles on the working electrode increases the surface area of the Au sensing microelectrode and offers well-resolved separation of dopamine and catechol in less than $60 \mathrm{~s}$ [105]. Absorption of self-assembled monolayer (SAM) of 3mercaptopropionic acid modifies the gold working microelectrode and enhances the limit of detection of dopamine [467]. Electroless plating and interface rotation of laminar flows with three multiphase fluids with density difference allows single and dual silver working electrode in a microchannel [468]. Electrodeposited Prussian blue film on the indium tin oxide, electrode catalyzes redox reaction and enhance electrochemical sensitivity [469]. Prussian blue film coated ITO electrode detected $0.1 \mathrm{mM}$ dopamine and catechol in a CE microfluidic device.

Metal wire [41, 58, 470], carbon fiber [38, 471] or bundle micro disk electrode [472, 473], and nano material [474] are applicable for integration with micro devices. Usually a guide tube $[39,39,475]$ or $3 \mathrm{D}$ adjuster [38, 476] is used to place the WE accurately to get good reproducibility.

\subsection{Miniaturisation}

A report on a portable capillary electrophoresis instrument with amperometric, potentiometric and conductometric detection is given by Kappes et al. [477]. Static high voltage power supply is essential for the stable EOF and pumping [478. 479]. In addition to the detection method, it is also necessary to consider development of a compact, small and portable HV power supply. HV power supply's dimensions, weight and power are the key parameters for the miniaturization and portability. Field portable miniaturized capillary electrophoresis instrument reduces the time, cost of the analysis, and avoid sample decomposition during transportation and preparation. A simplified detector with two electrodes for amperometric detection on microfluidic device appeared in 2001 [461]. In order to facilitate portable use, a number of efforts have focused on miniaturizing of the $\mathrm{HV}$ power supply by means of cell battery. Baldwin et al. [480] integrated the portable HV power supply and the electrochemical detection circuits for microfluidic device based capillary electrophoresis which lasted for 15 hours without charging. The compacted power supply and detector circuit, 4 in. $\times 6$ in. $\times 1$ in. in size and $0.35 \mathrm{~kg}$ in weight is ideal for microfluidic device applications. The efficiencies for dopamine and catechol were 54200 and 100400 plates $/ \mathrm{m}$, respectively under the electric field of $200 \mathrm{~V} / \mathrm{cm}$. The maximum electric strength of $500 \mathrm{~V} / \mathrm{cm}$ could be available. A miniaturized HV power supply for portable application has been de- veloped by Erickson et al. [481]. Pinched and gated injection modes have been achieved by a 3-channel HV power supply that ranges from 0 to $\pm 4000 \mathrm{~V}$ [482]. Kuban et al. developed battery powered portable capillary electrophoresis instrument with voltage capabilities up to $15 \mathrm{kV}$ for more than one working day [483]. The miniaturized HV power supply integrated with capacitively coupled contactless conductivity detection successfully separated and detected inorganic cations and anions [163, 483]. Gärtner et al. designed miniaturized $\mathrm{CE}$ instrument consists of miniature regulated unipolar power supply modules and CE chip holder with proper connection [484]. The total dimension of complete CE instrument was $19 \times 12 \times 8 \mathrm{~cm}^{3}$. (length $\times$ width $\times$ height $)$. Maximum voltage of the miniaturized power supply was recorded $4 \mathrm{kV}$ with current output $250 \mu \mathrm{A}$. Recently, Makarotseva et al. reported a miniaturized portable $\mathrm{CE}$ instrument equipped with a CCD detector and various injection devices for the analysis of the composition of degradation products of chemical warfare agents (CWA) [485]. The power supply system was based on 10 common AA size rechargeable batteries with an operating run time up to 4 hours without recharging. Valdez et al. reported wireless control microfluidic device based capillary electrophoresis and a mobile unit for chemical analysis [486]. The system consists of an embedded processor that is designed for digital control, decoding and applying of wirelessly transmitted test parameters, data acquisition and mobility control. Field programmable gate array (FPGA) board of the mobile platform performs all CE tests including high voltage power supply, injection, separation, pulsed ameperometric detection and transmission of the data [486].

\section{CONCLUSION}

This review has surveyed recent developments in capillary electrophoresis within microfluidic devices with electrochemical detection. Approaches to channel fabrication, surface modification for polymer microfluidic architecture, electrode manufacture and miniaturization of analytical system was discussed. Much work remains in optimizing of fabrication protocols, interfacing to the outside world and system integration. Developments within microfluidic devices will lead to low cost and rugged microfluidic systems that have high sensitivity and selectivity for a wide range of applications.

\section{REFERENCS}

[1] Manz, A.; Graber, N.; Widmer, H.M. Miniaturized total chemical analysis systems: A novel concept for chemical sensing. Sens. Actuators, B, 1990, 1(1-6), 244-248.

[2] Manz, A.; Harrison, D.J.; Verpoorte, E.M.J.; Fettinger, J.C. Paulus, A.; Ludi, H.; Widmer, H.M. Planar chips technology for miniaturization and integration of separation techniques into monitoring systems: Capillary electrophoresis on a chip. $J$. Chromatogr.A, 1992, 593(1-2), 253-258.

[3] Huo, Y.; Kok ,W.T. Recent applications in CEC. Electrophoresis, 2008, 29, 80-93.

[4] Poinsot, V.; Rodat, A.; Gavard, P.; Feurer, B.; Couderc, F. Recent advances in amino acid analysis by CE. Electrophoresis, 2008, 29(1), 207-223.

[5] Dabek-Zlotorzynska, E.; Celo, V.; Yassine, M.M. Recent advances in CE and CEC of pollutants. Electrophoresis, 2008, 29(1), 310323. 
[6] Hernández, L.S.; Crego, A.S.; Marina,M.S.; Ruiz,C.G. Sensitive chiral analysis by CE: An update. Electrophoresis, 2008, 29(1), 237-25.

[7] Kostal, V.; Arriaga, E.A. Recent advances in the analysis of biological particles by capillary electrophoresis. Electrophoresis, 2008, 29(12), 2578-2586.

[8] Herrero, M.; García-Cañas, V.; Simo, C.; Cifuentes, A. Recent advances in the application of capillary electromigration methods for food analysis and Foodomics. Electrophoresis, 2010, 31(1), 205-228.

[9] Kasicka, V. Recent developments in CE and CEC of peptides. Electrophoresis, 2008, 29(1), 179-206.

[10] Tagliaro,F.; Bortolotti,F. Recent advances in the applications of CE to forensic sciences (2005-2007). Electrophoresis, 2008, 29(1), 260-268.

[11] Kraly, J.R.; Holcomb, R.E.; Guan, Q.; Henry, C.S. Review: Microfluidic applications in metabolomics and metabolic profiling. Anal. Chim. Acta, 2009, 653(1), 23-35.

[12] Boyce, M.C. Determination of additives and organic contaminants in food by CE and CEC. Electrophoresis, 2007, 28(22), 4046-4062.

[13] Coufal, P.; Pacáková, V.; Tulík, K. An evaluation of the experimental approaches to detection of small ions in CE. Electrophoresis, 2007, 28(19), 3379-3389.

[14] Timerbaev, A.R. Recent trends in CE of inorganic ions: From individual to multiple elemental species analysis. Electrophoresis. 2007, 28(19), 3420-3435.

[15] Trapp, O. Investigation of the stereodynamics of molecules and catalyzed reactions by CE. Electrophoresis, 2010, 31(5), 786-813.

[16] Guihen, E.; O'Connor, W.T. Capillary and microchip electrophoresis in microdialysis: Recent applications. Electrophoresis, 2010, 31(1), 55-64.

[17] Sánchez-Hernández, L.; García-Ruiz, C.; Marina, M.L.; Crego, A.L. Recent approaches for enhancing sensitivity in enantioseparations by CE. Electrophoresis, 2010, 31(1), 28-43.

[18] Floyd, T.M.; Schmidt, M.A.; Jensen, K.F. Silicon micromixers with infrared detection for studies of liquid-phase reactions. Ind. Eng. Chem. Res., 2005, 44(8), 2351-2358.

[19] Chen, L.; Choo, J. Recent advances in surface-enhanced Raman scattering detection technology for microfluidic chips. Electrophoresis, 2008, 29(9), 1815-1828.

[20] Myers, F.B.; Lee, L.P. Innovations in optical microfluidic technologies for point-of-care diagnostics. Lab Chip, 2008, 8(12), 2015-2031.

[21] Militropoulou, M.; Lecomte, C.; Bayle, C.; Couderc, F.; Karamanos, N.K. Laser-induced fluorescence as a powerful detection tool for capillary electrophoretic analysis of heparin/heparan sulfate disaccharides. Biomed. Chromatogr., 2003, 17(1), 39-4.

[22] Poinsot, V.; Bayle, C.; Couderc, F. Recent advances in amino acid analysis by capillary electrophoresis. Electrophoresis, 2003, 24(2223), 4047-4062.

[23] Johnson, M.E.; Landers, J.P. Fundamentals and practice for ultrasensitive laser-induced fluorescence detection in microanalytical systems. Electrophoresis, 2004, 25(21-22), 35133527.

[24] Go tz, S.; Karst, U. Recent developments in optical detection methods for microchip separations. Anal. Bioanal.Chem., 2007, 387(1), 183-192.

[25] Schulze, P.; Belder, D. Label-free fluorescence detection in capillary and microchip electrophoresis. Anal. Bioanal.Chem., 2009, 393(2), 515-525.

[26] Vilkner, T.; Janasek, D.; Manz, A. Micro Total Analysis Systems. Recent Developments. Anal.Chem, 2004, 76(12), 3373-3386.

[27] Reyes, D.R.; Iossifidis, D.; Auroux, P.A.; Manz, A. Micro Total Analysis Systems. 1. Introduction,Theory, and Technology. Anal.Chem., 2002, 74(12), 2623-2636.

[28] Auroux, P.A.; Iossifidis, D.; Reyes, D.R.; Manz, A. Micro Total Analysis Systems. 2. Analytical Standard Operations and Applications. Anal.Chem., 2002, 74(12), 2637-2652.

[29] Vandaveer, W.R.; Pasas-Farmer, S.A.; Martin, R.S.; Lunte, S.M. Recent developments in amperometric detection for microchip capillary electrophoresis. Electrophoresis, 2002, 23(21), 36673677.

[30] Vandaveer, W.R.; Pasas-Farmer, S.A.; Fischer, D. J.; Frankenfeld,
C. N.; Lunte, S. M. Recent developments in electrochemical detection for microchip capillary electrophoresis. Electrophoresis, 2004, 25(21-22), 3528-3549.

[31] Du, Y.; Wang, E. Capillary electrophoresis and microchip capillary electrophoresis with electrochemical and electrochemiluminescence detection. J. Sep. Sci., 2007, 30(6), 875890 .

[32] Woolley, A.T.; Lao, K.; Glazer, A.N.; Mathies, R.A. Capillary Electrophoresis Chips with Integrated Electrochemical Detection. Anal.Chem., 1998, 70(4), 684-688.

[33] Wu, Y.; Lin, J.-M. Determination of phenol in landfill leachate by using microchip capillary electrophoresis with end-channel amperometric detection. J.Sep.Sci., 2006, 29(1), 137-143.

[34] Martin, R.S. Interfacing amperometric detection with microchip capillary electrophoresis. Methods in Mololecular Biology., 2006 , $339,85-112$

[35] Huang, X.; Zare, R.N.; Sloss, S.; Ewing, A.G. End-column detection for capillary zone electrophoresis. Anal.Chem., 1991, 63(2), 189-192.

[36] Wang, J.; Tian, B.M.; Sahlin, E. Micromachined Electrophoresis Chips with Thick-Film Electrochemical Detectors. Anal.Chem., 1999, 71(23), 5436-5440.

[38] Hilmi, A.; Luong, J.H.T. Micromachined Electrophoresis Chips with Electrochemical Detectors for Analysis of Explosive Compounds in Soil and Groundwater. Environ. Sci. Technol., 2000, 34(14), 3046-3050.

[38] Bao, N.; Xu, J.J.; Dou, Y.H.; Cai, Y.; Chen, H.Y.; Xia, X.H. Electrochemical detector for microchip electrophoresis of poly(dimethylsiloxane) with a three-dimensional adjustor. $J$. Chromatogr. A., 2004, 1041(1-2), 245-248.

[39] Zeng, Y.; Chen, H.; Pang, D.-W.; Wang, Z.-L.; Cheng, J.-K. Microchip Capillary Electrophoresis with Electrochemical Detection. Anal.Chem., 2002, 74(10), 2441-2445.

[40] Castaño-Álvarez, M.; Fernandez-Abedul, M.T.; Costa-García, A Poly(methylmethacrylate) and Topas capillary electrophoresis microchip performance with electrochemical detection Electrophoresis, 2005, 26(16), 3160-3168.

[41] Castaño-Álvarez, M.; Pozo Ayuso, D.F.; García Granda, M.; Fernández-Abedul, M.T.; Rodríguez García, J.; Costa-García, A. Critical points in the fabrication of microfluidic devices on glass substrates. Sens.Actuators, B, 2008, 130(1), 436-448

[42] Wu, Y.-Y.; Qu, F.; Lin, J.-M. Microchip capillary electrophoresis with an end-channel amperometric detector and its preliminary application. Chin. J. Chem., 2005, 23(2), 155-159.

[43] Liu, J.; Pan, T.; Woolley, A.T.; Lee, M.L. Surface-Modified Poly(methyl methacrylate) Capillary Electrophoresis Microchips for Protein and Peptide Analysis. Anal. Chem., 2004, 76(23), 69486955.

[44] Wang, K.; He, F.-Y.; Liu, A.-L.; Xu, J.-J.; Chen, H.-Y.; Xia, X.-H Novel Coupling Mechanism-Based Imaging Approach to Scanning Electrochemical Microscopy for Probing the Electric Field Distribution at the Microchannel End. Langmuir, 2006, 22(16), 7052-7058.

[45] Wang, K.; Jia, W.-Z.; Xia, X.-H. Electric-field distribution at the end of a charged capillary - A coupling imaging study. ChemPhysChem, 2008, 9(14), 2109-2115.

[46] Wallenborg, S.R.; Nyholm, L.; Lunte, C.E. End-Column Amperometric Detection in Capillary Electrophoresis: Influence of Separation-Related Parameters on the Observed Half-Wave Potential for Dopamine and Catechol. Anal.Chem., 1999, 71(3), 544-549.

[47] Ertl, P.; Emrich, C.A.; Singhal, P.; Mathies, R.A. Capillary Electrophoresis Chips with a Sheath-Flow Supported Electrochemical Detection System. Anal.Chem., 2004, 76(13), 3749-3755.

[48] Inoue, J.; Kaneta, T.; Imasaka, T. A sheath-flow electrochemical detector for capillary electrophoresis. J. Capillary Electrophor Microchip Technol., 2007, 10(3-4), 69-73.

[49] Wilke, R.; Bu ttgenbach, S. A micromachined capillary electrophoresis chip with fully integrated electrodes for separation and electrochemical detection. Biosens. Bioelectron., 2003, 19(3), 149-153.

[50] Dawoud, A.A.; Kawaguchi, T.; Markushin, Y.; Porter, M.D.; Jankowiak, R. Separation of catecholamines and dopamine-derived 
DNA adduct using a microfluidic device with electrochemical detection. Sens. Actuators, B, 2006, 120(1), 42-50.

[51] Wang, J.; Muck Jr. A.; Chatrathi, M.P.; Chen, G.; Mittal, N.; Spillman, S.D.; Obeidat, S. Bulk modification of polymeric microfluidic devices. Lab Chip., 2005, 5(2), 226-230.

[52] Wang, Y.; Chen, H. Integrated capillary electrophoresis amperometric detection microchip with replaceable microdisk working electrode: II. Influence of channel cross-sectional area on the separation and detection of dopamine and catechol. $J$. Chromatogr. A, 2005, 1080(2), 192-198.

[53] Klett, O.; Bjo refors, F.; Nyholm, L. Elimination of High-Voltage Field Effects in End Column Electrochemical Detection in Capillary Electrophoresis by Use of On-Chip Microband Electrodes. Anal.Chem., 2001, 73(8), 1909-1915.

[54] Wang, Y.; Chen, H.; He, Q.; Soper, S.A. A high performance polycarbonate clectrophoresis microchip with integrated threeelectrode system for end-channel amperometric detection. Electrophoresis, 2008, 29(9), 1881-1888.

[55] Castaño-Álvarez, M.; Fernandez-Abedul, M.T.; Costa-García, A. Amperometric detector designs for capillary electrophoresis microchips. J.Chromatog r.A, 2006, 1109(2), 291-299 .

[56] Castaño-Álvarez, M.; Fernández-Abedul, M.T.; Costa-García, A. Electroactive intercalators for DNA analysis on microchip electrophoresis. Electrophoresis, 2007, 28(24), 4679-4689.

[57] Pozo-Ayuso, D.F.; Castaño-Álvarez, M.; Fernández-la-Villa, A.; García-Granda, M.; Fernández-Abedul, M.T.; Costa-García, A.; Rodríguez-García, J. Fabrication and evaluation of single- and dual-channel (П-design) microchip electrophoresis with electrochemical detection. J.Chromatogr.A, 2008, 180(1-2), 193202.

[58] Castaño-Álvarez, M.; Fernández-Abedul, M.T.; Costa-García, A. Analytical performance of $\mathrm{CE}$ microchips with amperometric detection. Instrum Sci. Technol., 2006, 34(6), 697-710.

[59] Castaño-Álvarez, M.; Fernández-Abedul, M.T.; Costa-García, A. Procedure 48 Separation and amperometric detection of hydrogen peroxide and l-ascorbic acid using capillary electrophoresis microchips. Compre. Anal. Chem. 2007, 49(16), e343-e349.

[60] Castaño-Álvarez, M.; Fernández-Abedul, M.T.; Costa-García, A. Amperometric PMMA-microchip with integrated gold working electrode for enzyme assays. Anal. Bioanal.Chem., 2005, 382(2), 303-310

[61] Wang, W.; Jin, W. Determination of Glutathione in a Single Human Hepatocarcinoma Cell Using a Microfluidic Device Coupled with Electrochemical Detection., Chin J Chromatogr., 2007, 25(6), 799-803.

[62] Castaño-Álvarez, M.; Fernández-la-Villa, A.; Pozo-Ayuso, D.F.; Fernández-Abedul, M.T.; Costa-García, A. Multiple-point electrochemical detection for a dual-channel hybrid PDMS-glass microchip electrophoresis device. Electrophoresis, 2009, 30(19), 3372-3380.

[63] Castaño-Álvarez, M.; Fernández-Abedul, M.T.; Costa-García, A.; Agirregabiria, M.; Fernández, L.J.; Ruano-López, J.M.; BarredoPresa, B. Fabrication of SU-8 based microchip electrophoresis with integrated electrochemical detection for neurotransmitters. Talanta, 2009, 80(1), 24-30.

[64] Klett, O.; Nischang, I.; Nyholm, L. Deviceless decoupled electrochemical detection of catecholamines in capillary electrophoresis using gold microband array electrodes. Electrophoresis, 2002, 23(21), 3678-3682.

[65] Baldwin, R.P.; Roussel, T.J.; Crain, M.M.; Bathlagunda, V.; Jackson, D.J.; Gullapalli, J.; Conklin, J.A.; Pai, R.; J.F., Naber.; Walsh, K.M.; Keynton, R.S. Fully Integrated On-Chip Electrochemical Detection for Capillary Electrophoresis in a Microfabricated Device. Anal.Chem., 2002, 74(15), 3690-3697.

[66] Chu, Q.; Fu, L.; Guan, Y.; Ye, J. Determination and Differentiation of Flos Chrysanthemum Based on Characteristic Electrochemical Profiles by Capillary on Characteristic Electrochemical Profiles by Capillary. J. Agric. Food Chem., 2004, 52(26), 7828-7833.

[66] Guan, Y.; Wu, T.; Lin, M.; Ye, J. Determination of Pharmacologically Active Ingredients in Sweet Potato (Ipomoea batatas L.) by Capillary Electrophoresis with Electrochemical Detection. J. Agric. Food Chem., 2006, 54(1), 24-28.

[68] Peng, Y.; Chu, Q.; Liu, F.; Ye, J. Determination of Phenolic Constituents of Biological Interest in Red Wine by Capillary
Electrophoresis with Electrochemical Detection. J. Agric. Food Chem., 2004, 52(2), 153-156.

[69] Peng, Y.; Zhang, Y.; Ye, J. Determination of Phenolic Compounds and Ascorbic Acid in Different Fractions of Tomato by Capillary Electrophoresis with Electrochemical Detection. J. Agric. Food Chem., 2008, 56(8), 1838-1844.

[70] Kok, W.Th.; Sahin, Y. Solid-state Field Decoupler for Off-Column Detection in Capillary Electrophoresis. Anal.Chem., 1993, 65(18), 2497-2501.

[71] Zhang, S.S.; Yuan, Z.B.; Liu, H.X.; Zou, H.; Wu, Y.J. On-column amperometric detection in capillary electrophoresis with an improved high-voltage electric field decoupler. J. Chromatogr. A, 2000, 872(1-2), 259-268.

[72] Wallingford, R.A.; Ewing, A.G. Capillary Zone Electrophoresis with Electrochemical Detection. Anal.Chem.,1987, 59(14), 17621766.

[73] Yik, Y.F.; Lee, H.K.; Li, S.F.Y.; Khoo, S.B. Micellar electrokinetic capillary chromatography of vitamin B6 with electrochemical detection. J. Chromatogr. A, 1991, 585(1), 139-144.

[74] O'Shea, T.J.; Greenhagen, R.D.; Lunte, S.M.; Lunte, C.E.; Smyth, M.R.; Radzik, D.M.; Watanabe, N. Capillary electrophoresis with electrochemical detection employing an on-column Nafion joint. $J$. Chromatogr. A, 1992, 593(1-2), 305-312.

[75] Zhang, S.S.; Liu, H.X.; Wu, Y.J.; Yu, C.L. On-column amperometric detection of ofloxacin and pasiniazid in urine by capillary electrophoresis with an improved fractured joint and small detection cell. Analyst, 2001, 126(4), 441-445.

[76] Chen, I.-C.; Whang, C.-W. Capillary electrophoresis with amperometric detection using a porous cellulose acetate joint. $J$. Chromatogr. A, 1993, 644, 208-212.

[77] Kim, J.-H.; Kang, C.J.; Jeon, D.; Kim, Y.-S. A disposable capillary electrophoresis microchip with an indium tin oxide decoupler/amperometric detector. Microelectron. Eng., 2005, 7879(1-4), 563-570.

[78] Sha, B.-B.; Yin, X.-B.; Zhang, X.-H.; He, X.-W.; Yang, W.-L. Capillary electrophoresis coupled with electrochemical detection using porous etched joint for determination of antioxidants. J.Chromatog r.A, 2007, 1167(1), 109-115.

[79] Yin, X.-B.; Wang, E. Capillary electrophoresis coupling with electrochemiluminescence detection: A review. , Anal. Chim. Acta, 2005, 533(2), 113-120.

[80] Rossier, J.S.; Schwarz, A.; Reymond, F.; Ferrigno, R.; Bianchi, F.; Girault, H.H. Microchannel networks for electrophoretic separations. Electrophoresis, 1999, 20(4-5), 727-731.

[81] Rossier, J.S.; Ferrigno, R.; Girault, H.H. Electrophoresis with electrochemical detection in a polymer microdevice. $J$ ElectroAnal. Chem., 2000, 492(1), 15-22.

[82] Chen, D.-C.; Hsu, F.-L.; Zhan, D.-Z.; Chen, C.-H. Palladium Film Decoupler for Amperometric Detection in Electrophoresis Chips. Anal.Chem., 2001, 73(4), 758-762.

[84] Lai, S.; Cao, X.; Lee, L.J. A Packaging Technique for Polymer Microfluidic Platforms. Anal. Chem., 2004, 76(4), 1175-1183.

[84] Vickers, J.A., Henry, C.S. Simplified current decoupler for microchip capillary electrophoresis with electrochemical and pulsed amperometric detection. Electrophoresis, 2005, 26(24), 4641-4647.

[85] Lacher, N.A.; Lunte, S.M.; Martin, R.S. Development of a Microfabricated Palladium Decoupler/ Electrochemical Detector for Microchip Capillary Electrophoresis Using a Hybrid Glass/Poly(dimethylsiloxane) Device. Anal.Chem., 2004, 76(9), 2482-2491.

[86] Osbourn, D.M.; Lunte, C.E. On-Column Electrochemical Detection for Microchip Capillary Electrophoresis. Anal.Chem., 2003, 75(11), 2710-2714.

[87] Dawoud, A.A.; Kawaguchi, T.; Jankowiak, R. Integrated microfluidic device with an electroplated palladium decoupler for electrochemical detection of the 8-hydroxy-deoxyguanosine (8OH-dG) DNA adduct. 2006 NSTI Nanotechnology Conference and Trade Show - NSTI Nanotech 2006 Technical Proceedings 2, 2006, 678-681.

[88] Kovarik, M.L.; Li, M.W.; Martin, R.S. Integration of a carbon microelectrode with a microfabricated palladium decoupler for use in microchip capillary electrophoresis/electrochemistry. Electrophoresis, 2005, 26(1), 202-210. 
[89] Dawoud, A.A.; Kawaguchi, T.; Jankowiak, R. Integrated microfluidic device with an electroplated palladium decoupler for more sensitive amperometric detection of the 8-hydroxydeoxyguanosine (8-OH-dG) DNA adduct. Anal. Bioanal.Chem., 2007, 388(1), 245-252.

[90] Wu, C.-C.; Wu, R.-G.; Huang, J.-G.; Lin, Y.-C.; Chang, H.-C. Three-Electrode Electrochemical Detector and Platinum Film Decoupler Integrated with a Capillary Electrophoresis Microchip for Amperometric Detection. Anal.Chem., 2003, 75(4), 947-952.

[91] Du, Y.; Yan, J.; Zhou, W.; Yang, X.; Wang, E. Direct electrochemical detection of glucose in human plasma on capillary electrophoresis microchips. Electrophoresis, 2004, 25(21-22), 3853-3859.

[92] Lin, K.-W.; Huang, Y.-K.; Su, H.-L.; Hsieh, Y.-Z. In-channel simplified decoupler with renewable electrochemical detection for microchip capillary electrophoresis. Anal. Chim. Acta, 2008, 619(1), 115-121.

[93] Chen, H.; Yuan, L.; Song, W.; Wu, Z.; Li, D. Biocompatible polymer materials:Role of protein-surface interactions. Prog. Polym. Sci., 2008, 33(11), 1059-1087.

[94] Chen, C.-M.; Chang, G.-L.; Lin, C.-H. Performance evaluation of a capillary electrophoresis electrochemical chip integrated with gold nanoelectrode ensemble working and decoupler electrodes. $J$. Chromatogr. A, 2008, 1194(2), 231-236.

[95] Arnett, S.D.; Osbourn, D.M.; Moore, K.D.; Vandaveer, S.S.; Lunte, C.E. Determination of 8-oxoguanine and 8-hydroxy-2'deoxyguanosine in the rat cerebral cortex using microdialysis sampling and capillary electrophoresis with electrochemical detection. J. Chromatog r.B, 2005, 827(1), 16-25.

[96] Da Silva, D.L.P.; Ru ttinger, H.H.; Mrestani, Y.; Baum, W.F.; Neubert, R.H.H. Development of capillary electrophoresis methods for quantitative determination of taurine in vehicle system and biological media. Electrophoresis, 2006, 27(12), 2330-2337.

[97] Martin, R.S.; Ratzlaff, K.L.; Huynh, B.H.; Lunte, S.M. In-Channel Electrochemical Detection for Microchip Capillary Electrophoresis Using anElectrically Isolated Potentiostat. Anal.Chem., 2002, 74(5), 1136-1143

[98] Xu, J.-J.; Bao, N.; Xia, X.-H.; Peng, Y.; Chen, H.-Y. Electrochemical Detection Method for Nonelectroactive and Electroactive Analytes in Microchip Electrophoresis. Anal.Chem., 2004, 76(23), 6902-6907.

[99] Xu, J.-J.; Wang, A.-J.; Chen, H.-Y. Electrochemical detection modes for microchip capillary electrophoresis. Trends Anal.Chem., 2007, 26(2), 125-132.

[100]. Xu, J.-J.; Bao, N.; Xia, X.-H.; Peng, Y., Chen, H.-Y. Electrochemical Detection Method for Nonelectroactive and Electroactive Analytes in Microchip Electrophoresis. Anal. Chem., 2005, 76(23), 69026907.

[101] Xu, J.-J.; Peng, Y.; Bao, N.; Xia, X.-H.; Chen, H.-Y. Simple method for the separation and detection of native amino acids and the identification of electroactive and non-electroactive analytes. $J$. Chromatogr. A, 2005, 1095(1-2), 193-196.

[102] Xu, J.-J.; Peng, Y.; Bao, N.; Xia, X.-H.; Chen, H.-Y. In-channel indirect amperometric detection of nonelectroactive anions for electrophoresis on a poly(dimethylsiloxane) microchip. Electrophoresis, 2005, 26(19), 3615-3610.

[103] Dossi, N.; Toniolo, R.; Pizzariello, A.; Susmel, S.; Perennes, F.; Bontempelli, G. A capillary electrophoresis microsystem for the rapid in-channel amperometric detection of synthetic dyes in food. J. Electroanal. Chem., 2007 , 601(1-2), 1-7.

[104] Chen, C.; Jong, H.H. Dual-Channel Method for Interference-Free In-Channel Amperometric Detection in Microchip Capillary Electrophoresis. Anal.Chem.,2007, 79(18), 7182-7186.

[105] Dawoud, A.A.; Kawaguchi, T.; Jankowiak, R. In-channel modification of electrochemical detector for the detection of biotargets on microchip. Electrochem. Commun., 2007, Vol. 9(7), 1536-1541.

[106] Ordeig, O.; Godino, N.; Del Campo, J.; Muñoz, F.X.; Nikolajeff, F., Nyholm, L. On-chip electric field driven electrochemical detection using a poly(dimethylsiloxane) microchannel with gold microband electrodes . Anal.Chem., 2008, 80(10),3622-3632.

[107] Li, X.-A.; Zhou, D.-M.; Xu, J.-J.; Chen, H.-Y. In-channel indirect amperometric detection of heavy metal ions for electrophoresis on a poly(dimethylsiloxane) microchip. Talanta, 2007, 71(3), 1130-
1135

[108] Suzuki, S.; Honda, S. Miniaturization in carbohydrate analysis. Electrophoresis, 2003, 24(21), 3577-3582.

[109] Weber, P.L.; Lunte, S.M. Capillary electrophoresis with pulsed amperometric detection of carbohydrates and glycopeptides. Electrophoresis, 1996, 17(2), 302-309.

[110] Wen, J.; Cassidy, R.M.; Baranski, A.S. Experimental factors in pulsed electrochemical detection in capillary electrophoresis. $J$. Chromatogr. A, 1998, 811(1-2), 181-192.

[111] Fanguy, J.C.; Henry, C.S. Pulsed amperometric detection of carbohydrates on an electrophoretic microchip. Analyst, 2002, 127(8), 1021-1023.

[112] Garcia, C.D.; Henry, C.S. Direct Determination of Carbohydrates, Amino Acids, and Antibiotics by Microchip Electrophoresis with Pulsed Amperometric Detection. Anal.Chem., 2003, 75(18), 47784783

[113] Garcia, C.D. Henry, C.S. Enhanced determination of glucose by microchip electrophoresis with pulsed amperometric detection. Anal. Chim. Acta, 2004, 508(1), 1-9.

[114] Garcia, C.D.; Henry, C.S. Direct detection of renal function markers using microchip $\mathrm{CE}$ with pulsed electrochemical detection. Analyst, 2004,129(7), pp. 579 - 584.

[115] García, C.D.; Engling, G.; Herckes, P.; Collett Jr.; J.L., Henry, C.S Determination of levoglucosan from smoke samples using microchip capillary electrophoresis with pulsed amperometric detection. Environ. Sci. Technol., 2005, 39(2), 618-623.

[116] Ding, Y.; Mora, M.F.; Garcia, C.D. Analysis of alkyl gallates and nordihydroguaiaretic acid using plastic capillary electrophoresis Microchips. Anal. Chim. Acta, 2006, 561(1-2), 126-132 .

[117] García, C.D.; Dressen, B.M.; Henderson, A.; Henry, C.S Comparison of surfactants for dynamic surface modification of poly(dimethylsiloxane) microchips. Electrophoresis, 2005, 26(3), 703-709.

[118] Ding, Y.; Mora, M.F.; Merrill, G.N.; Garcia, C.D. The effects of alkyl sulfates on the analysis of phenolic compounds by microchip capillary electrophoresis with pulsed amperometric detection Analyst, 2007, 132(10), 997-1004.

[119] Karuwan, C.; Mantim, T.; Chaisuwan, P.; Wilairat, P.; Grudpan, K.; Jittangprasert,P.; Einaga,Y.; Chailapakul, O.; Suntornsuk, L.; Anurukvorakun, O.; Nacapricha, D. Pulsed amperometry for antifouling of boron-doped diamond in electroanalysis of $\beta$-agonists: Application to flow injection for pharmaceutical analysis. Sensor, 2006, 6(12), 1837-1850.

[120] García, C.D.; Henry, C.S. Coupling capillary electrophoresis and pulsed electrochemical detection. Electroanalysis, 2005, 17(13), 1125-1131.

[121] García, C.D.; Henry, C.S. Comparison of pulsed electrochemical detection modes coupled with microchip capillary electrophoresis. Electroanalysis, 2005, 17(3), 223-230.

[122] Manica, D.P.; Mitsumori, Y.; Ewing, A.G. Characterization of Electrode Fouling and Surface Regeneration for a Platinum Electrode on an Electrophoresis Microchip. Anal.Chem., 2003 75(17), 4572-4577.

[123] Ding, Y.; Garcia, C.D. Pulsed amperometric detection with poly(dimethylsiloxane)-fabricated capillary electrophoresis microchips for the determination of EPA priority pollutants. Analyst, 2006, 131(2), 208-214.

[124] Guan, Y.; Chu, Q.; Fu, L.; Wu, T.; Ye, J. Determination of phenolic antioxidants by micellar electrokinetic capillary chromatography with electrochemical detection. Food Chem., 2006, 94(1), 167-162.

[125] Arslan, G.; Yazici, B.; Erbil, M. The effect of pH, temperature and concentration on electrooxidation of phenol. J. Haz. Mat.B, 2005 , 124(1-3), 37-43.

[126] Ding, Y.; Garcia, C.D. Application of microchip-CE electrophoresis to follow the degradation of phenolic acids by aquatic plants. Electrophoresis, 2006, 27(24), 5119-5127.

[127] Ding, Y.; Garcia, C.D. Determination of nonsteroidal antiinflammatory drugs in serum by microchip capillary electrophoresis with electrochemical detection. Electroanalysis, 2006, 18(22), 2202-2209.

[128] Bossier, J.S.; Roberts, M.A.; Ferrigno, R.; Girault, H.H Electrochemical Detection in Polymer Microchannels. Anal.Chem. 1999, 71(19), 4294-4299. 
[129] Ueno, K.; Kim, H.-B.; Kitamura, N. Characteristic Electrochemical Responses of Polymer Microchannel-Microelectrode Chips. Anal.Chem., 2003, 75(9), 2086-2091.

[130] Holland, L.A.; Leigh, A.M. Amperometric and voltammetric detection for capillary electrophoresis. Electrophoresis, 2002, 23(21), 3649-3658.

[131] Du, Z.; Gao, Q.; Feng, J.; Lu, Y.; Wang, J. Dynamic instabilities and mechanism of the electrochemical oxidation of thiosulfate. $J$. Phys. Chem. B, 2006, 110(51), 26098-26104.

[132] Basa, A.; Magnuszewska, J.; Krogulec, T.; Baranski, A.S. Cyclic chronopotentiometric determination of sugars at $\mathrm{Au}$ and $\mathrm{Pt}$ microelectrodes in flowing solutions . J. Chromatogr. A, 2007, 1150(1-2), 312-319.

[133] Henley, I.; Fisher, A. Computational electrochemistry: A model to studying ohmic distortion of voltammetry in multiple working electrode, microfluidic devices, an adaptive FEM approach. Electroanalysis, 2005, 17(3), pp. 255-262.

[134] Forry, S.P.; Murray, J.R.; Heien, M.L.A.V.; Locascio, L.E.; Wightman, R.M. Probing Electric Fields Inside Microfluidic Channels during Electroosmotic Flow with Fast-Scan Cyclic Voltammetry. Anal.Chem., 2004, 76(17), 4945-4950.

[135] Voinov, V.G.; Vasil'Ev, Y.V.; Morré, J.; Barofsky, D.F.; Deinzer, M.L.; Gonin, M., Egan, T.F.; Führer, K. A Resonant Electron Capture Time-of-Flight MS with Trochoidal Electron Monochromator. Anal.Chem., 2003; 75(13), 3301-3309.

[136] Hebert, N.E.; Kuhr, W.G.; Brazill, A.S. Microchip capillary electrophoresis coupled to sinusoidal voltammetry for the detection of native carbohydrates. Electrophoresis, 2002, 23(21), 3750-3759.

[137] Hebert, N.E.; Snyder, B.; McCreery, R.L.; Kuhr, W.G.; Brazill, S.A. Performance of Pyrolyzed Photoresist Carbon Films in a Microchip Capillary Electrophoresis Device with Sinusoidal Voltammetric Detection. Anal.Chem., 2003, 75(16), 4265-4271.

[138] Hebert, N.E.; Brazill, S.A. Microchip capillary gel electrophoresis with electrochemical detection for the analysis of known SNPs. Lab Chip, 2004, 3(4), 241-247.

[139] Wang, J.; Polsky, R.; Tian, B.; Chatrathi, M.P. Voltammetry on Microfluidic Chip Platforms. Anal.Chem., 2000, 72(21), 52855289.

[140] Ramaley, L.; Krause Jr. M.S. Theory of square wave voltammetry. Anal. Chem., 1969, 41(11),1362-1365.

[141] O'Dea, J.J.; Osteryoung, J.; Osteryoung, R.A. Theory of square wave voltammetry for kinetic systems. Anal. Chem., 1981, 53(4),695-701.

[142] Gerhardt, G.C.; Cassidy, R.M.; Baranski, A.S. Square-wave voltammetry detection for capillary electrophoresis. Anal.Chem., 1998, 70(10), 2167-2173.

[143] Lindsay, S.; Vázquez, T.; Egatz-Gómez, A.; Loyprasert, S.; Garcia, A.A.;Wang, J. Discrete microfluidics with electrochemical detection. Analyst, 2007, 132(5), 412-416.

[144] Krizkova, S.; Hrdinova, V.; Adam, V.; Burgess, E.P.J.; Kramer, K.J.; Masarik, M.; Kizek, R. Chip-based CE for avidin determination in transgenic tobacco and its comparison with square-wave voltammetry and standard gel electrophoresis. Chromatographia, 2008, 67, S75-S81.

[145] Zou, Z.; Jang, A.; MacKnight, E.; Wu, P.-M.; Do, J.; Bishop, P.L.; Ahn, C.H. Environmentally friendly disposable sensors with microfabricated on-chip planar bismuth electrode for in situ heavy metal ions measurement. Sens.Actuators B., 2008, 134(1), 18-24.

[146] Gharib Naseri, N.; Baldock, S.J.; Economou, A.; Goddard, N.J.; Fielden, P.R. Disposable electrochemical flow cells for catalytic adsorptive stripping voltammetry (CAdSV) at a bismuth film electrode (BiFE). Anal. Bio. Anal. Chem., 2008, 391(4), 12831292.

[147] Gharib Naseri, N.; Baldock, S.J.; Economou, A.; Goddard, N.J.; Fielden, P.R. Disposable injection-moulded cell-on-a-chip microfluidic devices with integrated conducting polymer electrodes for on-line voltammetric and electrochemiluminescence detection. Electroanalysis, 2008, 20(4), 448-454.

[148] Kokkinos, C.; Economou, A.; Raptis, I.; Speliotis, T. Disposable mercury-free cell-on-a-chip devices with integrated microfabricated electrodes for the determination of trace nickel(II) by adsorptive stripping voltammetry. Anal.Chim. Acta, 2008, 622(1-2), 111-118.

[149] Holland, L.A.; Leigh, A.M. Amperometric and voltammetric detection for capillary electrophoresis. Electrophoresis, 2002,
23(21), 3649-3658.

[150] Schwarz, M.A.; Hauser, P.C. Recent developments in detection methods for microfabricated analytical devices. Lab Chip, 2001, $1(1), 1-6$

[151] Liu, Y.; Garcia, C.D.; Henry, C.S. Recent progress in the development of $\mu$ TAS for clinical analysis. Analyst, 2003, 128(8), 1002-1008.

[152] Masár, M.; Žúborová, M.; Bielčíková, J.; Kaniansky, D.; Jöhnck, M.; Stanislawski, B. Conductivity detection and quantitation of isotachophoretic analytes on a planar chip with on-line coupled separation channels. J. Chromatogr. A, 2001, 916(1-2), 101-111.

[153] Gawron, A.J.; Scott Martin, R.; Lunte, S.M. New approaches for fabrication of microfluidic capillary electrophoresis devices with on-chip conductivity detection. Electrophoresis, 2001, 22(2), 235241.

[154] Galloway, M.; Stryjewski, W.; Henry, A.; Ford, S.M.; Llopis, S.; McCarley, R.L.; Soper, S.A. Contact Conductivity Detection in Poly(methyl methacylate)-Based Microfluidic Devices forAnalysis of Mono- and Polyanionic Molecules. Anal.Chem., 2002, 74(10), 2407-2415.

[155] Pumera, M.; Wang, J.; Opekar, F.; Jelinek, I.; Feldman, J.; Löwe, H.; Hardt, S. Contactless Conductivity Detector for Microchip Capillary Electrophoresis. Anal.Chem., 2002, 74(9), 1968-1971.

[156] Guijt, R.M.; Baltussen, E.; van der Steen, G.; Frank, J.; Billiet, H.A.H.; Laugere, F.; Vellekoop, M.J.; Berthold, A.; Sarro, P.M.; van Dedem, G.W.K. Capillary electrophoresis with on-chip fourelectrode capacitively coupled conductivity detection for application in bioanalysis. Electrophoresis, 2001, 22(12), 25372541.

[157] Mahabadi, K.A.; Rodriguez, I.; Hong, L.; Hauser, P.C.; de Rooij, N.F. Restrictive dual capacitively coupled contactless conductivity detection for microchip electrophoresis . Procedia Chem., 2009, $1(1), 1351-1354$.

[158] Kubáň, P.; Hauser, P.C. Contactless Conductivity Detection in Capillary Electrophoresis: A Review. Electroanalysis, 2004. 16(24), 2009-2021.

[159] Kubáň, P.; Hauser, P.C. Ten years of axial capacitively coupled contactless conductivity detection for CZE - A review. Electrophoresis, 2009, 30(1),176-188.

[160] Kubáň, P.; Hauser, P.C. Effects of the cell geometry and operating parameters on the performance of an external contactless conductivity detector for microchip electrophoresis. Lab Chip, 2005, 5(4), 407 - 415.

[161] Mu hlberger, H.; Hwang, W.; Guber, A.E.; Saile, V.; Hoffmann, W. Polymer lab-on-a-chip system with electrical detection. IEEE Sens. J., 2008, 8(5), 572-579.

[162] Hoffmann, W.; Mühlberger, H.; Demattio, H.; Gaš, B.; Guber, A.E.; Saile, V. Pushing capillary electrophoresis in chip format into the low cost region. ECS Trans., 2006, 3(10), 407-416.

[163] Kubáň, P.; Evenhuis, C.J.; Macka, M.; Haddad, P.R.; Hauser, P.C. Comparison of different contactless conductivity detectors for the determination of small inorganic ions by capillary electrophoresis. Electroanalysis, 2006, 18(13-14), 1289-1296.

[164] S olínová, V.; Kas ic ka, V. Recent applications of conductivity detection in capillary and chip electrophoresis. J. Sep. Sci., 2006, 29(12), 1743-1762.

[165] Kubáň, P.; Hauser, P.C. A review of the recent achievements in capacitively coupled contactless conductivity detection. Anal. Chim. Acta, 2008, 607(1),15-29.

[166] Wang, J.; Pumera, M. Dual Conductivity/Amperometric Detection System for Microchip Capillary Electrophoresis. Anal.Chem., 2002, 74(23), 5919-5923.

[167] Wang, J.; Chen, G.; Muck Jr.; A., Collins, G.E. Electrophoretic microchip with dual-opposite injection for simultaneous measurements of anions and cations. Electrophoresis, 2003, 24(21), 3728-3734.

[168] Wang, J., Chen, G., Muck Jr., A. Movable ContactlessConductivity Detector for Microchip Capillary Electrophoresis., Anal.Chem., 2003, 75(17), 4475-4479.

[169] Vázquez, M.; Frankenfeld, C.; Coltro, W.K.T.; Carrilho, E.; Diamond, D.; Lunte, S.M. Dual contactless conductivity and amperometric detection on hybrid PDMS/glass electrophoresis microchips. Analyst, 2010, 135(1), 96-103.

[170] Laugere, F.; Guijt, R.M.; Bastemeijer, J.; van der Steen, G.; 
Berthold, A.; Baltussen, E.; Sarro, P.; van Dedem, G.W.K.; Vellekoop, M.; Bossche, A. On-Chip Contactless Four-Electrode Conductivity Detection for Capillary Electrophoresis Devices. Anal.Chem., 2003, 75(2), 306-312.

[171] Kuban, P.; Hauser, P.C. Application of an external contactless conductivity detector for the analysis of beverages by microchip capillary electrophoresis. Electrophoresis, 2005, 26(16), 31693178.

[172] Wang, J.; Pumera, M. Nonaqueous Electrophoresis Microchip Separations: Conductivity Detection in UV-Absorbing Solvents. Anal.Chem., 2003, 75(2), 341-345.

[173] Gong, X. Y.; Hauser.P.C. Determination of different classes of amines with capillary zone electrophoresis and contactless conductivity detection. Electrophoresis, 2006, 27(2), 468-473.

[174] Tanyanyiwa, J.; Hauser, P.C. High-Voltage Capacitively Coupled Contactless Conductivity Detection for Microchip Capillary Electrophoresis. 2002, Anal.Chem., Vol. 74, p. 6378-6382.

[175] Tanyanyiwa, J.; Abad-Villar, E. M.; Hauser, P.C. Contactless conductivity detection of selected organic ions in on-chip electrophoresis. Electrophoresis, 2004, 25(6), 903-908.

[176] Abad-Villar, E.M.; Kubán̆, P.; Hauser, P.C. Evaluation of the detection of biomolecules in capillary electrophoresis by contactless conductivity measurement. J. Sep. Sci., 2006, 29(7), 1031-1037.

[177] Abad-Villar, E.M.; Etter, S.F.; Thiel, M.A.; Hauser, P.C. Determination of chlorhexidine digluconate and polyhexamethylene biguanide in eye drops by capillary electrophoresis with contactless conductivity detection. Anal Chim Acta,2006, 561(1-2), 133-137.

[178] Felix, F.S.; Quintino, M.S.M.; Carvalho, A.Z.; Coelho, L.H.G.; Do Lago, C.L.; Angnes, L. Determination of salbutamol in syrups by capillary electrophoresis with contactless conductivity detection (CE-C4D). J. Pharm Biomed Anal., 2006, 40(5), 1288-1292.

[179] Law, W.S.; Kubáň, P.; Yuan, L.L.; Zhao, J.H.; Li, S.F. Y.; Hauser, P.C. Determination of tobramycin in human serum by capillary electrophoresis with contactless conductivity detection. Electrophoresis, 2006, 27(10), 193-1938.

[180] Tu ma, P.; Samcová, E.; Ande lová, K. Determination of free amino acids and related compounds in amniotic fluid by capillary electrophoresis with contactless conductivity detection. $J$ Chromatogr B, 2006, 839(1-2), 12-18.

[181] Samcová, E.; Tu ma, P. Determination of Proteinogenic Amino Acids in Human Plasma by Capillary Electrophoresis with Contactless Conductivity Detection. Electroanalysis, 2006, 18(2),152-157.

[182] Kuban , P.; $\mathrm{S}$ te rbova, D.; Kuban , V. Separation of phenolic acids by capillary electrophoresis with indirect contactless conductometric detection. Electrophoresis, 2006, 27(7), 13681375.

[183] Abad-Villar, E.M.; Kubáň, P.; Hauser, P.C. Determination of biochemical species on electrophoresis chips with an external contactless conductivity detector. Electrophoresis, 2005, 26(19), 3609-3614

[184] Gong, X.Y.; Hauser, P.C. Enantiomeric separation of underivatized small amines in conventional and on-chip capillary electrophoresis with contactless conductivity detection. Electrophoresis, 2006, 27(21), 4375-4382.

[185] Law, W.S.; Kubáň, P.; Zhao, J.H.; Li, S.F.Y.; Hauser, P.C. Determination of vitamin $\mathrm{C}$ and preservatives in beverages by conventional capillary electrophoresis and microchip electrophoresis with capacitively coupled contactless conductivity. Electrophoresis, 2005, 26(24), 4648-4655.

[186] Wang, J.; Chen, G.; Muck, A.; Chatrathi, M.P.; Mulchandani, A.; Chen, W. Microchip enzymatic assay of organophosphate nerve agents. Anal.Chim.Acta, 2004, 505(2), 183-187.

[187] Ding, Y.; Rogers, K. Measurement of nitrogen mustard degradation products by poly(dimethylsiloxane) microchip electrophoresis with contactless conductivity detection. Electroanalysis, 2008, 20(20), 2192-2198.

[188] Vrouwe, E.X.; Luttge, R.; van den Berg, A. Direct measurement of lithium in whole blood using microchip capillary electrophoresis with integrated conductivity detection. Electrophoresis, 2004, 25(10-11), 1660-1667.

[189] Tanyanyiwa, J.; Hauser, P.C. Capillary and microchip electrophoresis of basic drugs with contactless conductivity detection. Electrophoresis, 2004, 25(17), 3010-3016.

[190] Prest, J.E.; Baldock, S.J.; Bektas, N.; Fielden, P.R.; Treves Brown, B.J.Single electrode conductivity detection for electrophoretic separation systems. J. Chromatogr. A, 1999, 836(1), 59-65.

[191] Qin, W.D.; Li, S.F.Y. Determination of chlorophenoxy acid herbicides by capillary electrophoresis with integrated potential gradient detection. Electrophoresis, 2003, 24(12-13), 2174-2179.

[192] Feng, H.-T.; Wei, H.-P.; Li, S.F.Y. On-chip potential gradient detection with a portable capillary electrophoresis system. Electrophoresis, 2004, 25(6), 909-913.

[193] Lichtenberg, J.; de Rooij, N.F.; Verpoorte, E. A microchip electrophoresis system with integrated in-plane electrodes for contactless conductivity detection. Electrophoresis, 2002, 23(21), 3769-3780.

[194] Xu, Y.; Qin, W.; Li, S.F.Y. Portable capillary electrophoresis system with potential gradient detection for separation of DNA fragments. Electrophoresis, 2005, Vol. 26(3), 517-523.

[195] Yuan, L.: Wei, H.; Li, S.F.Y. Direct determination of gentamicin components by capillary electrophoresis with potential gradient detection. Electrophoresis, 2005, 26(1), 196-201.

[196] Yuan, L.; Wei, H.; Feng, H.; Li, S.F.Y. Rapid analysis of native neomycin components on a portable capillary electrophoresis system with potential gradient detection. Anal.Bioanal. Chem. 2006, 385(8), 1575-1579.

[197] Fan, Y.; Gan, X.; Li, S.; Qin, W.A rapid CE-potential gradient detection method for determination of quinolones. Electrophoresis, 2007, 28(22), 4101-4107.

[198] Tanyanyiwa, J.; Leuthardt, S.; Hauser, P.C. Conductimetric and potentiometric detection in conventional and microchip capillary electrophoresis. Electrophoresis, 2002, 23(21), 3659-3666.

[199] Nagels, L.J.; Everaert, J.; Bohets, H.; Vissers, B.; Skwierawska, A. Sadowska, K. Potentiometric detection of organic ionics in separation methods: A critical evaluation. Polish J. Chem., 2008, 82(6), 1199-1205.

[200] Da Silva, I.S.; Richter, E.M.; Do Lago, C.L.; Gutz, I.G.R.; Tanaka, A.A.; Angnes, L. FIA-potentiometry in the sub-Nernstian response region for rapid and direct chloride assays in milk and in coconut water. Talanta, 2005, 67(3), 651-657.

[201] Kulapin, A.I.;Chernova, R.K.;Kulapina, E.G.;Mikhaleva, N.M Separate detection of homologous surfactants by means of solidcontact unmodified and modified with molecular sieves potentiometric sensors., Talanta, 2005, 66(3), 619-626.

[202] Kulapina, E.G.; Mikhaleva, N.M. The analysis of multicomponent solutions containing homologous ionic surfactant with sensor arrays. Sens. Actuators B:Chem:, 2005, 106, 271-277.

[203] Tantra, R.; Manz, A. Integrated Potentiometric Detector for Use in Chip-Based Flow Cells. Anal.Chem., 2000, 72(13), 2875-2878.

[204] Sekula, J.; Everaert, J.; Bohets, H.; Vissers, B.; Pietraszkiewicz, M.; Pietraszkiewicz, O.; Prez, F.D.; Vanhoutte, K.; Prus, P.; Nagels, L.J. Coated wire potentiometric detection for capillary electrophoresis studied using organic amines, drugs, and biogenic amines. Anal.Chem., 2006, 78(11), 3772-3779

[205] Chevallier, L.; Di Bartolomeo, E.; Traversa, E.; Mori, M.; Sadaoka, Y. Potentiometric detection of VOCs using non-nernstian SmFeO 3Pt/YSZ/Pt sensors. Materials Research Society Symposium Proceedings . 2007, 972, 373-378.

[206] Klett, O.; Nyholm, L. Separation High Voltage Field Driven OnChip Amperometric Detection in Capillary Electrophoresis. Anal.Chem, 2003, 75, 1245-1250.

[207] Becker, H.; Gartner, C. Polymer microfabrication methods for microfluidic analytical application. Electrophoresis, 2000, 21(1), 12-26.

[208] Esch, M.B.; Kapur, S.; Irizarry, G.; Genova, V. Influence of master fabrication techniques on the characteristics of embossed microfluidic channels. Lab chip, 2003, 3(2), 121 - 127.

[209] Becker, H., Heim, U. Polymer hot embossing with silicon master structures . Sens. Mater., 1999, 11(5), 297-304.

[210] Venkatesh, V.C. C. Precision manufacture of spherical and aspheric surfaces on plastics, glass, silicon and germanium. Sci., 2003, 84(9), 1211-1219

[211] Fleischer, J.; Masuzawa, T.; Schmidt, J.; Knoll, M. New applications for micro-EDM . J. Mater. Process. Technol., 2004, 149(1-3), 246-249 . 
[212] De Souza, A.F.; Coelho, R.T. Experimental investigation of feed rate limitations on high speed milling aimed at industrial applications. Int. J. Adv. Manuf. Technol., 2007, 32(11-12), 11041114 .

[213] Kopac, J.; Balic, J.; Cus, F. Sustainable 3D mould design and manufacturing. PICMET: Portland International Center for Management of Engineering and Technology. 2008. 4599625, 204209.

[214] Uhlmann, E.; Piltz, S.; Doll, U. Machining of micro/miniature dies and moulds by electrical discharge machining - Recent development. J. Mater. Process. Technol. , 2005, 167(2-3), 488493.

[215] Almeida, F.A.; Sacramento, J.; Oliveira, F.J.; Silva, R.F. Microand nano-crystalline CVD diamond coated tools in the turning of EDM graphite. Surf. Coat. Technol., 2008, 203(3-4), 271-276.

[216] Steigert, J.; Haeberle, S.; Brenner, T.; Mu ller, C.; Steinert, C.P.; Koltay, P.; Gottschlich, N.; Reinecke, H.; Ru he, J.; Zengerle, R.; Ducree, J. Rapid prototyping of microfluidic chips in COC. $J$. Micromech. Microeng., 2007, 17(2), 333-341.

[217] Maurya, D.K.; Ng, W.Y.; Mahabadi, K.A.; Liang, Y.N.; Rodriguez, I. Fabrication of lab-on chip platforms by hot embossing and photo pattering. Biotechnol. J., 2007, 2(11), 13811388.

[218] Ehrfeld, W.; Lehr, H.; Michel, F.; Wolf, A.; Gruber, H.P.; Bertholds, A. Microelectro discharge machining as a technology in micromachining. Proceedings of SPIE - The International Society for Optical Engineering . 1996. 2879, 332-337 .

[219] MacGeough, J.A.; Leu, M.C.; Rajurkar, K.P.; De Silva, A.K.M.; Liu, Q. Electroforming process and application to micro/macro manufacturing . CIRP Annals - Manuf. Technol, 2001, 50(2), 499514 .

[220] Guttmann, M., Mehne, C.; Wissmann, M.; Hartmann, M.; Heckle, M. Electrodeposition for replication of microstructured plastic surfaces as an alternative manufacturing method for moulding tools. Galvanotechnik, 2006, 97(10), 2530-2536+VIII

[221] Meyer, P.; Schulz, J.; Hahn, L.; Saile, V.Why you will use the deep X-ray LIG(A) technology to produce MEMS? Microsyst. Technol., 2008, 14(9-11), 1491-1497.

[222] Mappes, T.; Worgull, M.; Heckele, M.; Mohr, J. Submicron polymer structures with X-ray lithography and hot embossing. Microsyst. Technol., 2008, 14(9-11), 1721-1725.

[223] Matsumoto, Y.; Setomoto, M.; Noda, D.; Hattori, T.Cylindrical coils created with 3D X-ray lithography and metallization. Microsyst. Technol., 2008, 14(9-11), 1373-1379.

[224] Voigt, A.; Heinrich, M.; Gruetzner, G.; Kouba, J.; Scheunemann, H.-U.; Rudolph, I. A new UV sensitive positive resist for X-ray masks manufacture. Microsyst. Technol., 2008, 14(9-11), 14471450 .

[225] Khan Malek, C.; Duffait, R. Packaging using hot-embossing with a polymeric intermediate mould. Int. J. Adv. Manuf. Technol., 2007, 33(1-2), 187-190.

[226] Weng, Y.-J.; Yang, S.- Y.; Weng, Y.-C.; Wang, L.A. Fabrication of buried waveguide microstructure using gas-assisted micro/nanoimprinting with soft mold. Polym. Adv. Technol. , 2007, 18(12), 993-998.

[227] Lee, S.-W.; Kim, D.-J.; Ahn, Y.; Chai, Y.G. Simple structured polydimethylsiloxane microvalve actuated by external air pressure. Proceedings of the Institution of Mechanical Engineers, Part C: Journal of Mechanical Engineering Science . 2006. 220(8),12831288.

[228] Abgrall, P.; Conedera, V.; Camon, H.; Gue, A.-M.; Nguyen, N.-T. SU-8 as a structural material for labs-on-chips and microelectromechanical systems (review). Electrophoresis, 2007, 28(24), 4539-4551.

[229] Hwang, H.; Kang, G.; Yeon, J.H.; Nam, Y.; Park, J.-K. Direct rapid prototyping of PDMS from a photomask film for micropatterning of biomolecules and cells. Lab Chip, 2009, 9(1), 167-170.

[230] Henry, A.C.; Waddell, E.A.; Shreiner, R.; Locascio, L.E. Control of electroosmotic flow in laser-ablated and chemically modified hot imprinted poly(ethylene terephthalate glycol)microchannels. Electrophoresis, 2002, 23(5), 791-798.

[231] Matsui, K.; Kawaji, I.; Utsumi, Y.; Ukita, Y.; Asano, T.; Takeo, M.; Kato, D.-I.; Negoro, S. Immunoassay using microfluid filters constructed by deep X-ray lithography. Biosci. Biotechnol.
Biochem., 2007, 71(12), 3098-3101.

[232] Pérennés, F.; Marmiroli, B.; Tormen, M.; Matteucci, M.; Di Fabrizio, E. Replication of deep x-ray lithography fabricated microstructures through casting of soft material. J. Microlith. Microfab. Microsys., 2006, 5(1), art 011007

[233] Abgrall, P.; Gué, A.-M. Microfluidic device technologies: Making a microfluidic network and coupling it into a complete microsystem - A review. J. Micromech. Microeng., 2007, 17(5), R15-R49.

[234] McDonald, J.C.; Duffy, D.C.; Anderson, J.R.; Chiu, D.T.; Wu, H.; Schueller, O.J.A.; Whitesides, G.M. Fabrication of microfluidic systems in poly(dimethylsiloxane). Electrophoresis, 2000, 21(1), 27-40.

[235] Yu, Y.; Ikeda, T. Soft actuators based on liquid-crystalline elastomers. Angew. Chem. Int. Ed. 2006, 45(33), 5416-5418.

[236] Becker, H., Ga rtner, C. Polymer microfabrication technologies for microfluidic systems. Anal. Bioanal. Chem., 2008, 390(1), 89111.

[237] Draghi, L.; Cigada, A. Nanostructured surfaces for biomedical applications. Part I: Nanotopography. J. Appl. Biomater. Biomech., 2007, 5(2), 61-69.

[238] Weibel, D.B.; DiLuzio, W.R.; Whitesides, G.M. Microfabrication meets microbiology. Nat. Rev. Microbiol., 2007, 5(3), 209-218 .

[239] Godara, P.; McFarland, C.D.; Nordon, R.E. Design of bioreactors for mesenchymal stem cell tissue engineering. J. Chem. Technol. Biotechnol., 2008, 83(4), 408-420 .

[240] Falconnet, D.; Csucs, G.; Michelle Grandin, H.; Textor, M. Surface engineering approaches to micropattern surfaces for cell-based assays. Biomaterials, 2006, 27(16), 3044-3063.

[241] Zhang, Y., Lo; C.-W.; Taylor, J.A.; Yang, S. Replica molding of high-aspect-ratio polymeric nanopillar arrays with high fidelity. Langmuir, 2006, 22(20), 8595-8601 .

[242] Natarajan, S.; Chang-Yen, D.A.; Gale, B.K. Large-area, highaspect-ratio SU-8 molds for the fabrication of PDMS microfluidic devices. J. Micromech. Microeng. , 2008, 18(4), art. no. 045021.

[243] Lee, K.; Kim, C.; Shin, K.S.; Lee, J.W.; Ju, B.-K.; Kim, T.S.; Lee, S.-K.; Kang, J.Y. Fabrication of round channels using the surface tension of PDMS and its application to a 3D serpentine mixer. $J$. Micromech. Microeng. 2007, 17(8), 1533-1541.

[244] Lin, F.; Butcher, E.C. T cell chemotaxis in a simple microfluidic device. Lab Chip, 2006, 6(11), 1462-1469.

245] Yoon, T.-H.; Lee, H.-J.; Yan, J.; Kim, D.-P. Fabrication of SiCbased ceramic microstructures from preceramic polymers with sacrificial templates and lithographic techniques-A review. $J$. Ceram. Soc. Jpn., 2006, 114(1330), 473-479.

[246] Muck Jr., A.; Wang, J.; Jacobs, M.; Chen, G.; Chatrathi, M.P.; Jurka, V.; Výborný, Z.; Spillman, S.D.; Sridharan, G.; Schoning, M.J. Fabrication of Poly(methyl methacrylate) Microfluidic Chips by Atmospheric Molding. Anal. Chem, 2004, 76(8), 2290-2297.

[247] Duffy, D.C.; McDonald, J.C.; Schueller, O.J.A.; Whitesides, G.M. Rapid Prototyping of Microfluidic Systems in Poly(dimethylsiloxane). Anal.Chem., 1998, 70(23), 4974-4984.

[248] Kimerling, T.E.; Liu, W.; Kim, B.H.; Yao, D.Rapid hot embossing of polymer microfeatures . Microsyst. Technol., 2006, 12(8),730735.

[249] Grewell, D.; Mokhtarzadeh, A.; Benatar, A.; Lu, C.; James Lee, L. In:Feasibility of selected methods for embossing micro-features in thermoplastics. Annual Technical Conference - ANTEC, Conference Proceedings, 2003, 1, 1094-1098.

[250] Seunarine, K.; Gadegaard, N.; Riehle, M.O.; Wilkinson, C.D.W. Optical heating for short hot embossing cycle times., Microelectron. Eng., 2006, 83(4-9), 859-863.

[251] Liu, S.-J.; Dung, Y.-T. Ultrasonic vibration hot embossing. Int. Polym. Proc., 2005, 20(4), 449-452.

[252] Yao, D.; Nagarajan, P.; Li, L.; Yi, A.Y. A strategy for rapid thermal cycling of molds in thermoplastic processing. J. Manuf. Sci. Eng., 2006, 128(4), 837-843.

[253] Grande, J.A. Micro-thermoforming makes its debut. Plast. Technol., 2006, 52(11), 37-41.

[254] Giselbrecht, S.; Gietzelt, T.; Gottwald, E.; Trautmann, C.; Truckenmuller, R.; Weibezahn, K.F.; Welle, A. 3D tissue culture substrates produced by microthermoforming of pre-processed polymer films. Biomed. Microdevices , 2006, 8(3),191-199.

[255] Truckenmüller, R.; Giselbrecht, S.; Van Blitterswijk, C.; 
Dambrowsky, N.; Gottwald, E.; Mappes, T.; Rolletschek, A.; Saile, V; Trautmann, C.; Weibezahn, K.-F.; Welle, A. Flexible fluidic microchips based on thermoformed and locally modified thin polymer films. Lab Chip, 2008, 9(8), 1570-1579.

[256] Giboz, J.; Copponnex, T.; Méle, P. Microinjection molding of thermoplastic polymers: A review. J. Micromech. Microeng., 2007, 17(6), R96-R109.

[257] Chien, R.-D. Micromolding of biochip devices designed with microchannels. Sens. Actuators, A, 2006, 128(2), 238-247.

[258] Jiang, B.-Y.; Shen, R.-X.; Shen, L.-J.; Hu, J.-L. Influence of processing parameters in injection molding on replication fidelity of microstructure parts. Optics and Precision Engineering, 2008, 16(2), 248-256.

[259] Madou, M.; Zoval, J.; Jia, G.; Kido, H.; Kim, J. Kim, N. Lab on a CD. Annu. Rev. Biomed. Eng., 2006, 8, 601-628.

[260] Yasukawa, T.; Glidle, A.; Nomura, M.; Cooper, J.M. Fabrication of robust 2-D and 3-D microfluidic networks for lab-on-a-chip bioassays. J. Microelectromech. Syst., 2005, 14(4), 839-846.

[261] Abgrall, P.; Lattes, C.; Conédéra, V.; Dollat, X.; Colin, S.; Gué, A.M. A novel fabrication method of flexible and monolithic 3D microfluidic structures using lamination of SU-8 films. $J$. Micromech. Microeng., 2006, 16(1), 113-121.

[262] Agirregabiria, M.; Blanco, F.J.; Berganzo, J.; Arroyo, M.T.; Fullaondo, A.; Mayora, K.; Ruano-López, J.M. Fabrication of SU-8 multilayer microstructures based on successive CMOS compatible adhesive bonding and releasing steps. Lab Chip, 2005, 5(5), 545552.

[263] Tuomikoski, S. and Franssila, S. Wafer-level bonding of MEMS structures with SU-8 epoxy photoresist. Physica Scripta T, 2004, T114, 223-226.

[264] Holland, A., Cher, C., Rosengarten, G., Simon, D. Plasma etching of thermoset polymer films for microchannels. Smart Mater. Struct., 2006, 15(1), S104-S111.

[265] Tsougeni, K.; Papageorgiou, D.; Tserepi, A.; Gogolides, E. "Smart" polymeric microfluidics fabricated by plasma processing: Controlled wetting, capillary filling and hydrophobic valving. Lab Chip, 2010, 10(4), 462-469.

[266] Yao, X.; Chen, Z.; Chen, G. Fabrication of PMMA microfluidic chips using disposable agar hydrogel templates. Electrophoresis, 2009, 30(24), 4225-4229.

[267] Panda, P.; Ali, S.; Lo, E.; Chung, B.G.; Hatton, T.A.; Khademhosseini, A.; Doyle, P.S. Stop-flow lithography to generate cell-laden microgel particles. Lab Chip, 2008, 8(7), 1056-1061.

[268] Golden, A.P; Tien, J. Fabrication of microfluidic hydrogels using molded gelatin as a sacrificial element. Lab Chip, 2007, 7(6), 720725 .

[269] Becker, H.; Locascio, L.E. Polymer microfluidic devices. Talanta, 2002, 56(2), 267-287.

[270] Roberts, M.A.; Rossier, J.S.; Bercier, P.; Girault, H. UV Laser Machined Polymer Substrates for the Development of Microdiagnostic Systems. Anal. Chem., 1997, 69(11), 2035-2042.

[271] Srinivasan, R.; Braren, B. Ultraviolet laser ablation of organic polymers. Chem. Rev., 1989, 89(6), 1303-1316.

[272] Rossier, J.; Reymond, F.; Michel, P.E. Polymer microfluidic chips for electrochemical and biochemical analyses. Electrophoresis, 2002, 23(6), 858-867.

[273] Rossier, J.S.; Vollet, C.; Carnal, A.; Lagger, G.; Gobry, V.; Girault, H.H.; Michel, P.; Reymond, F. Plasma etched polymer microelectrochemical systems. Lab Chip, 2002, 293), 145-150.

[274] Tsougeni, K.; Petrou, P.S.; Tserepi, A.; Kakabakos, S.E.; Gogolides, E. Nano-texturing of poly(methyl methacrylate) polymer using plasma processes and applications in wetting control and protein adsorption. Microelectron. Eng., 2009, 86(4), 14241427.

[275] Tsougeni, K.; Vourdas, N.; Tserepi, A.; Gogolides, E.; Cardinaud, C. Mechanisms of oxygen plasma nanotexturing of organic polymer surfaces: From stable super hydrophilic to super hydrophobic surfaces. Langmuir, 2009, 25(19), 11748-11759.

[276] Gonin, Y.; Munnik, F.; Benninger, F.; Mikhai lov, S. Creating sub-surface channels in PMMA with ion beam lithography in only one step. App. Surface Sci., 2003, 217(1-4), 289-293.

[277] Gorelick, S.; Puttaraksa, N.; Sajavaara, T.; Laitinen, M.; Singkarat, S.; Whitlow, H.J. Fabrication of microfluidic devices using MeV ion beam Programmable Proximity Aperture Lithography (PPAL).
Nucl. Instr. and Meth. in Phys. Res. B, 2008, 266(10), 2461-2465.

[278] Chen, Z.F.; Gao, Y.H.; Lin, J.M.; Su, R.G.; Xie, Y. Vacuumassisted thermal bonding of plastic capillary electrophoresis microchip imprinted with stainless steel template. J.Chromatogr.A, Vol. 2004, 1038(1-2), 239-245.

[279] Sayah, A.; Solignac, D.; Cueni, T.; Gijs, M.A.M. Development of novel low temperature bonding technologies for microchip chemical analysis applications. Sens. Actuators A, 2000, 84(1), 103-108.

[280] Graß, B.; Neyer, A.; Johnck, M.; Siepe, D.; Eisenbeiss, F.; Weber, G.; Hergenröder, R. New PMMA-microchip device for isotachophoresis with integrated conductivity detector. Sens.Actuators B, 2001, 72(3), 249-258.

[281] Song, L.G.; Fang, D.F.; Kobos, R.K.; Pace, S.J.; Chu, B. Separation of double-stranded DNA fragments in plastic capillary electrophoresis chips by using E99P69E99 as separation medium. Electrophoresis, 1999, 20(14), 2847-2855.

[282] Wu, Z.; Nguyen, N.-T. Convective-diffusive transport in parallel lamination micromixers. Microfluid. Nanofluid., 2005, 1(3), 208217.

[283] Rossier, J.S.; Bercier, P.; Schwarz, A.; Loridant, S.; Girault, H.H. Topography, Crystallinity and Wettability of Photoablated PET Surfaces. Langmuir, 1999, 15(15), 5173-5178.

[284] Metz, S.; Holzer, R.; Renaud, P. Polyimide-based microfluidic devices. Lab Chip, 2001, 1(1), 29-34.

[285] Abgrall, P.; Charlot, S.; Fulcrand, R.; Paul, L.; Boukabache, A.; Gué, A.-M.Low-stress fabrication of 3D polymer free standing structures using lamination of photosensitive films. Microsyst. Technol., 2008, 14(8), 1205-1214.

[286] Matthias, T.; Mittendorfer, G.; Thanner, C.; Lindner, P.; Glinsner, T.; Dragoi, V. Adhesive wafer bonding with SU-8 intermediate layers for micro-fluidic applications. ECS Transactions, 2006, 3(6), 369-375.

[287] Tsao, C.W.; Hromada, L.; Liu, J.; Kumar, P.; DeVoe, D.L. Low temperature bonding of PMMA and COC microfluidic substrates using UV/ozone surface treatment. Lab Chip, 2007, 7(4), 499-505.

[288] Ussing, T.; Petersen, L.V.; Nielsen, C.B.; Helbo, B.; Højslet, L. Micro laser welding of polymer microstructures using low power laser diodes. Int. J. Adv. Manuf. Technol. 2007, 33(1), 198-205.

[289] Glasgow, I.K.; Beebe, D.J., White, V.E. Design rules for polyimide solvent bonding. Sens.Mater., 1999, 11(5), 269-278.

[290] Wang, J.; Pumera, M.; Chatrathi, M.P.; Escarpa, A.; Konrad, R.; Griebel, A.; Dörnger, W.; Löwe, H. Towards disposable lab-on-achip: Poly(methylmethacrylate) microchip electrophoresis device with electrochemical detection. Electrophoresis, 2002, 23(4), 596601.

[291] Kelly, R.T.; Pan, T.; Woolley, A.T. Phase-changing sacrificial materials for solvent bonding of high-performance polymeric capillary electrophoresis microchips. Anal.Chem., 2005, 77(11), 3536-3541

[292] Brown, L.; Koerner, T.; Horton, J.H.; Oleschuk, R.D. Fabrication and characterization of poly(methylmethacrylate) microfluidic devices bonded using surface modifications and solvents. Lab Chip, 2006, 6(1), 66-73.

[293] Lin, C.-H.; Chao, C.-H.; Lan, C.-W. Low azeotropic solvent for bonding of PMMA microfluidic devices. Sens. Actuators, B, 2007, 121(2), 698-705

[294] Fuentes, H.V.; Woolley, A.T. Phase-changing sacrificial layer fabrication of multilayer polymer microfluidic devices. Anal.Chem, 2008, 80(1), 333-339.

[295] Ng, S.H.; Tjeung, R.T.; Wang, Z.F.; Lu, A.C.W.; Rodriguez, I.; De Rooij, N.F. Thermally activated solvent bonding of polymers. Microsys. Tech., 2008, 14(6), 753-759.

[296] Tsao, C.-W.; DeVoe, D.L. Bonding of thermoplastic polymer microfluidics. Microfluid. Nanofluid. 2009, 6 (1), 1-16.

[297] Lee, J.N.; Park, C.; Whitesides, G.M. Solvent Compatibility of Poly(dimethylsiloxane)-Based Microfluidic Devices. Anal. Chem., 2003, 75(23), 6544-6554.

[298] Shadpour, H; Musyimi, H; Chen, J; Soper, S.A. Physiochemical properties of various polymer substrates and their effects on microchip electrophoresis performance. J. Chromatogr. A, 2006, 1111(2), 238-251.

[299] Lee, G.B.; Lin, C.H.; Lee, K.H.; Lin, Y.F. On the surface modification of microchannels for microcapillary electrophoresis 
chips. Electrophoresis, 2005, 26(24), 4616-4624.

[300] Kirby, B.J; Hasselbrink, E.F. Zeta potential of microfluidic substrates: 2. Data for polymers. Electrophoresis, 2004, 25(2), 203-213.

[301] Johnson, T.J.; Waddell, E.A.; Kramer, G.W.; Locascio, L.E. Chemical mapping of hot-embossed and UV-laser-ablated microchannels in poly(methyl methacrylate) using carboxylate specific fluorescent probes. Appl. Surf. Sci., 2001, 181(1-2), 149159.

[302] Pugmire, D.L.; Waddell, E.A.; Haasch, R.; Tarlov, M.J.; Locascio, L.E. Surface Characterization of Laser-Ablated Polymers Used for Microfluidics. Anal. Chem., 2002, 74(4), 871-878.

[303] Shariff, K.; Ghosal, S. Peak tailing in electrophoresis due to alteration of the wall charge by adsorbed analytes a: Numerical simulations and asymptotic theory. Anal. Chim. Acta., 2004, 507(1), 87-93.

[304] Chen, H; Yuan, L; Wu, Z; Li, D. Biocompatible polymer materials:Role of protein-surface interactions. Prog. Polym. Sci., 2008, 33(11), 1059-1087.

[305] Belder, D.; Ludwig, M. Surface modification in microchip electrophoresis. Electrophoresis, 2003, 24(21), 3595-3606.

[306] Makamba, H.; Kim, J.H.; Lim, K.; Park, N.; Hahn, J.H. Surface modification of poly(dimethylsiloxane) microchannels. Electrophoresis, 2003, 24(21), 3607-3619.

[307] Doherty, E.A.S.; Meagher, R.J.; Albarghouthi, M.N.; Barron, A.E. Microchannel wall coatings for protein separations by capillary and chip electrophoresis. Electrophoresis, 2003, 24(1-2), 34-54.

[308] Dolnik, V. Wall coating for capillary electrophoresis on microchips. Electrophoresis, 2004, 25 (21-22), 3589-3601.

[309] Kumara, A.; Srivastavaa, A.; Galaevb, I.A.; Mattiasson, B. Smart polymers: Physical forms and bioengineering applications. Prog. Polym. Sci., 2007, 32(10), 1205-1237.

[310] Sikanen, T.; Tuomikoski, S.; Ketola, R.A.; Kostiainen, R.; Franssila, S.; Kotiaho, T. Characterization of SU-8 for electrokinetic microfluidic applications. Lab Chip, 2005, 5(8), 888896.

[311] Sikanen, T.; Zwinger, T.; Tuomikoski, S.; Franssila, S.; Lehtiniemi, R.; Fager, C.-M.; Kotiaho, T.; Pursula, A. Temperature modeling and measurement of an electrokinetic separation chip. Anal. Chem., 2007, 79(23), 9135-9144.

[312] Sikanen, T.; Heikkilä, L.; Tuomikoski, S.; Ketola, R.A.; Kostiainen, R.; Franssila, S., Kotiaho, T. Performance of SU-8 microchips as separation devices and comparison with glass microchips. Anal. Chem., 2007, 79(16), 6255-6263.

[313] Sikanen, T.; Zwinger, T.; Tuomikoski, S.; Franssila, S.; Lehtiniemi, R.; Fager, C.-M.; Kotiaho, T.; Pursula, A. Temperature modeling and measurement of an electrokinetic separation chip. Microfluid. Nanofluid., 2008, 5(4), 479-491.

[314] Zhou, M.X; Foley, J.P. Quantitative theory of electroosmotic flow in fusedsilica capillaries using an extended site-dissociation-sitebinding model. Anal.Chem, 2006, 78(6), 1849-1858.

[315] Danger, G., Pascal, R. and Cottet, H. Non-uniform surface charge distributions in CE: Theoretical and experimental approach based on Taylor dispersion. Electrophoresis, 2008, 29(20), 4226-4237.

[316] Liu, A.L.; He, F.Y.; Hu, Y.L.; Xia, X.H. Plastified poly(ethylene terephthalate) (PET)-toner microfluidic chip by direct-printing integrated with electrochemical detection for pharmaceutical analysis. Talanta, 2006, 68(4), 1303-1308.

[317] He, F.Y., Liu, A.L. and Xia, X.H. Poly(dimethylsiloxane) microchip capillary electrophoresis with electrochemical detection for rapid measurement of acetaminophen and its hydrolysate. Anal. Bioanal. Chem., 2004, 379(7-8), 1062-1067.

[318] He, F.-Y.; Liu, A.-L.; Yuan, J.-H.; Coltro, W.K.T.; Carrilho, E.; Xia, X.-H. Electrokinetic control of fluid in plastified laser-printed poly(ethylene terephthalate)-toner microchips. Anal. bioanal. Chem., 2005, 382(1),192-197.

[319] Yu, H.; He, F.-Y.; Lu, Y.; Hu, Y.-L.; Zhong, H.-Y.; Xia, X.-H. Improved separation efficiency of neurotransmitters on a native printed capillary electrophoresis microchip simply by manipulating electroosmotic flow. Talanta, 2008, 75(1), 43-48.

[320] Barker, S.L.R.; Tarlov, M.J.; Canavan, H.; Hickman, J.J.; Locascio, L.E. Plastic Microfluidic Devices Modified with Polyelectrolyte Multilayers. Anal. Chem., 2000, 72(20), 4899-4903.

[321] Ocvirk, G.; Munroe, M.; Tang, T.; Oleschuk, R.; Westra, K.;
Harrison, D.J. Electrokinetic control of fluidic flow in native poly(dimethylsiloxyne) capillary electrophoresis devices. Electrophoresis , 2000, 21(1), 107-115.

[322] Soper, S.A.; Henry, A.C.; Vaidya, B.; Galloway, M.; Wabuyele, M.; McCarley, R.L. Surface modification of polymer-based microfluidic devices. Anal. Chim. Acta., 2002, 470(1), 87-99.

[323] Hu, S.W.; Ren, X.Q.; Bachman, M.; Sims, C.E.; Li, G.P.; Allbritton, N.L. Cross-linked coatings for electrophoretic separations in poly(dimethylsiloxane) microchannels. Electrophoresis., 2003, 24(21), 3679-3688.

[324] Hu, S.W.; Ren, X.Q.; Bachman, M.; Sims, C.E.; Li, G.P.; Allbritton, N.L. Surface Modification of Poly(dimethylsiloxane) Microfluidic Devices by Ultraviolet Polymer Grafting. Anal. Chem., 2002, 74(16), 4117-4123.

[325] Hu, S.W.; Ren, X.Q.; Bachman, M.; Sims, C.E.; Li, G.P.; Allbritton, N.L. Surface-Directed, Graft Polymerization within Microfluidic Channels. Anal. Chem., 2004, 76(7), 1865-1870.

[326] Johnson, T.J.; Waddell, E.A.; Kramer, G.W.; Locascio, L.E. Chemical mapping of hot-embossed and UV-laser-ablated microchannels in poly(methyl methacrylate) using carboxylate specific fluorescent probes. Appl. Surf. Sci., 2001,Vol. 181(1-2), 149-159.

[327] Chen, L.; Ren, J.; Bi, R.; Chen, D. Ultraviolet sealing and poly(dimethylacrylamide) modification for poly(dimethylsiloxane)/glass microchips. Electrophoresis, 2004, 25(6), 914-921.

[328] Lai, S.Y.; Cao, X.; Lee, L.J. A Packaging Technique for Polymer Microfluidic Platforms. Anal. Chem., 2004, 76(4), 1175-1183.

[329] Baryla, N.E; Lucy, C.A. Semi-permanent surfactant coatings for inorganic anion analysis in capillary electrophoresis. $J$ Chromatogr.A, 2002, 956(1-2), 271-277.

[330] Booker, C.J.; Yeung, K.K.-C. In-capillary protein enrichment and removal of nonbuffering salts using capillary electrophoresis with discontinuous buffers. Anal.Chem., 2008, 80(22), 8598-8604.

[331] Xuan, X.; Li, D. Analytical study of Joule heating effects on electrokinetic transportation in capillary electrophoresis. $J$. Chromatogr. A , 2005, 1064(2), 227-237.

[332] Xuan, X.; Hu, G.; Li, D. Joule heating effects on separation efficiency in capillary zone electrophoresis with an initial voltage ramp. Electrophoresis, 2006, 27(16), 3171-3180.

[333] Cao, J.; Hong, F.-J.; Zheng, P. Influence of Joule heating effects on sample band transport in capillary zone electrophoresis . Chemical Engineering (China), 2008, 36(7), 71-78.

[334] Cetin, B.; Li, D.Effect of Joule heating on electrokinetic transport. Electrophoresis, 2008, 29(5), 994-1005.

[335] Evenhuis, C.J.; Hruska, V.; Guijt, R.M.; Macka, M.; Gas , B.; Marriott, P.J.; Haddad, P.R. Reliable electrophoretic mobilities free from Joule heating effects using CE. Electrophoresis, 2007, 28(20), 3759-3766.

[336] Xuan, X.; Li, D. Joule heating effects on peak broadening in capillary zone electrophoresis . J. Micromech. Microeng., 2004, 14(8), 1171-1180.

[337] Xuan, X.; Li, D. Band-broadening in capillary zone electrophoresis with axial temperature gradients. Electrophoresis , 2005, 26(1), 166-175.

[338] Tang, G.; Yan, D.; Yang, C.; Gong, H.; Chai, J.C.; Lam, Y.C. Assessment of Joule heating and its effects on electroosmotic flow and eletrophoretic transport of solutes in microfluidic channels. Electrophoresis , 2006, 27(3), 628-639.

[339] Cao, J.; Hong, F.J.; Cheng, P. Numerical study of radial temperature gradient effect on separation efficiency in capillary electrophoresis. Int. Commun. Heat Mass Transfer , 2007, 34(910), 1048-1055.

[340] Tang, G.Y.; Yang, C.; Gong, H.Q.; Chai, J.C.; Lam, Y.C. Numerical simulation of Joule heating effect on sample band transport in capillary electrophoresis. Anal. Chim. Acta, 2006, 561(1-2), 138-149.

[341] Tang, G.Y.; Yang, C.; Chai, C.J.; Gong, H.Q. Modeling of electroosmotic flow and capillary electrophoresis with the Joule heating effect: The Nernst-Planck equation versus the Boltzmann distribution. Langmuir, 2003, 19(26), 10975-10984.

[342] Erdmann, E.; Oyanader, M.A.; Arce, P. Effect of the Joule heating and of the material voids on free-convective transport in porous or fibrous media with applied electrical fields. Electrophoresis, 2005, 
26(15), 2867-2877.

[343] Trapp, O. A dynamic molecular probe to investigate catalytic effects and Joule heating in enantioselective MEKC. Electrophoresis, 2007, 28(4), 691-696.

[344] Evenhuis, C.J.; Guijt, R.M.; Macka, M.; Marriott, P.J.; Haddad, P.R. Temperature profiles and heat dissipation in capillary electrophoresis . Anal.Chem., 2006, 78(8), 2684-2693.

[345] Bai, X.X.; Roussel, C.; Jensen, H.; Girault, H.H. Polyelectrolytemodified short microchannel for cation separation. Electrophoresis, 2004, 25(6), 931-935.

[346] Mora, M.F; Garcia, C.D. Electrophoretic separation of environmentally important phenolic compounds using montomorillonite-coated fused-silica capillaries. Electrophoresis, 2007, 28(8), 1197-1203.

[347] Danger, G.; Ramonda, M.; Cottet, H. Control of the EOF in CE using polyelectrolytes of different charge densities. Electrophoresis, 2007, 28(6), 925-931.

[348] MacDonald, A.M; Lucy, C.A. Highly efficient protein separations in capillary electrophoresis using a supported bilayer/diblock copolymer coating. J. Chromatogr. A, 2006, 1130, 265-271.

[349] Zhang, R; Somasundaran, P. Advances in adsorption of surfactants and theirmixtures at solid/solution interfaces. Adv. Colloid Interface Sci., 2006, 123-126, 213-229.

[350] Youssouf Badal, M.; Wong, M.; Chiem, N.; Salimi-Moosavi, H.; Harrison, D.J. Protein separation and surfactant control of electroosmotic flow in poly(dimethylsiloxane)-coated capillaries and microchips. J. Chromatogr. A, 2002, 947(2), 277-286.

[351] Dou, Y.-H.; Bao, N.; Xu, J.-J.; Chen, H.-Y.A dynamically modified microfluidic poly(dimethylsiloxane) chip with electrochemical detection for biological analysis. Electrophoresis , 2002, 23(20), 3558-3566.

[352] Dou, Y.-H.; Bao, N.; Xu, J.-J.; Meng, F.; Chen, H.-Y.Separation of proteins on surface-modified poly(dimethylsiloxane) microfluidic devices. Electrophoresis, 2004, 25(17), 3024-3031.

[353] Xu, Y.; Li, J.; Wang, E. Microchip micellar electrokinetic chromatography based on one functionalized ionic liquid and its excellent performance on proteins separation. J. Chromatogr. A, 2008, 1207(1-2), 175-180.

[354] Xu, Y., Jiang, $\mathrm{H}$. and Wang, E. Ionic liquid-assisted PDMS microchannel modification for efficiently resolving fluorescent dye and protein adsorption. Electrophoresis, 2007, 28(24), 4597-4605.

[355] Galli, V; Barbas, C. Capillary electrophoresis for the analysis of short-chain organic acids in coffee. J. Chromatogr. A, 2004, 1032(1-2), 299-304.

[356] Kim, J.A.; Lee, J.Y.; Seong, S.; Cha, S.H.; Lee, S.H.; Kim, J.J.; Park, T.H. Fabrication and characterization of a PDMS-glass hybrid continuous-flow PCR chip. Biochem. Eng. J., 2006, 29(1), 91-97.

[357] Huang, B.; Wu, H.; Kim, S.; Zare, R.N. Coating of poly(dimethylsiloxane) with n-dodecyl- $\beta$-D-maltoside to minimize nonspecific protein adsorption. Lab chip, 2005, 5(10), 1005-1007.

[358] Deyl, Z; Miksik, I; Eckhardt, A. Comparison of standard capillary and chip separations of sodium dodecylsulfate-protein complexes. J. Chromatogr. A, 2003, 990(1-2), 153-158.

[359] Baryla, N.E; J.E, Melanson; McDermott, M.T; Lucy, C.A. Characterization of surfactant coatings in capillary electrophoresis by atomic force microscopy. Anal. Chem., 2001, 73(19), 45584565 .

[360] Seo, J; Lee, L.P. Effects on wettability by surfactant accumulation/depletion in bulk polydimethylsiloxane (PDMS). Sens. Actuators B, 2006, 119(1), 192-198.

[361] Wei, W; Ju, H. Application of dodecyldimethyl (2-hydroxy-3sulfopropyl) ammonium in wall modification for capillary electrophoresis separation ofprotein. Electrophoresis, 2005, 26(3), 586-592.

[362] Pollard, J.M; Shi, A.J; Goklen, K.E. Solubility and partitioning behavior of surfactants and additives used in bioprocesses. $J$. Chem. Eng. Data, 2006, 51(1), 230-236.

[363] Kirby, B.J; Hasselbrink, E.F. Zeta potential of microfluidic substrates: 1.Theory, experimental techniques, and effects on separations. Electrophoresis, 2004, 25(2), 187-202.

[364] Ping, G; Zhu, B; Jabasini, M; Xu, F; Oka, H; Sugihara, H; Baba, Y. Analysis of Lipoproteins by Microchip Electrophoresis with High Speed and High Reproducibility. Anal.Chem., 2005, 77(22), 7282-
7287

[365] Davalos, R.V.; McGraw, G.J.; Wallow, T.I.; Morales, A.M. Krafcik, K.L.; Fintschenko, Y.; Cummings, E.B.; Simmons, B.A. Performance impact of dynamic surface coatings on polymeric insulator-based dielectrophoretic particle separators . Anal. Bioanal.Chem., 2008, 390(3), 847-855.

[366] Pranaityte, B; Padarauskas. Characterization of the SDS-induced electroosmotic flow in micellar electrokinetic chromatography with cationic polyelectrolyte-coated capillaries. Electrophoresis, 2006, 27(10), 1915-1921.

[367] Vittal, R; Gomathi, H; Kim, K.-J. Beneficial role of surfactants in electrochemistry and in the modification of electrodes. Adv. Colloid Interface Sci, 2006, 119(1), 55-68.

[368] Johnson, T.J.; Ross, D.; Gaitan, M.; Locascio, L.E. Laser Modification of Preformed Polymer Microchannels: Application To Reduce Band Broadening around Turns Subject to Electrokinetic Flow. Anal.Chem., 2001, 73(15), 3656-3661.

[369] McCarley, R.L.; Vaidya, B.; Wei, S.; Smith, A.F.; Patel, A.B.; Feng, J.; Murphy, M.C.; Soper, S.A. Resist-Free Patterning of Surface Architectures in Polymer-Based Microanalytical Devices. J. Am. Chem. Soc., 2005, 127(3), 842-843.

[370] Hiratsuka, A.; Fukui, H.; Suzuki, Y.; Muguruma, H.; Sakairi, K.; Matsushima, T.; Maruo, Y.; Yokoyama, K. Sulphur dioxide plasma modification on poly(methyl methacrylate) for fluidic devices. Curr. Appl Phys., 2008, 8(2), 198-205.

[371] Martin, I.T.; Dressen, B.; Boggs, M.; Liu, Y.; Henry, C.S.; Fisher, E.R. Plasma modification of PDMS microfluidic devices for control of electroosmotic flow. Plasma Processes Polym. , 2007, 4(4), 414-424.

[372] Muck, A; Ne`sn erov`a, P; Pichov`a, I; Svato`, A. Fast prototyping of hydrophobic disposable polymer support arrays for matrixassisted laserdesorption/ionization-time of flight-mass spectrometry of proteins by atmospheric molding. Electrophoresis, 2005, 26(14), 2835-2842.

[373] Waddell, E. A; Shreeves, S; Carrell, H; Perry, C; Reid, B.A; McKee, J. Surface modification of Sylgard 184 polydimethylsiloxane by $254 \mathrm{~nm}$ excimer radiation and characterization by contact angle goniometry, infrared spectroscopy, atomic force and scanning electron microscopy. Appl. Surf. Sci., 2008, 254(17), 5314-5318.

[374] Long, T.M; Prakash, S; Shannon, M.A; Moore, J.S. Water-Vapor Plasma-Based Surface Activation for Trichlorosilane Modification of PMMA. Langmuir, 2006, 22(9), 4104-4109.

[375] Kitagawa, F; Kubota, K; Sueyoshi, K; Otsuka, K. Rectifying Properties and Photoconductivity of Tetraruthenated Nickel Porphyrin Films. Adv. Mater, 2006,7(6), 554-559.

[376] Luo, Y; Huang, B; Wu, H; Zare; R.N. Controlling Electroosmotic Flow in Poly(dimethylsiloxane) Separation Channels by Means of Prepolymer Additives. Anal. Chem., 2006, 78(13), 4588-4592.

[377] Hoa, Z.; Chen, H.; Zhu, X.; Li, J.; Lui, C. Modification of amorphous poly(ethylene terephthalate) surface by UV light and plasma for fabrication of an electrophoresis chip with an integrated gold microelectrode. J. Chromatogr. A , 2008, 1209(1-2), 246-252.

[378] Vickers, J.A; Caulum, M.M; Henry, C.S. Generation of Hydrophilic Poly(dimethylsiloxane) for High-Performance Microchip Electrophoresis. Anal. Chem., 2006, 78(21), 7446-7452.

[379] Muck, A; Ibáñez; Stauber, E.J; Mansourova, M; Svato, A Atmospheric molding of ionic copolymer MALDI-TOF/MS arrays: A new tool for protein identification/profiling. Electrophoresis, 2006, 27(24), 4952-4959.

[380] Erny, G.L.; Elvira, C.; San Román, J.; Cifuentes, A. Capillary electrophoresis using copolymers of different composition as physical coatings: A comparative study. Electrophoresis, 2006, 26(5-6), 1041-1049.

[381] Peterson, D.S.; Rohr, T.; Svec, F.; Frechet, J.M.J. Enzymatic Microreactor-on-a-Chip: Protein Mapping Using Trypsin Immobilized on Porous Polymer Monoliths Molded in Channels of Microfluidic Devices. Anal.Chem., 2002, 74(16), 4081-4088.

[382] Wang, J.; Muck, A.; Chatrathi, M. P.; Chen, G.; Mittal, N.; Spillman, S. D.; Obeidat, S. Bulk modification of polymeric microfluidic devices. Lab Chip., 2005, 5(2), 226-230.

[383] Brown, L; Koerner.T; Horton, J.H; Oleschuk, R.D. Fabrication and characterization of poly(methylmethacrylate) microfluidic devices bonded using surface modifications and solvents. Lab Chip, 2006, 
2006, 6(1), 66-73.

[384] Qu, H.; Wang, H.; Huang, Y.; Zhong, W.; Lu, H.; Kong, J.; Yang, P.; Liu, B. Stable Microstructured Network for Protein Patterning on a Plastic Microfluidic Channel: Strategy and Characterization of On-Chip Enzyme Microreactors. Anal.Chem., 2004, 76(21), 64266433.

[385] Bi, H.; Zhong, W.; Meng, S.; Kong, J.; Yang, P.; Liu, B. Construction of a biomimetic surface on microfluidic chips for biofouling resistance. Anal. Chem., 2006, 78(10), 3399-3405.

[386] Courtois, J.; Szumski, M.; Bystrom, E.; Iwasiewicz, A.; Shchukarev, A.; Irgum, K. A study of surface modification and anchoring techniques used in the preparation of monolithic microcolumns in fused silica capillaries. J.Sep.Sci., 2006, 29(1), 14-24.

[387] Sebastiano, R; Mendiet, M.E; Antonioli, P; Bossi, A; Righetti, P.G; Citterio, A. Organic and inorganic di-cations for capillary silica coating and EOF modulation in CE:Example of application in PEG analysis. Electrophoresis, 2006, 27(8), 1495-1501.

[388] Jiang, X., Chen, H.-Y., Galvan, G., Yoshida, M., Lahann, J. Vaporbased initiator coatings for atom transfer radical polymerization. Adv. Funct. Mater., 2008, 18(1), 27-35.

[389] Chen, H.-Y., Elkasabi, Y. and Lahann, J. Surface modification of confined microgeometries via vapor-deposited polymer coatings. $J$. Am. Chem. Soc., 2006, 128(1), 374-380.

[390] Chen, H.-Y.; McClelland, A.A.; Chen, Z., Lahann, J. Solventless adhesive bonding using reactive polymer coatings. Anal. Chem., 2008, 80(11), 4119-4124.

[391] Xiao, D; Le, T.V; Wirth, M.J. Surface Modification of the Channels of Poly(dimethylsiloxane) Microfluidic Chips with Polyacrylamide for Fast Electrophoretic Separations of Proteins. Anal. Chem., 2004, 76(7), 2055-2061.

[392] Liu, J.; Pan, T.; Woolley, A.T.; Lee, M.L. Surface-Modified Poly(methyl methacrylate) Capillary Electrophoresis Microchips for Protein and Peptide Analysis. Anal. Chem., 2005, 76(23), 69486955.

[393] Sun, X; Liu, J; Lee, M.L. Surface Modification of GlycidylContaining Poly(methyl methacrylate) Microchips Using SurfaceInitiated Atom-Transfer Radical Polymerization. Anal. Chem., 2008, 80(3), 856-863

[394] Sun, X; Lui, J; Lee, M.L. Surface modification of polymer microfluidic device using in-channelk atom transfer radical polymerization. Electrophoresis, 2008, 29(3), 2760-2767.

[395] Witek, M.A.; Wei, S.; Vaidya, B.; Adams, A.A.; Zhu, L.; Stryjewski, W.; McCarley, R.L.; Soper, S.A. Cell transport via electromigration in polymer-based microfluidic devices. Lab Chip, 2004, 4(5), 464-472.

[396] Efimenko, K., Wallace, W.E. ; Genzer, J. Surface modification of Sylgard-184 poly(dimethyl siloxane) networks by ultraviolet and ultraviolet/ozone treatment. J. Colloid Interface Sci., 2002, 252(2), 306-315.

[397] Roman, G.T.; Hlaus, T.; Bass, K.J.; Seelhammer, T.G.; Culbertson, C.T. Sol-Gel Modified Poly(dimethylsiloxane) Microfluidic Devices with High Electroosmotic Mobilities and Hydrophilic Channel Wall Characteristics. Anal.Chem., 2005, 77(5), 14141422.

[398] Wu, D.P.; Luo, Y.; Zhou, X.M.; Dai, Z.P.; Lin, B.C. Multilayer poly(vinyl alcohol)-adsorbed coating on poly(dimethylsiloxane) microfluidic chips for biopolymer separation. Electrophoresis, 2005, 26(1), 211-218.

[399] Qian, T.; Li, Y.; Wu, Y.; Zheng, B.; Ma, H. Superhydrophobic poly(dimethylsiloxane) via surface-initiated polymerization with ultralow initiator density. Macromolecules, 2008, 41(18), 66416645.

[400] Niu, Z.; Gao, F.; Jia, X.; Zhang, W.; Chen, W.; Qian, K. Synthesis studies of sputtering $\mathrm{TiO}_{2}$ films on poly(dimethylsiloxane) for surface modification. Colloid Surf. A Physicochem. Eng. Aspects, 2006, 272(3),170-175.

[401] Feng, J.-T.; Zhao, Y.-P. Influence of different amount of Au on the wetting behavior of PDMS membrane. Biomed. Microdevices, 2008, 10(1), 65-72.

[402] Ma, K.-S.; Reza, F.; Saaem, I.; Tian, J. Versatile surface functionalization of cyclic olefin copolymer (COC) with sputtered $\mathrm{SiO}_{2}$ thin film for potential BioMEMS applications. J. Mater. Chem., 2009, 19(42), 7914-7920.
[403] Goyal, A.; Kumar, A.; Patra, P.K.; Mahendra, S.; Tabatabaei, S.; Alvarez, P.J.J.; John, G.; Ajayan, P.M. In situ synthesis of metal nanoparticle embedded free standing multifunctional PDMS films. Macromol. Rapid Commun., 2009, 30(13), 1116-1122.

[404] Patrito, N.; McLachlan, J.M.; Faria, S.N.; Chan, J.; Norton, P.R. A novel metal-protected plasma treatment for the robust bonding of polydimethylsiloxane. Lab Chip, 2007, 7(12), 1813-1818.

[405] Fan, D.-H.; Yuan, S.-W.; Shen, Y.-M. Surface modification with BSA blocking based on in situ synthesized gold nanoparticles in poly(dimethylsiloxane) microchip. Colloids Surf., B , 2010, 75(2), 608-6111.

[406] Bani-Yaseen, A.D.; Kawaguchi, T.; Jankowiak, R. Electrochemically deposited metal nanoparticles for enhancing the performance of microfluidic MEMS in biochemical analysis. Int. J. Nanomanuf., 2009, 4(1), pp. 99-107.

[407] Qiu, J.-D.; Wang, L.; Liang, R.-P.; Wang, J.-W. Microchip CE analysis of amino acids on a titanium dioxide nanoparticles-coated PDMS microfluidic device with in-channel indirect amperometric detection. Electrophoresis, 2009, 30(19), 3472-3479.

[408] Zhou, J.; Ellis, A.V.; Voelcker, N.H. Recent developments in PDMS surface modification for microfluidic devices. Electrophoresis, 2010, 31(1), 2-16.

[409] Nagel, J.; Brauer, M.; Hupfer, B.; Grundke, K.; Schwarz, S. Lehmann, D. Investigations on the reactive surface modification of polycarbonate by surface-reactive injection molding. J. Appl. Polym. Sci., 2004, 93(3), 1186-1191.

[410] Liu, J.; Lee, M.L. Permanent surface modification of polymeric capillary electrophoresis microchips for protein and peptide analysis. Electrophoresis, 2006, 27(18), 3533-3546

[411] Liu, J.; Lee, M.L. Permanent surface modification of polymeric capillary electrophoresis microchips for protein and peptide analysis.Electrophoresis, 2006, 27(18), 3533-3546.

[412] Stachowiak, T.B.; Rohr, T.; Hilder, E.F.; Peterson, D.S.; Yi, M.Q.; Svec, F.; Frechet, J.M.J. Fabrication of porous polymer monoliths covalently attached to the walls of channels in plastic microdevices. Electrophoresis, 2003, 24(21),3689-3693.

[413] Aura, S.; Sikanen, T.; Kotiaho, T.; Franssila, S. Novel hybrid material for microfluidic devices. Sens. Actuators, B , 2008, 132(2), 397-403

[414] Wyzkiewicz, I.; Gorniak, N.; Jakubowska, M.; Brzózka, Z.; Dybko, A. In Hybrid microstructures for capillary electrophoresis with micro-channel in photosensitive layer. Proceedings of SPIE - The International Society for Optical Engineering. 2008, 69371R.

[415] Aura, S.; Sikanen, T.; Kotiaho, T.; Franssila, S. Novel hybrid material for microfluidic devices. In TRANSDUCERS and EUROSENSORS '07 - 4th International Conference on Solid-State Sensors, Actuators and Microsystems, 2007,1821-1824. 4300509.

[416] Bi, H; Li, S.M.Y; Guo, K; Chen, Y; Kong, J; Yang, P; Zhong, W; Liu, B. Deposition of PEG onto PMMA microchannel surface to minimize nonspecific adsorption. Lab Chip, 2006, 6(6), 769-775.

[417] Kim, S.J; Song, Y.A; Skipper, P.K; Han, J. Electrohydrodynamic Generation and Delivery of Monodisperse Picoliter Droplets Using a Poly(dimethylsiloxane) Microchip. Anal. Chem., 2006, 78(23), 8011-8019.

[418] Wu, D; Zhao, B; Dai, Z; Qin, Z; Lin, B. Grafting epoxy-modified hydrophilic polymers onto poly(dimethylsiloxane) microfluidic chip to resist nonspecific protein adsorption. Lab Chip, 2006, 6(7), 942-947.

[419] Wang, D.; Oleschuk, R.D.; Horton, J.H. Surface modification of poly(dimethylsiloxane) with a perfluorinated alkoxysilane for selectivity toward fluorous tagged peptides. Langmuir, 2008, 24(3), 1080-1086.

[420] Ross, D.; Johnson, T.J.; Locascio, L.E. Imaging of Electroosmotic Flow in Plastic Microchannels. Anal.Chem., 2001,73(11), 2509 2515 .

[421] Zangmeister, R.A.; Tarlov, M.J. UV Graft Polymerization of Polyacrylamide Hydrogel Plugs in Microfluidic Channels. Langmuir, 2003, 19(17), 6901-6904.

[422] Lin, Y.W; Chang, Y.H. Modification of poly(methyl methacrylate) microchannels for highly efficient and reproducible electrophoretic separations of double-stranded DNA. J. Chromatogr. A, 2005 , 1073(1-2), 191-199.

[423] Muck, A; Svatǒs, A. Chemical modification of polymeric microchip devices. Talanta , 2007,74(3), 333-341. 
[424] Goddard, J.M; Talbert, J.N; Hotchkiss, J.H. Covalent attachment of lactase to low density polyethylene films. J Food Science , 2007, 72(1), E36-41.

[425] Alferiev, I.S.; Connolly, J.M.; Stachelek, S.J.; Ottey, A; Rauova, L.; Levy.R.J. Surface heparinization of polyurethane via bromoalkylation of hard segment nitrogens. Biomacromolecules, 2006, 7(1), 317-322

[426] Goddard, J.M; Hotchkiss, J.H. Polymer surface modification for the attachment of bioactive compounds. Prog. Polym. Sci, 2007, 32(7), 698-725.

[427] Roddy, E.S.; Xu, H.W.; Ewing, A.G. Ongoing development of twodimensional polyacrylamide gel electrophoresis data standards. Electrophoresis, 2004, 25(2), 297-308.

[428] Yang, Z.; Maeda, R. A world-to-chip socket for microfluidic prototype development. Electrophoresis, 2002, 23(20), 3474-3478.

[429] Martin, R.S.; Gawron, A.J.; Lunte, S.M.; Henry, C.S. DualElectrode Electrochemical Detection for Poly(dimethylsiloxane)Fabricated Capillary Electrophoresis Microchips. Anal.Chem., 2000, 72(14), 3196-3202.

[430] Shin, D.; Tryk, D.A.; Fujishima, A.; Muck, A.; Chen, G.; Wang, J. Microchip capillary electrophoresis with a boron-doped diamond electrochemical detector for analysis of aromatic amines. Electrophoresis, 2004, 25(17), 3017-3023.

[431] Wang, J.; Chatrathi, M.P.; Tian, B.M.; Polsky, R. Capillary Electrophoresis Chips with Thick-Film Amperometric Detectors: Separation and Detection of Hydrazine Compounds. Electroanalysis, 2000, 12(9), 691-694.

[432] Wang, J.; Chatrathi, M.P.; Tian, B.M. Microseparation Chips for Performing Multienzymatic Dehydrogenase/Oxidase Assays: Simultaneous Electrochemical Measurement of Ethanol and Glucose. Anal.Chem., 2001, 76(6), 1296-1300.

[433] Wang, J.; Chen,G.; Chatrathi,M.P.; Musameh,M. Capillary Electrophoresis Microchip with a Carbon Nanotube-Modified Electrochemical Detector. Anal.Chem., 2004, 76(2), 298-302.

[434] Wang, J.; Chatrathi, M.P.; Tian, B.M.; Polsky, R. Microfabricated Electrophoresis Chips for Simultaneous Bioassays of Glucose, Uric Acid, Ascorbic Acid, and Acetaminophen. Anal.Chem., 2001,72(11), 2514-2418.

[435] Wang, J.; Chatrathi, M.P.; Tian, B.M. Micromachined Separation Chips with a Precolumn Reactor and End-Column Electrochemical Detector. Anal.Chem., 2000,72(23), 5774-5778.

[436] Wang, J.; Pumera, M.; Chatrathia, M.P.; Rodriguez, A.; Spillman, S.; Martin, R.S.; Lunte, S.M. Thick-Film Electrochemical Detectors for Poly(dimethylsiloxane)-based Microchip Capillary Electrophoresis. Electroanalysis, 2002, 14(18),1251-1255.

[437] Wang, J.; Chatrathi, M.P.; Mulchandani, A.; Chen, W. Capillary Electrophoresis Microchips for Separation and Detection of Organophosphate Nerve Agents. Anal.Chem., 2001, 73(8), 18041808.

[438] Johirul, M.; Shiddiky, A.; Kim, R.-E.; Shim, Y.-B. Microchip capillary electrophoresis with a cellulose-DNA-modified screenprinted electrode for the analysis of neurotransmitters. Electrophoresis, 2005, 26(15), 3043-3052

[439] Musameh, M.; Wang, J.; Merkoci, A.; Lin, Y. Low-potential stable NADH detection at carbon-nanotube-modified glassy carbon electrodes. Electrochem. Commun., 2002, 4(10), 743-746.

[440] Crevillén, A.G.; Pumera, M.; González, M.C.; Escarpa, A. Carbon nanotube disposable detectors in microchip capillary electrophoresis for water-soluble vitamin determination: Analytical possibilities in pharmaceutical quality control. Electrophoresis, 2008, 29(14), 2997-3004

[441] Pumera, M.; Merkoc i, A.; Alegret, S. Carbon nanotube detectors for microchip CE: Comparative study of single-wall and multiwall carbon nanotube, and graphite powder films on glassy carbon, gold, and platinum electode surfaces. Electrophoresis, 2007, 28(8), 1274-1280.

[442] Liu, Y., Vickers, J.A. and Henry, C.S. Simple and Sensitive Electrode Design for Microchip Electrophoresis/Electrochemistry. Anal.Chem., 2004, 76(5), 1513-1517.

[443] Martin, R.S.; Gawron, A.J.; Fogarty, B.A.; Regan, F.B.; Dempsey, E.; Lunte, S.M. Carbon paste-based electrochemical detectors for microchip capillary electrophoresis/electrochemistry. Analyst, 2001, 126(3), 277-280.

[444] Gawron, A.J.; Martin, R.S.; Lunte, S.M. Fabrication and evaluation of a carbon-based dual-electrode detector for poly(dimethylsiloxane) electrophoresis chips. Electrophoresis, 2001,22(2), 242-248

[445] Kikura-Hanajiri, R.; Martin, R.S.; Lunte, S.M. Indirect Measurement of Nitric Oxide Production by Monitoring Nitrate and Nitrite Using Microchip Electrophoresis with Electrochemical Detection. Anal.Chem., 2002, 74(24), 6370-6377.

[446] Kovarik, M.L.; Torrence, N.J.; Spence, D.M.; Martin, R.S Fabrication of carbon microelectrodes with a micromolding technique and their use in microchip-based flow analyses. Analyst, 2004, 129(5), 400-405.

[447] Walker, C.E.; Xia, Z.; Foster, Z.S.; Lutz, B.J.; Fan, Z.H Investigation of airbrushing for fabricating microelectrodes in microfluidic devices. Electroanalysis, 2008, 20(6), 663-670.

[448] Gavin, P.F.; Ewing, A.G. Characterization of Electrochemica Array Detection for Continuous Channel Electrophoretic Separations in Micrometer and Submicrometer Channels. Anal.Chem., 1997, 69(18), 3838-3845.

[449] Wen, J.; Cassidy, R.M. Anodic and cathodic pulse amperometric detection of metal ions separated by capillary electrophoresis. Anal. Chem., 1996, 68(8), 1047-1053.

[450] Wang, J.; Yang, Z.; Wang, X.; Yang, N. Capillary electrophoresis with gold nanoparticles enhanced electrochemiluminescence for the detection of roxithromycin. Talanta, 2008, 76(1), 85-90.

[451] Pumera, M.; Llopis, X.; Merkoc i, A.; Alegret, S. Microchip capillary electrophoresis with a single-wall carbon nanotube/gold electrochemical detector for determination of aminophenols and neurotransmitters. Microchim. Acta, 2006, 152(3-4), 261-265.

[452] Wang, J.; Pumera, M. Microchip flow-injection analysis of trace 2,4,6-trinitrotoluene (TNT) using mercury-amalgam electrochemical detector. Talanta, 2006, 69(4),984-987.

[453] Park, J.; Quaiserová-Mocko, V.; Pecková, K.; Galligan, J.J.; Fink, G.D.; Swain, G.M. Fabrication, characterization, and application of a diamond microelectrode for electrochemical measurement of norepinephrine release from the sympathetic nervous system. Diamond Relat. Mater. 2006, 15(4-8), 761-772.

[454] Pecková, K.; Mocko, V.; Opekar, F.; Swain, G.M.; Zima, J.; Barek J. Miniaturized amperometric detectors for HPLC and capillary zone electrophoresis. Chemicke Listy, 2006, 100(2), 124-132

[455] Muna, G.W.; Quaiserová-Mocko, V.; Swain, G.M. Chlorinated phenol analysis using off-line solid-phase extraction and capillary electrophoresis coupled with amperometric detection and a borondoped diamond microelectrode. Anal. Chem., 2005, 77(20), 65426548.

[456] Muna, G.W.; Quaiserova-Mocko, V.; Swain, G.M. The analysis of chlorinated phenol solutions by capillary electrophoresis coupled with direct and indirect amperometric detection using a borondoped diamond microelectrode. Electroanalysis, 2005, 17(13), 1160-1170

[457] Quaiserová-Mocko, V.; Novotný, M.; Schaefer, L.S.; Fink, G.D.; Swain, G.M. CE coupled with amperometric detection using a boron-doped diamond microelectrode: Validation of a method for endogenous norepinephrine analysis in tissue. Electrophoresis, 2008, 29(2), 441-447.

[458] Chen, G. Carbon nanotube and diamond as electrochemical detectors in microchip and conventional capillary electrophoresis. Talanta, 2007, 74(3), 326-332.

[459] Gao, C.; Chang, M.; Shen, H.; Shen, F. Boron doped diamond microelectrode. Chemistry Bulletin / Huaxue Tongbao, 2008 , 71(12), 912-917.

[460] Hilmi, A.; Luong, J.H.T. Electrochemical Detectors Prepared by Electroless Deposition for Microfabricated Electrophoresis Chips. Anal.Chem., 2000, 72(19), 4677-4682.

[461] Schwarz, M.A.; Galliker, B.; Fluri, K.; Kappes, T.; Hauser, P.C. A two-electrode configuration for simplified amperometric detection in a microfabricated electrophoretic separation device. Analyst, 2001, 126(2), 147-151.

[462] Yan J.L; Du, Y.; Liu, J.F.; Cao, W.D.; Sun, X.H.; Zhou, W.H.; Yang, X.R.; Wang, E.K. Fabrication of Integrated Microelectrodes for Electrochemical Detection on Electrophoresis Microchip by Electroless Deposition and Micromolding in Capillary Technique. Anal.Chem., 2003, 75(20), 5406-5412.

[463] Delvaux, M., Walcarius, A. and Demoustier-Champagne, S Bienzyme HRP-GOx-modified gold nanoelectrodes for the 
sensitive amperometric detection of glucose at low overpotentials. Biosens. Bioelectron, 2005, 20, 1587-1594.

[464] Wang, J.; Chen, G.; Chatrathi, M. P. Nickel Amperometric Detector Prepared by Electroless Deposition for Microchip Electrophoretic Measurement of Alcohols and Sugars. Electroanalysis, 2004, 16(19), 1603-1608.

[465] Kong, Y.; Chen, H.; Wang, Y.Soper,S.A. Fabrication of a gold microelectrode for amperometric detection on a polycarbonate electrophoresis chip by photodirected electroless plating. Electrophoresis, 2006, 27(14), 2940-2950.

[466] Wang, Y.; Chen, H.; He, Q.; Soper, S.A. A high performance polycarbonate clectrophoresis microchip with integrated threeelectrode system for end-channel amperometric detection. Electrophoresis, 2008, 29(9), 1881-1888.

[467] Wang, Y.; Luo, J.; Chen, H.; He, Q.; Gan, N.; Li, T. A microchipbased flow injection-amperometry system with mercaptopropionic acid modified electroless gold microelectrode for the selective determination of dopamine. Anal. Chim. Acta, 2008, 625(2), 180187.

[468] Paek, S.H., Choi, Y.K. and Kim, D.S. Selective microfabrication of silver electrodes inside a microchannel by multiphase laminar flow with density difference. Microelectron. Eng., 2008, 87(5-8),13751378.

[469] In-Je, Y.I.; Kim, J.-H.; Kang, C.J.; Choi, Y.J.; Lee, K.; Kim, Y.-S. A novel electrochemical detector using prussian blue modified indium tin oxide electrode. Jpn. J. Appl. Phys., Part 1, 2006, 45(1B), 438-441.

[470] Lee, H.L.; Chen, S.C. Microchip capillary electrophoresis with amperometric detection for several carbohydrates. Talanta, 2004, 64(1), 210-216

[471] Li, X.-A.; Zhou, D.-M.; Xu, J.-J.; Chen, H.-Y. Determination of chloride, chlorate and perchlorate by PDMS microchip electrophoresis with indirect amperometric detection. Talanta, 2008, 75(1), 157-162.

[472] Xia, F.; Jin, W.; Yin, X.; Fang, Z. Single-cell analysis by electrochemical detection with a microfluidic device. $J$. Chromatogr. A, 2005, 1063(1-2), 227-233.

[473] Wang, W.; Han, S.; Jin, W. Determination of lactate dehydrogenase isoenzymes in single rat glioma cells by capillary electrophoresis with electrochemical detection .J. Chromatogr. B , 2006, 831(1-2), 57-62.

[474] Wang, J.; Chen, G.; Wang, M.; Chatrathi, M.P. Carbonnanotube/copper composite electrodes for capillary electrophoresis microchip detection of carbohydrates. Analyst, 2004, 129(6), 512 515.

[475] Wu, Y.-Y.: Qu, F.; Lin, J.-M. Microchip capillary electrophoresis with an end-channel amperometric detector and its preliminary application. Chin. J. Chem., 2005, 23(2), 155-159.

[476] Yao, X.; Wang, J.; Zhang, L.; Yang, P.; Chen, G. A threedimensionally adjustable amperometric detector for microchip electrophoretic measurement of nitroaromatic pollutants . Talanta, 2006, 69(5),1285-1291.

[477] Kappes, T.; Galliker, B.; Schwarz, M.A.; Hauser, P.C. Portable capillary electrophoresis instrument with amperometric, potentiometric and conductometric detection. Trac-Trend Anal. Chem., 2001, 20(3), 133-139.

[478] Wu, Z.; Liu, A.Q.; Hjort, K. Microfluidic continuous particle/cell separation via electroosmotic-flow- tuned hydrodynamic spreading. J. Micromech. Microeng., 2007, 17(10), 1992-1999.

[479] Roman, G.T.; Kennedy, R.T. Fully integrated microfluidic separations systems for biochemical analysis. J. Chromatogr. A, 2007, 1168(1-2), 170-188.

[480] Jackson, D.J.; Naber, J.F.; Roussel, T.J.; Crain, M.M.; Walsh, K.M.; Keynton, R.S.; Baldwin, R.P. Portable High-Voltage Power Supply and Electrochemical Detection Circuits for Microchip Capillary Electrophoresis. Anal.Chem., 2003, 75(14), 3643-3649.

[481] Erickson, D.; Sinton, D.; Li, D. A miniaturized high-voltage integrated power supply for portable microfluidic applications. Lab Chip, 2004, 4(2), 87-90.

[482] Garcia,C.D.;Liu,Y.; Anderson,P.;Henry, C.S. Versatile 3-channel high-voltage power supply for microchip capillary electrophoresis. Lab Chip, 2003, 3(4), 324-328.

[483] Kubán , P.; Nguyen, H.T.A.; Macka, M.; Haddad, P.R.; Hauser, P.C. New fully portable instrument for the versatile determination of cations and anions by capillary electrophoresis with contactless conductivity detection. Electroanalysis, 2007, 19(19-20), 20592065.

[484] Gärtner, C.; Hoffmann, W.; Demattio, H.; Clemens, T.; Klotz, M.; Klemm, R.; Becker, H. Portable integrated capillaryelectrophoresis system using disposable polymer chips with capacitively coupled contactless conductivity detection for on-site analysis of foodstuff. In Proceedings of SPIE -- The International Society for Optical Engineering. 2009.

[485] Makarõtševa, N.; Seiman, A.; Vaher, M.; Kaljurand, M. Analysis of the degradation products of chemical warfare agents using a portable capillary electrophoresis instrument with various sample injection devices. Procedia Chem., 2010, 2(1), 20-25.

[486] Valdez, D.C.; Berg, C.; Bergeron, P.; Mora, M.F.; Garcia, C.D.; Ayon, A.A. Wireless control of microchip capillary electrophoresis with a mobile platform. In DTIP of MEMS and MOEMS Symposium on Design, Test, Integration and Packaging of MEMS/MOEMS. 2009, 150-152. 